Issued: December 1999

An Assessment of the MCNP4C

Weight Window

Christopher N. Culbertson*

John S. Hendricks

*Graduate Research Assistant at Los Alamos. Purdue University, West Lafayette, IN 47907

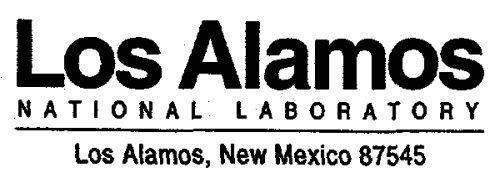




\section{DISCLAIMER}

This report was prepared as an account of work sponsored by an agency of the United States Government. Neither the United States Government nor any agency thereof, nor any of their employees, make any warranty, express or implied, or assumes any legal liability or responsibility for the accuracy, completeness, or usefulness of any information, apparatus, product, or process disclosed, or represents that its use would not infringe privately owned rights. Reference herein to any specific commercial product, process, or service by trade name, trademark, manufacturer, or otherwise does not necessarily constitute or imply its endorsement, recommendation, or favoring by the United States Government or any agency thereof. The views and opinions of authors expressed herein do not necessarily state or reflect those of the United States Government or any agency thereof. 


\section{DISCLAIMER}

Portions of this document may be illegible in electronic image products. Images are produced from the best available original document. 


\title{
AN ASSESSMENT OF THE MCNP4C WEIGHT WINDOW
}

\author{
by
}

Christopher N. Culbertson and John S. Hendricks

\begin{abstract}
U)
A new, enhanced weight window generator suite has been developed for $\mathrm{MCNP}^{1}$ version $4 \mathrm{C}$. The new generator ${ }^{2,3}$ correctly estimates importances in either a user-specified, geometry-independent, orthogonal grid or in MCNP geometric cells. The geometry-independent option alleviates the need to subdivide the MCNP cell geometry for variance reduction purposes. In addition, the new suite corrects several pathologies in the existing MCNP weight window generator. The new generator is applied in a set of five variance reduction problems. The improved generator is compared with the weight window generator applied in MCNP4B. The benefits of the new methodology are highlighted, along with a description of its limitations. We also provide recommendations for utilization of the weight window generator.
\end{abstract}




\section{INTRODUCTION}

\section{A. Description of MCNP}

MCNP is a general-purpose $\underline{\text { Monte }}$ Carlo $\underline{N}$-Particle code that can be used for neutron, photon, electron, or coupled neutron/photon/electron transport, including the capability to calculate eigenvalues for critical systems. The code treats an arbitrary three-dimensional configuration of materials in geometric cells bounded by first-and second-degree surfaces and fourth-degree elliptical tori.

Pointwise cross-section data are used. For neutrons, all reactions given in a particular cross-section evaluation (such as ENDF/B-VI) are accounted for. Thermal neutrons are described by both the free gas and $S(\alpha, \beta)$ models. For photons, the code takes account of incoherent and coherent scattering, the possibility of fluorescent emission after photoelectric absorption, absorption in pair production with local emission of annihilation radiation, and bremsstrahlung. A continuous slowing down model is used for electron transport that includes positrons, $\mathrm{k} \mathrm{x}$-rays, and bremsstrahlung, but it does not include external or self-induced fields.

Important standard features that make MCNP very versatile and easy to use include a powerful general source, criticality source, and surface source; both geometry and output tally plotters; a rich collection of variance reduction techniques; a flexible tally structure; and an extensive collection of cross-section data.

\section{B. How to Use This Report}

We envision three uses of this report.

First, as a validation document. This assessment validates the MCNP4C weight window generator. If you just want a document to prove it works, put this on your shelf and read no further.

Second, as a handbook for using weight windows in MCNP. See the guidelines for use, Section VII.

Third, for training in using MCNP in shielding problems. You should probably read the entire report and try the problems described with the proposed methodology. 


\section{Contents}

The contents of this assessment report are:

1. Introduction

2. Variance Reduction and Weight Windows

The weight window variance reduction technique and the weight window generator which computes weight window values is described.

3. Objectives

This assessment of the MCNP4C weight windows was needed to verify that the new MCNP4C treatment of cell-based weight windows is as least as good as the MCNP4B treatment it replaced, to determine the worth of mesh-based windows relative to cell based windows, and to demonstrate to what degree the meshbased windows reduce the need to subdivide problem geometries for variance reduction.

4. Methodology

We describe our methodology for assessing the MCNP4C weight windows and weight window generator.

\section{Model Descriptions}

The weight window assessment was done with five shielding problems. These were taken from the MCNP neutron ${ }^{4}$ and photon ${ }^{5}$ benchmark reports, the MCNP test set, and a sample problem for variance reduction. ${ }^{6}$ All 5 problems have well-defined, highly optimized importance functions honed by experts but without the benefits of the new weight window generator.

6. Results

Our data from the assessment of the MCNP4C weight windows and weight window generator is presented. We observe that the MCNP4C capabilities are generally superior to those of MCNP4B and that the new mesh generator can provide a superior importance function even when geometries are not subdivided for variance reduction.

\section{Guidelines}

Our experience in using the MCNP4C weight windows and weight window generator has provided a recommended set of guidelines for their utilization. 
8. Recommendations for Future MCNP Development

Our experience with the MCNP4C windows indicates where future improvements in MCNP may be desirable.

9. Conclusions

\section{VARIANCE REDUCTION AND WEIGHT WINDOWS}

There are four classes of Monte Carlo variance reduction techniques that range from the trivial to the esoteric.

Truncation Methods are the simplest of variance reduction methods. They speed up calculations by truncating parts of phase space that do not contribute significantly to the solution. The simplest example is geometry truncation in which unimportant parts of the geometry are simply not modeled. Other truncation methods available in MCNP are energy cutoff and time cutoff.

Population Control Methods use particle splitting and Russian roulette to control the number of samples taken in various regions of phase space. In important regions many samples of low weight are tracked, while in unimportant regions few samples of high weight are tracked. A weight adjustment is made to ensure that the problem solution remains unbiased; that is, weight is preserved. Specific population control methods available in MCNP are geometry splitting and Russian roulette, energy splitting/roulette, weight cutoff, and weight windows.

Modified Sampling Methods alter the statistical sampling to better sample important regions of phase space. For any Monte Carlo event it is possible to sample from any arbitrary distribution rather than the physical probability as long as the particle weights are then adjusted to compensate. Thus, with modified sampling methods, sampling is done from distributions that send particles in desired directions or into other desired regions of phase space such as time or energy, or change the location or type of collisions. Modified sampling methods in MCNP include the exponential transform, implicit capture, forced collisions, source biasing, photon reaction biasing, and neutron-induced photon production biasing.

Partially-Deterministic Methods are the most complicated class of variance reduction methods. They circumvent the normal random walk process by using deterministic-like techniques, such as next event estimators, or by controlling of the random number sequence. In 
MCNP these methods include point detectors, DXTRAN, and differential operator perturbations.

\section{A. Weight Windows}

The weight window is a space-energy-dependent splitting and Russian roulette technique. For each space-energy phase space cell, the user supplies a lower weight bound. The upper weight bound is a user-specified multiple of the lower weight bound. These weight bounds define a window of acceptable weights. If a particle is below the lower weight bound, Russian roulette is played, and the particle's weight is either increased to a value within the window or the particle is terminated. If a particle is above the upper weight bound, it is split so that all the split particles are within the window. No action is taken for particles within the window.

Three important weights define the weight window in a space-energy cell

1. $\mathrm{W}_{\mathrm{L}}$, the lower weight bound,

2. $W_{S}$, the survival weight for particles playing roulette, and

3. $W_{U}$, the upper weight bound.

The user specifies $W_{L}$ for each space-energy cell on $W W N$ cards. $W_{S}$ and $W_{U}$ are calculated using two problem-wide constants, $\mathrm{C}_{S}$ and $\mathrm{C}_{\mathrm{U}}$ (entries on the WWP card), as $\mathrm{W}_{\mathrm{S}}=$ $C_{S} W_{L}$ and $W_{U}=C_{U} W_{L}$. Thus, all cells have an upper weight bound $C_{U}$ times the lower weight bound and a survival weight $\mathrm{C}_{S}$ times the lower weight bound.

Although the weight window can be effective when used alone, it was designed for use with other biasing techniques that introduce a large variation in particle weight. In particular, a particle may have several "unpreferred" samplings, each of which will cause the particle weight to be multiplied by a weight factor substantially larger than one. Any of these weight multiplications by itself is usually not serious, but the cumulative weight multiplications can seriously degrade calculational efficiency. Worse, the error estimates may be misleading until enough extremely high-weight particles have been sampled.

Although it is impossible to eliminate all pathologies in Monte Carlo calculations, a properly specified weight window goes far toward eliminating pathologically high-weight particles. As soon as the weight gets above the weight window, the particle is split and subsequent weight multiplications will thus be multiplying only a fraction of the particle's weight (before splitting). Thus, it is hard for the tally to be severely perturbed by a particle of 
extremely large weight. In addition, low-weight particles are rouletted, so time is not wasted following particles of insignificant weight.

One cannot ensure that every history contributes the same score (a zero variance solution), but by using a window inversely proportional to the importance, one can ensure that the mean score from any track in the problem be roughly constant. (A weight window generator exists to estimate these importance reciprocals.) In other words, the window is chosen so that the track weight times the mean score (for unit track weight) is approximately constant. Under these conditions, the variance is due mostly to the variation in the number of contributing tracks rather than the variation in track score.

Thus far, two things remain unspecified about the weight window: the constant of inverse proportionality and the width of the window. It has been observed empirically that an upper weight bound five times the lower weight bound works well, but the results are reasonably insensitive to this choice anyway. The constant of inverse proportionality is chosen so that the lower weight bound in some reference cell is chosen appropriately. In most instances the constant should be chosen so that the source particles start within the window.

\section{B. Weight Window Generator}

The generator is a method that automatically generates weight window importance functions. The task of choosing importances by guessing, intuition, experience, or trial and error is simplified and insight into the Monte Carlo calculation is provided. Although the window generator has proved very useful, two caveats are appropriate. The generator is by no means a panacea for all importance sampling problems and certainly is not a substitute for thinking on the user's part. In fact, in most instances, the user will have to decide when the generator's results look reasonable and when they do not. After these disclaimers, one might wonder what use to make of a generator that produces both good and bad results. To use the generator effectively, it is necessary to remember that the generated parameters are only statistical estimates and that these estimates can be subject to considerable error. Nonetheless, practical experience indicates that a user can learn to use the generator effectively to solve some very difficult transport problems. Note that this importance estimation scheme works regardless of what other variance reduction techniques are used in the calculation. We provide guidelines for using the weight window generator in Section VII. 


\section{Weight Window Generator Theory}

The importance of a particle at a point $P$ in phase space equals the expected score a unit weight particle will generate. Imagine dividing the phase space into a number of phase space "cells" or regions. The importance of a cell then can be defined as the expected score generated by a unit weight particle after entering the cell. Thus, with a little bookkeeping, the cell's importance can be estimated as

Importance (expected score) $=$ total score because of particles entering the cell/total weight entering the cell

After the importances have been generated, MCNP assigns weight windows inversely proportional to the importances. Then MCNP supplies either card images or an auxiliary file of the weight windows for use in a subsequent calculation. The WWGE card defines the energy or time phase space division used to generate the weight windows. The constant of proportionality is specified on the WWG card.

\section{Limitations of the Weight-Window Generator}

The principal problem encountered when using the generator is bad estimates of the importance function because of the statistical nature of the generator. In particular, unless a phase space region is sampled adequately, there will be either no generator importance estimate or an unreliable one. The generator often needs a very crude importance guess just to get any tally; that is, the generator needs an initial importance function to estimate a (we hope) better one for subsequent calculations. Fortunately, in most problems the user can guess some crude importance function sufficient to get enough tallies for the generator to estimate a new set of weight windows. Because the weight windows are statistical, several iterations usually are required before the optimum importance function is found for a given tally. The first set of generated weight windows should be used in a subsequent calculation, which generates a better set of windows, etc. See the guidelines in Section VII.

In addition to iterating on the generated weight windows, the user must exercise some degree of judgment. Specifically, in a typical generator calculation, some generated windows will look suspicious and will have to be reset. In MCNP this task is simplified for cell-based weight windows by an algorithm that automatically scrutinizes importance functions, either input by the user or generated by a generator. By flagging the generated windows that are more than a factor of 4 different from those in adjacent cells, often it is easy to determine which generated weight windows are likely to be statistical flukes that should be revised before the 
next generator iteration. For example, suppose the lower weight bounds in adjacent cells were $0.5,0.3,0.9,0.05,0.03,0.02$, etc.; here the user would probably want to change the 0.9 to something like 0.1 to fit the pattern, reducing the 18:1 ratio between cells 3 and 4 . The weight window generator also will fail when phase space is not sufficiently subdivided and no single set of weight window bounds is representative of the whole region. It is necessary to turn off the weight windows (by setting a lower bound of zero) or to further subdivide the geometry or energy or time phase space.

In MCNP4C mesh-based weight windows can be used to avoid modifying the geometry if the problem description is too coarse for cell-based weight windows. However, mesh-based weight windows have even more statistical fluctuations and are more difficult to adjust.

\section{OBJECTIVES}

There are many questions surrounding the new capabilities in MCNP4C. Whether MCNP4C generates and utilizes cell-based windows more or less efficiently than MCNP4B needs to be demonstrated. A thorough comparison of the mesh-based techniques to cell-based techniques is also desired. The addition of the weight window mesh introduced new parameters and techniques, which must be investigated as thoroughly as the application of the mesh. The location of coarse meshing and the number of fine gridding will influence the performance the mesh applying runs. Too coarse a mesh will produce a crude estimate of the importance function, whereas too fine a mesh will produce zero-windows due to insufficient sampling in addition to burdening the calculation. Finally, a primary purpose of mesh-based windows is to eliminate the tedious and error prone work of subdividing a geometry; we compare the performance of a simply defined problem using a mesh versus a fully divided problem using cell-based importances to assess whether subdivision of geometries is still required for variance reduction.

\section{METHODOLOGY}

To assess the new weight window and weight window generator capabilities of MCNP we have chosen five test problems. These problems all required strongly geometric dependent importance functions, with cell-based importances or weight windows varying over several orders of magnitude. These problems also have expert-determined importance functions. Our 
comparisons of the new capabilities are to problems that were optimized by experts as much as possible before the new methods were available; they demonstrate the improvements over the best that could be done previously rather than some poor importance function where almost anything is better. The benchmark problems are described in Section V.

Each test was simplified to its basic elements, including the source definition, geometry, and the optimized tally. Five copies of the problem were then created. The first was altered to generate cell-based weight windows for execution in MCNP4C, whereas the second was altered to generate cell-based weight windows for execution in MCNP4B. The third copy was altered to produce mesh-based weight windows using the cell-based importances or weight windows provided in the original problem. It was assumed that an expert user generated these importances and that they reflect a greater degree of insight and experience than most users of the code possess. The fourth copy created mesh-based weight windows but used either one or zero (binary) values for the initial importances.

Most difficult variance reduction problems are set up using many more geometric cells than are needed to describe the physical geometry of the problem. Typically one mean free path of the transported particle is used as a standard unit of subdivision length to aid in numerical calculation of a smoothly varying importance function throughout the problem. This results in ten to one hundred times more MCNP cell descriptions than are necessary to fully describe the model. A driving force behind the inception of mesh-based weight windows was the elimination of this tedious and error-prone pursuit; the fifth copy was simplified to contain only as many cells as were reasonably necessary to describe the problem. This fifth copy created a mesh using binary-valued importances in these new cells.

The MCNP4C cell-based weight window enhancements were assessed on the basis of generation and utilization of weight windows. Using MCNP4C and MCNP4B on the first and second copies to first generate nearly converged sets of cell-based weight windows, the output weight windows are applied as input to both MCNP4B and MCNP4C, resulting in four total runs applying newly generated cell-based weight windows. The figures of merit are then compared. The mesh-based weight windows generated were applied with the aforementioned variations and the results were compared to the results of the cell-based techniques.

Applying weight-window based variance reduction techniques in MCNP must usually be done as an iterative process. A thoughtful balance must be kept between generating an adequately converged set of windows and not devoting too much computation time towards 
this end. A set of windows generated by a run with $0.1 \%$ error will perform better than a set generated from a run with $30 \%$ error, but there is no reason to apply the more converged set because a sufficient solution has already been determined. We recommend that $10-20 \%$ error on the window-generating run should provide the necessary balance. Another recommendation is to run until the slope in the tally statistical analysis is greater than 3 .

Before the figures of merit are compared, however, a problem must be run long enough to meet several criteria indicating a converged solution. A run using an expert generated set of cell importances was run for $10^{7}$ histories typically to obtain a solution for comparison.

Note: The available installation packages for MCNP4B and MCNP4C apply different mcsetup.for routines. This application results in slightly different optimization options, and therefore the codes are not truly comparable. A large performance variation was observed which was solely due to this compilation variation. The solution to this problem was to consistently apply the mcsetup.for from MCNP4C for both MCNP4B and MCNP4C installation procedures.

\section{MODEL DESCRIPTIONS}

Five problems were selected to test the new features of MCNP4C. The problems chosen were: the skyshine and air over ground problems from the photon benchmark set, ${ }^{5}$ the fusion shielding from the neutron benchmark set, ${ }^{4}$ the oil well logging problem from the MCNP test set, and a neutron problem taken from the introductory and advanced classes on MCNP offered by the X-CI group in X-Division at Los Alamos National Laboratory. ${ }^{6}$

\section{A. Skyshine}

The photon skyshine problem ${ }^{5}$ is illustrated in Fig. 5.1. It consists of an infinitely opaque, open-top drum containing a cesium-137 point source resulting in a beam cone approximately $150^{\circ}$ pointed skyward. The drum sets on $9 \mathrm{~cm}$ of dirt with a hemisphere of air $1.2 \mathrm{~km}$ in radius surrounding the drum above the dirt. The rest of the world is modeled as void. For this study, the ring detectors were removed from all locations except at $0.7 \mathrm{~km}$ from the source, which was the most difficult tally. Additionally, thick target bremsstrahlung was turned off using the phys:p $2 j 1$ entry for efficiency. The exclusion of thick target bremsstrahlung treatment should not affect the relative performance when comparing importance functions. The base model input file used in all runs is appended as A1. The variations implemented on 
the base model to produce the runs in this assessment are detailed in A2 as obtained by the UNIX diff utility. The purpose of each of the runs listed in A2 is briefly described in table A3. Input for the simplified geometry is listed as A4. The complex description of the problem required 19 cells, whereas the simple model using mesh-based variance reduction required only 5.

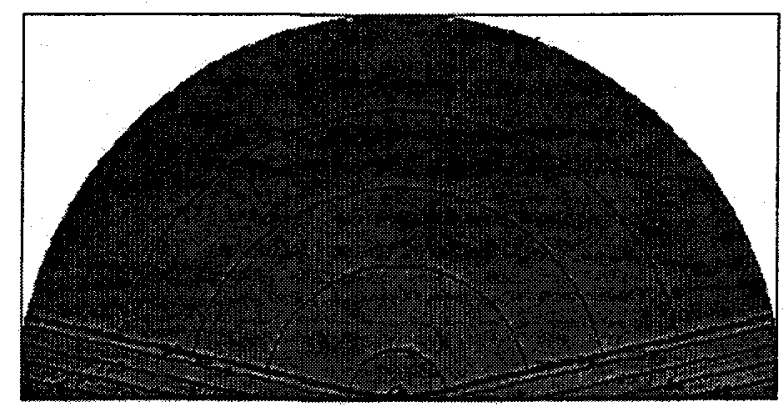

Fig. 5.1: Skyshine geometry plot from MCNP plotter.

\section{B. Fusion Shielding}

The seventh configuration of the fusion shielding iron benchmark problem ${ }^{4}$ was chosen, with a $55.88-\mathrm{cm}$-thick shield wall. The problem consists of $14 \mathrm{MeV}$ D-T fusion neutron source in a cement shield structure. An experimental shield configuration consisting of iron and borated polyethylene is placed between the beamline and an off-axis point detector. A stainless steel sheet is also used between the detector and the source. The cement walls of the experiment room are fully modeled, including three open doorways. Plots of the top view and side view are seen in Figs. 5.2 and 5.3. The base model used in all runs is appended as B1. The variations implemented on the base model to produce the runs in this assessment are detailed in B2 as obtained by the UNIX diff utility. The purpose of each of the runs listed in B2 is briefly described in table B3. Input for the simplified geometry is listed as B4. The complex description of the problem required 179 cells, whereas the simple model using mesh-based variance reduction required only 53 .

\section{Air Over Ground}

The photon air-over-ground deep penetration problem ${ }^{5}$ is illustrated in Fig. 5.4. A planar cobalt-60 source is distributed across a $1 \mathrm{~km}$ disc. Below the disc is soil; above, air. A detector at the center of the disc collects information on the modeled fallout dose levels. The base model used in all runs is appended as $\mathrm{C} 1$. The variations implemented on the base model 
to produce the runs in this assessment are detailed in $\mathrm{C} 2$ as obtained by the UNIX diff utility. The purpose of each of the runs listed in C2 is briefly described in Table C3. Input for the simplified geometry is listed as $\mathrm{C} 4$. The complex description of the problem required 122 cells, whereas the simple model using mesh-based variance reduction required only 4.

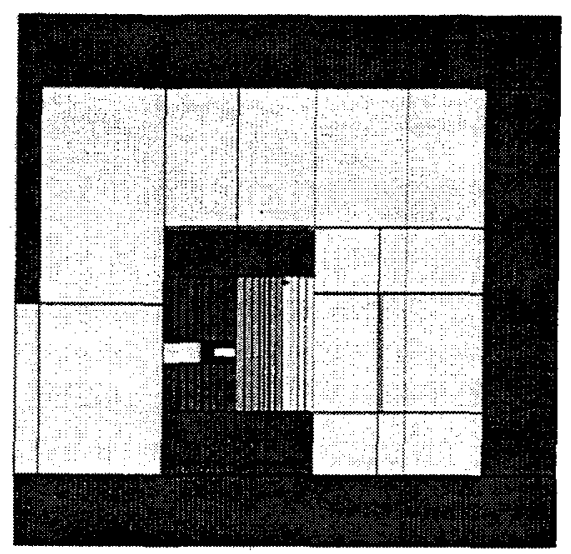

Fig. 5.2: Side view of the fusion problem geometry from MCNP plotter.

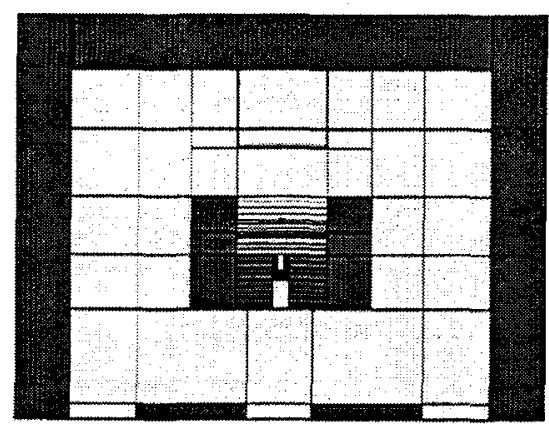

Fig. 5.3: Top view of the fusion problem geometry from MCNP plotter.

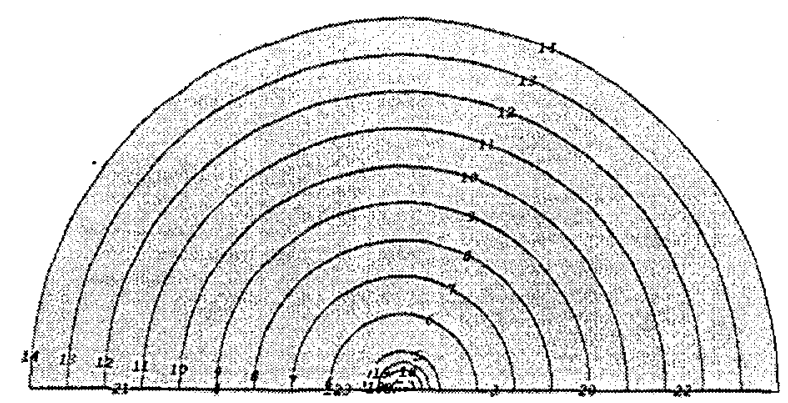

Fig. 5.4: Air over ground geometry plot from MCNP plotter 


\section{Oil Well Logging}

The oil well logging problem is from the MCNP4B test set and is illustrated in Fig. 5.5. In this problem, near and far helium-3 detectors are modeled to detect a signal from a neutron source in an iron rod (sonde). This iron sonde is deployed down a cylindrical shaft filled with water and surrounded with limestone. The sonde is placed off-center of the well axis. The neutron source emits over a continuum up to $11 \mathrm{MeV}$ and the tallies are binned into ten energy groups, allowing a spectrum to be analyzed. Only the far, optimized tally was retained in the model. The base model used in all runs is appended as D1. The variations implemented on the base model to produce the runs in this assessment are detailed in D2 as obtained by the UNIX diff utility. The purpose of each of the runs listed in D2 is briefly described in table D3. Input for the simplified geometry is listed as D4. The complex description of the problem required 231 cells, whereas the simple model using mesh-based variance reduction required only 7 .

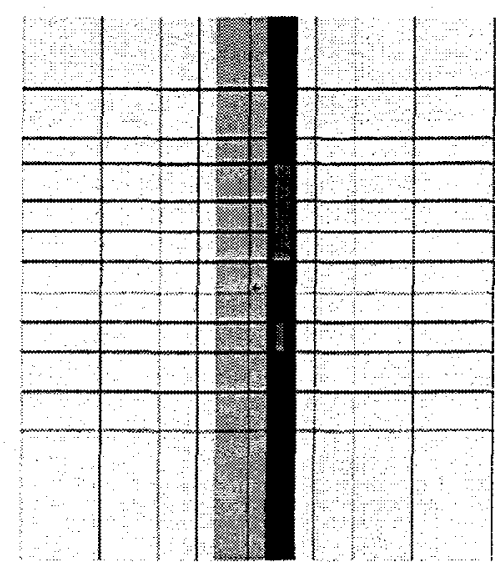

Fig. 5.5: Oil well logging problem geometry plot from MCNP plotter.

\section{E. MCNP Class Variance Reduction Problem}

The sample problem for variance reduction, ${ }^{6}$ which is used in the MCNP introductory and advanced classes to illustrate a truly challenging variance reduction problem, is illustrated in Fig. 5.6. It consists of a 20 -m-deep cylindrical well filled at the bottom with $180 \mathrm{~cm}$ of cement. A perfect absorber of zero importance surrounds the well, while a hundredth-density cement cell at the top of the well caps an intermediate region of void of unity importance. A detector outside the top of the well tallies neutrons introduced beneath the cement. The exponential transform, a DXTRAN sphere, forced collisions, and a point detector are all used. 
The base model used in all runs is appended as E1. The variations implemented on the base model to produce the runs in this assessment are detailed in E2 as obtained by the UNIX diff utility. The purpose of each of the runs listed in E2 is briefly described in Table E3. Input for the simplified geometry is listed as E4. The complex description of the problem required 23 cells, whereas the simple model using mesh-based variance reduction required only 7 .

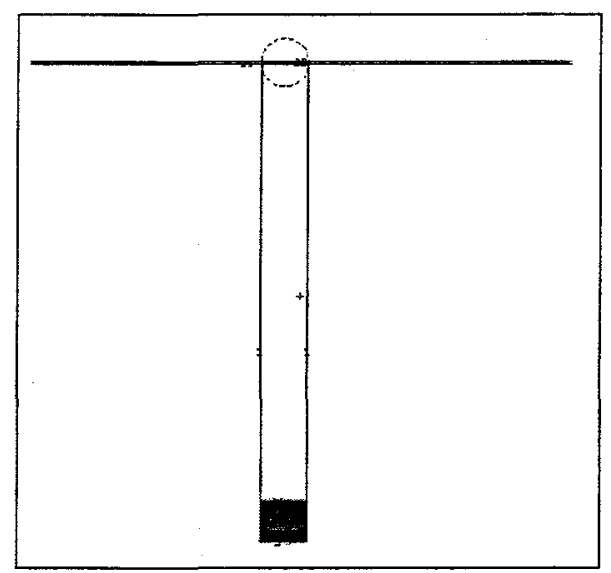

Fig. 5.6: Class variance reduction geometry plot from MCNP plotter.

\section{RESULTS}

\section{A. Window Utilization}

\section{Skyshine Problem.}

Given identical input weight windows, MCNP4C utilizes weight windows as effectively as MCNP4B, as seen in the figure-of-merit comparison shown in Fig. 6.1a. The $4 \mathrm{C}$ runs performed $1 \%$ slower than the $4 \mathrm{~B}$ runs, which is statistically insignificant.

Note that the run with windows generated and applied in $4 \mathrm{C}$ was performed using the wwout/wwinp feature. As MCNP4B does not allow automation of the weight window iteration process, the output weight windows were added by hand to the input files in the second generation for the other 3 runs. 


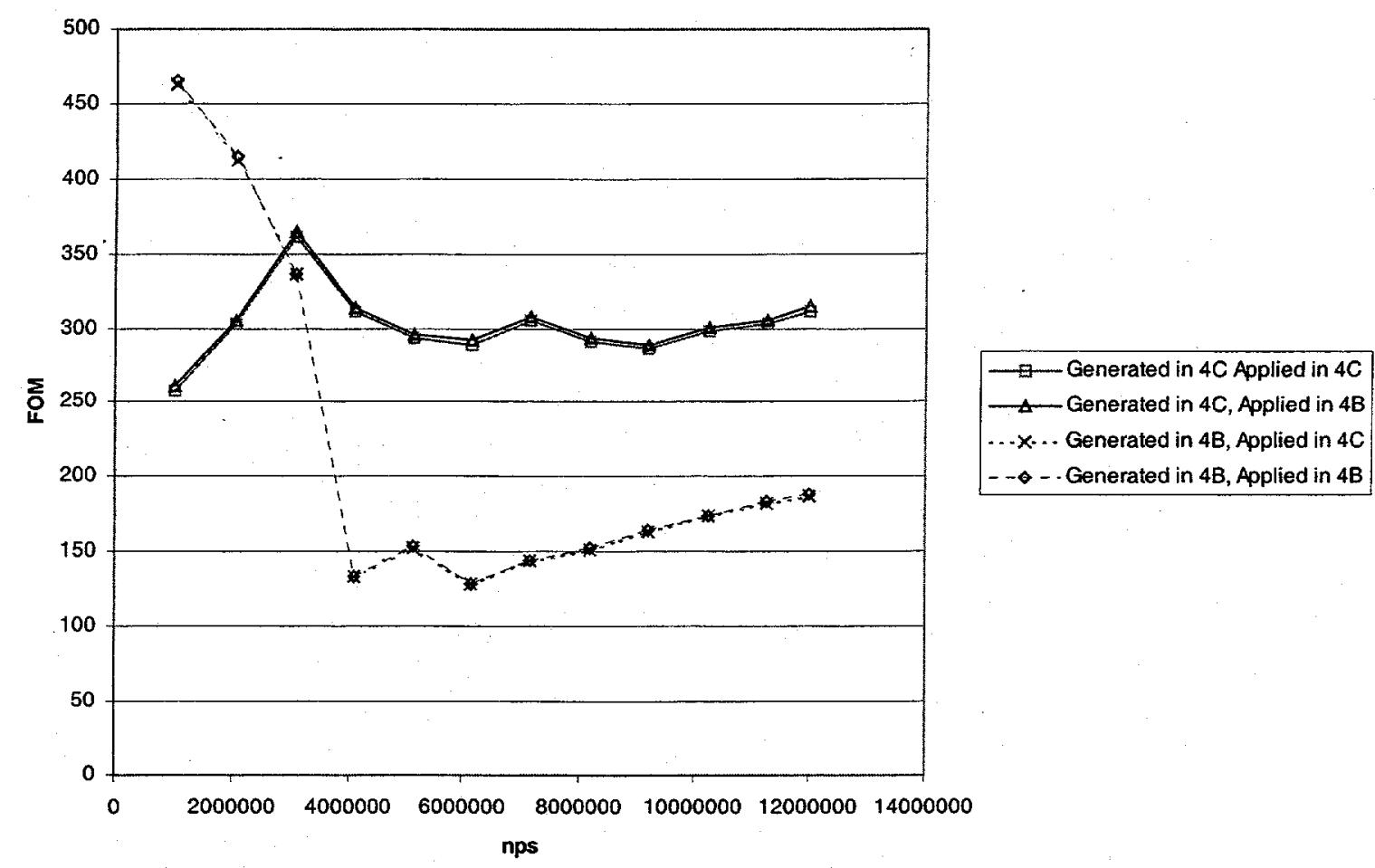

Fig. 6.1a: Skyshine problem.

\section{Fusion Problem}

Given identical input weight windows, MCNP4C utilized weight windows comparably or a little less effectively than MCNP4B. This is most easily observed in the figure-of-merit comparison shown in Fig. 6.1b. The results show a $6.5 \%$ improvement in $4 \mathrm{~B}$ over $4 \mathrm{C}$ for the runs in which the windows were generated in $4 \mathrm{C}$. The runs in which the weight windows were supplied by $4 \mathrm{~B}$ indicate nearly identical performance between $4 \mathrm{C}$ and $4 \mathrm{~B}$.

\section{Air Over Ground Problem}

Given identical input weight windows, MCNP4C utilized weight windows slightly more effectively than MCNP4B. This is most easily observed in the figure-of-merit comparison shown in Fig. 6.1c . The results show a total of only 6\% variation between all of the runs, but indicate higher performance when windows are run in $4 \mathrm{C}$ as opposed to $4 \mathrm{~B}$. Runs executed with $4 \mathrm{C}$ performed $5.5 \%$ higher than those executed with $4 \mathrm{~B}$ when applying $4 \mathrm{~B}$ generated windows. Runs executed with $4 \mathrm{C}$ performed $4.5 \%$ better than those executed with $4 \mathrm{~B}$ when applying $4 \mathrm{C}$ windows. The poor convergence is due to the mismatch of weight windows and source spatial bias described later. 


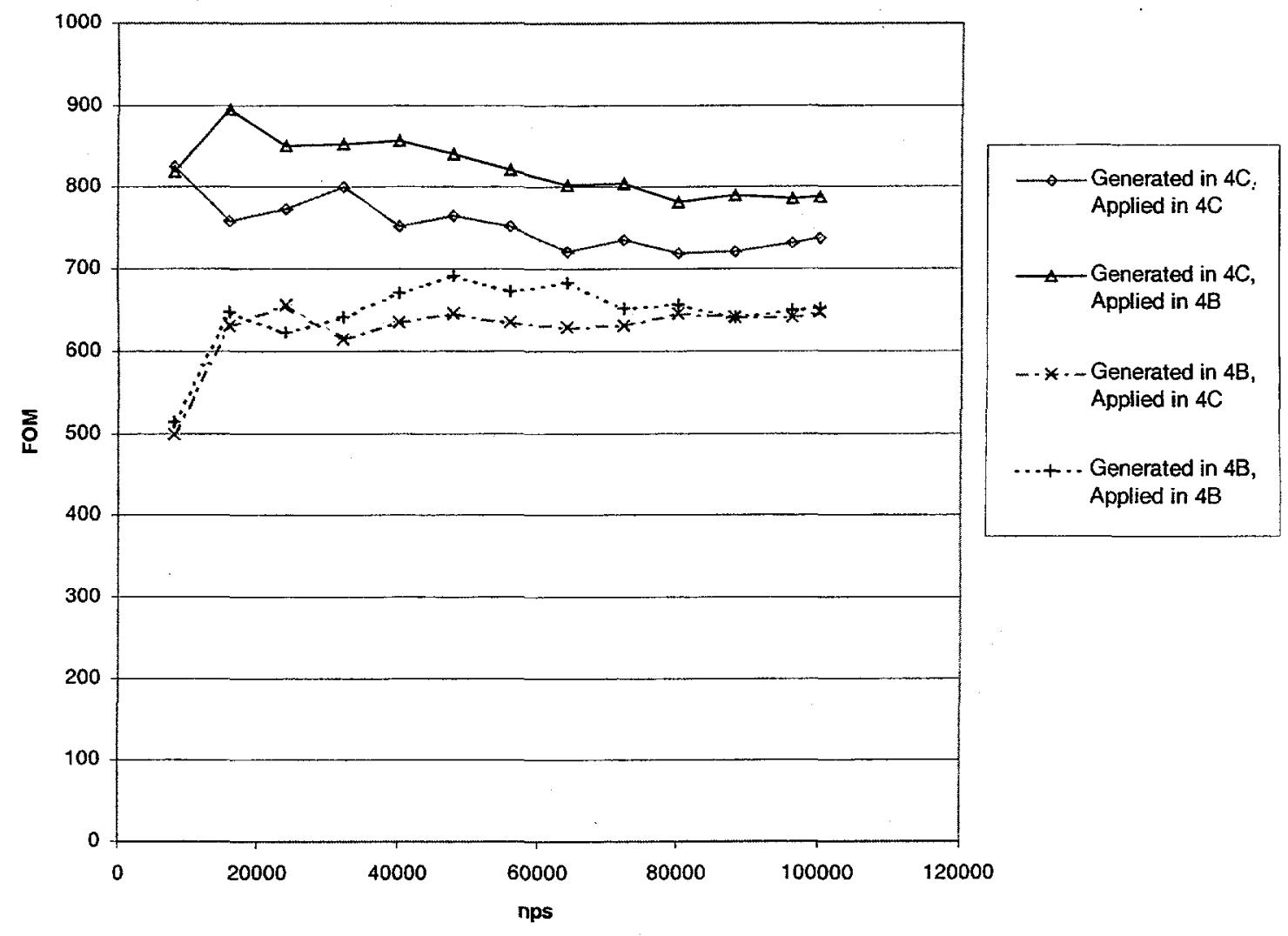

Fig. 6.1b: Fusion problem.

\section{Class Variance Reduction Problem}

Given identical input weight windows, MCNP4C utilized weight windows comparably to MCNP4B in this problem as can be observed in the figure-of-merit comparison shown in Fig. 6.1d. The final results showed a $1.5 \%$ performance improvement running in $4 \mathrm{C}$ compared to $4 \mathrm{~B}$ when using $4 \mathrm{C}$ windows. A $1.3 \%$ improvement was observed when running in $4 \mathrm{C}$ compared to $4 \mathrm{~B}$ when applying $4 \mathrm{~B}$ windows. 


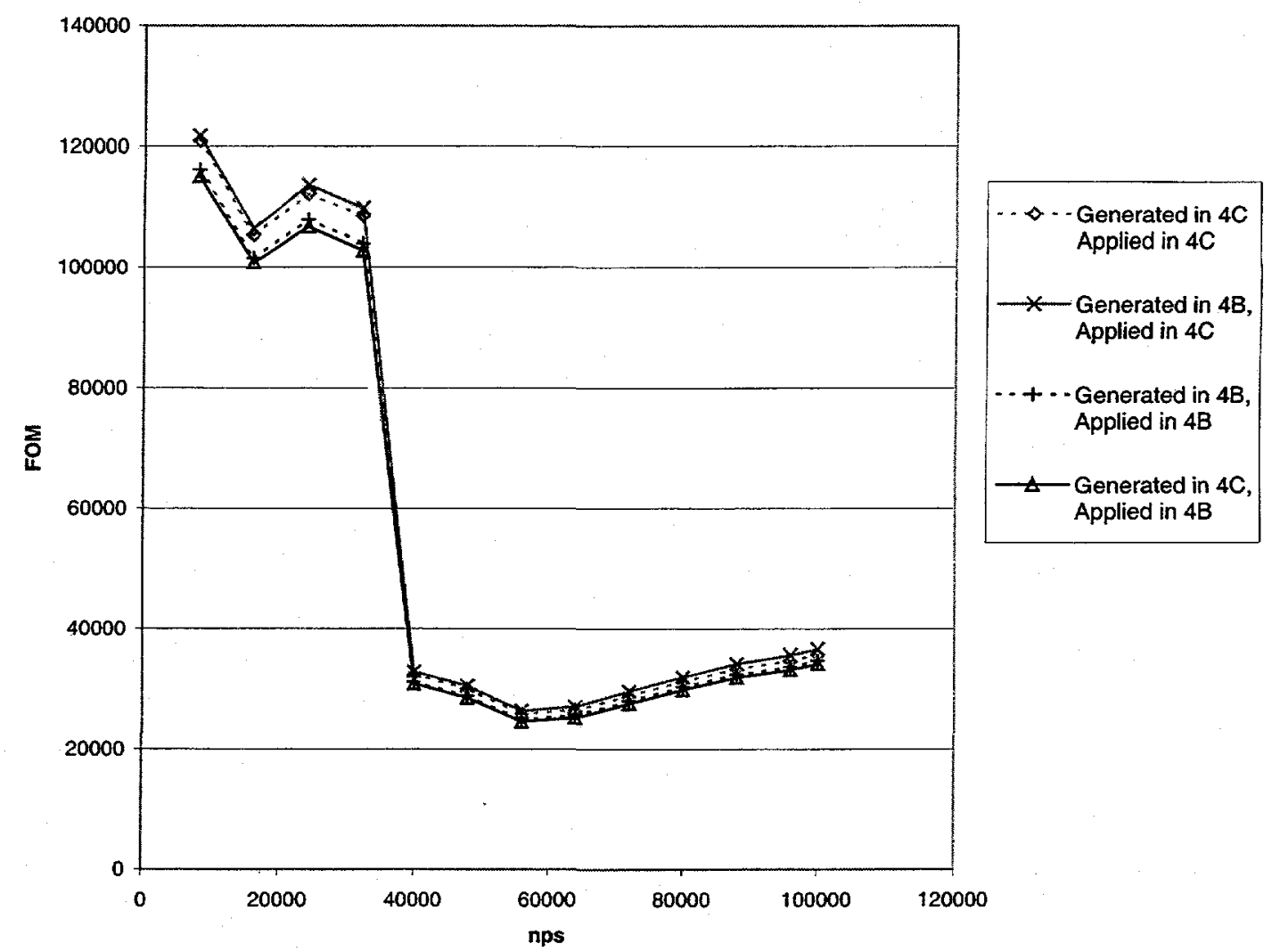

Fig. 6.1c: Air over ground problem.

\section{Oil Well Problem}

Given identical input weight windows, MCNP4C utilized weight windows more effectively than MCNP4B in this problem as is most easily observed in the figure-of-merit comparison shown in Fig. 6.1e. The results show an $11.8 \%$ improvement in $4 \mathrm{C}$ over $4 \mathrm{~B}$ for the runs in which the windows were generated in $4 \mathrm{C}$. The runs in which the weight windows were supplied by $4 \mathrm{~B}$ indicate an $11.9 \%$ improvement in $4 \mathrm{C}$ over $4 \mathrm{~B}$. 


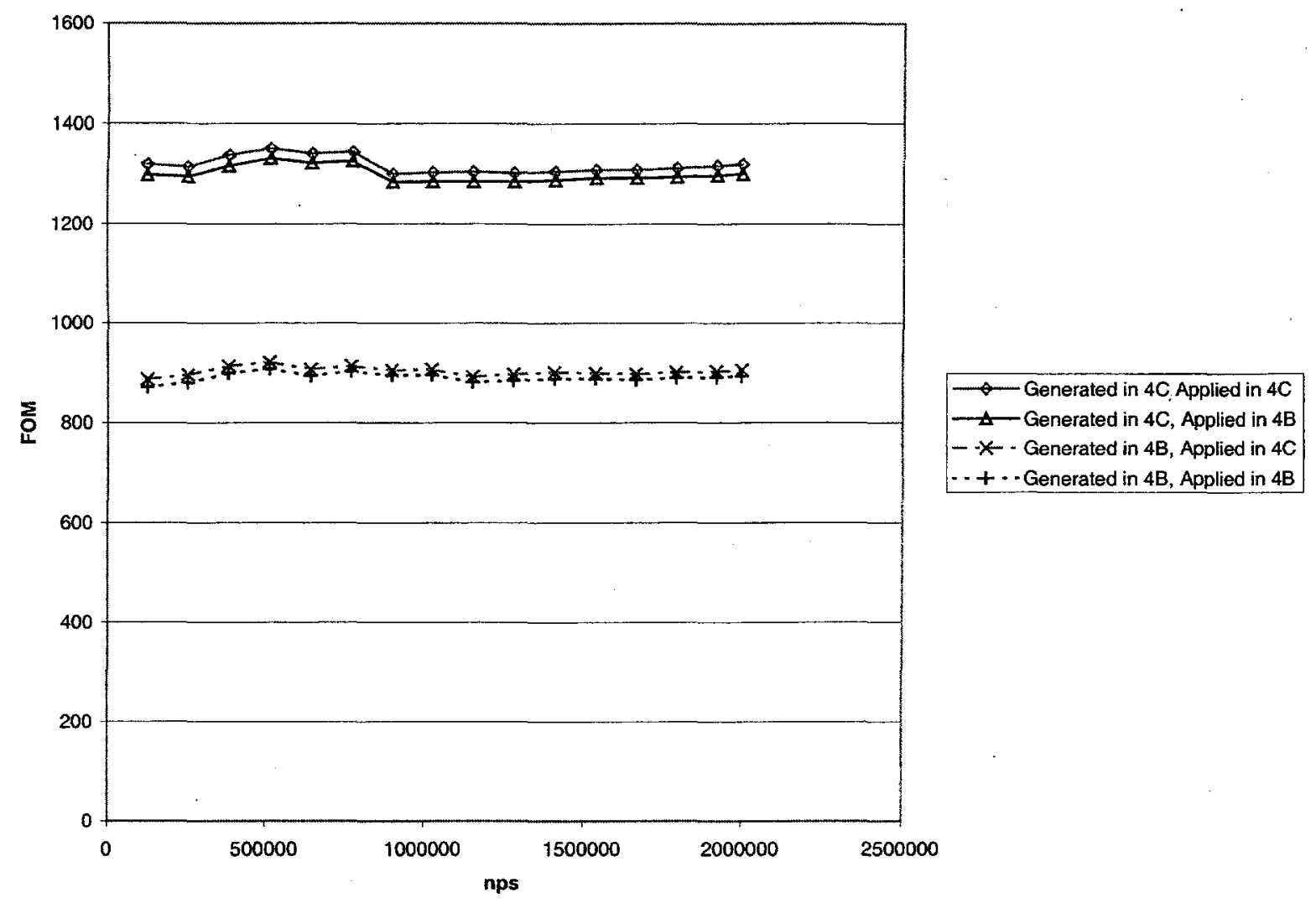

Fig. 6.1d: Class problem.

\section{B. Window Generation}

\section{Skyshine Problem}

MCNP4C generates cell-based weight windows more effectively than MCNP4B, as demonstrated in Fig. 6.1a. The weight windows generated in 4B evidently lead to poor convergence as suggested by the sharp fall in the figure-of-merit and a slope just under 3 , although the calculated means were correct in all cases. Windows generated in $4 \mathrm{C}$ outperformed $4 \mathrm{~B}$ windows by $66.8 \%$ when executed in $4 \mathrm{C}$. When executed in $4 \mathrm{~B}, 4 \mathrm{C}$ windows outperformed $4 \mathrm{~B}$ windows by $67.6 \%$.

\section{Fusion Problem}

MCNP4C generates cell-based weight windows more effectively than MCNP4B, as demonstrated in Fig. 6.1b. The windows generated with $4 \mathrm{C}$ outperformed the windows generated by $4 \mathrm{~B}$ by $14.7 \%$ when executed in $4 \mathrm{C}$. When executed in $4 \mathrm{~B}, 4 \mathrm{C}$ windows outperformed $4 \mathrm{~B}$ windows by $20.8 \%$. 


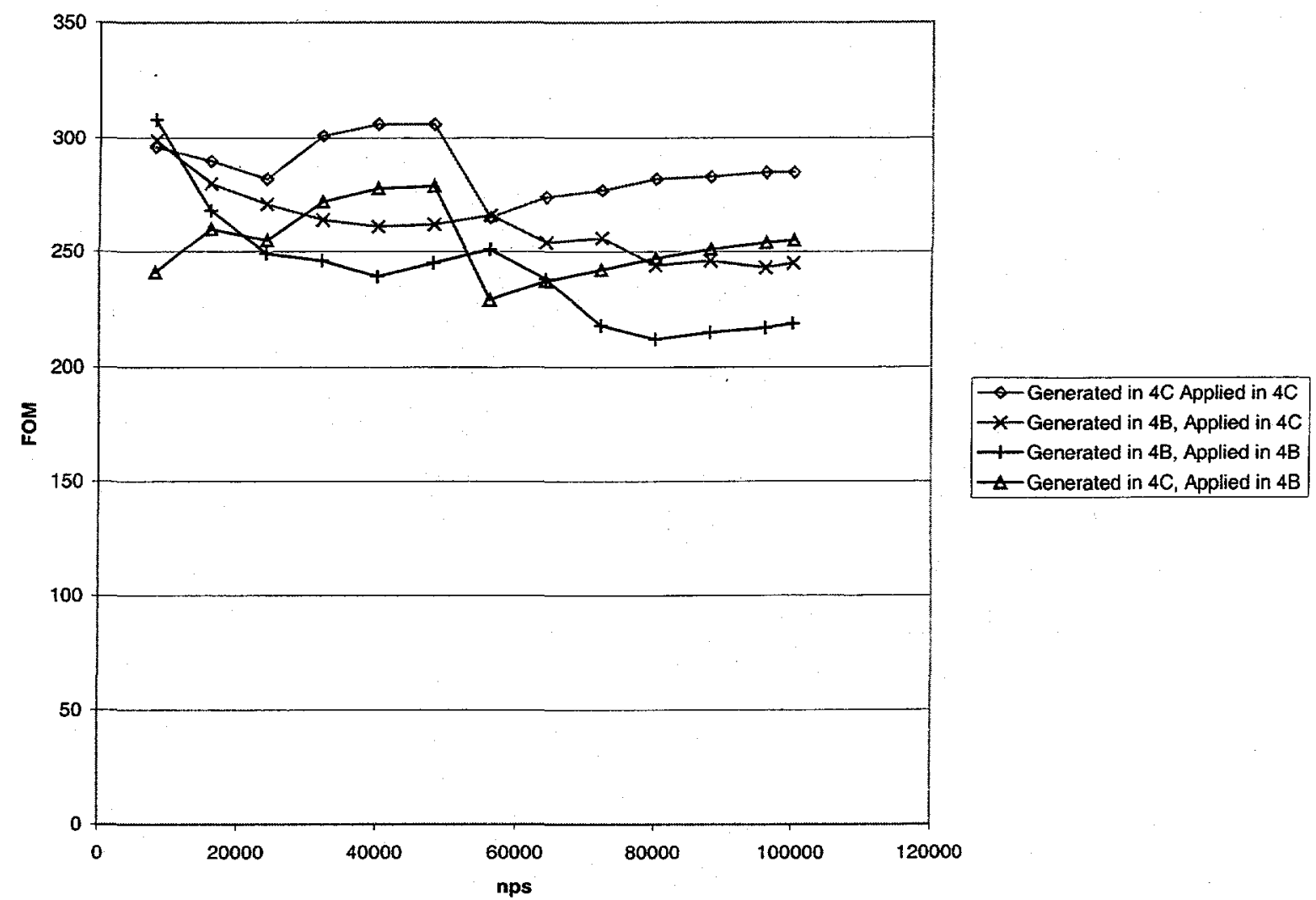

Fig. 6.1e: Oil well logging.

\section{Air Over Ground Problem}

MCNP4C generated cell-based windows slightly less effectively that MCNP4B in this particular problem, as demonstrated in Fig. 6.1c. Runs executed in $4 \mathrm{C}$ performed $2.5 \%$ slower with windows generated in $4 \mathrm{C}$ than with window generated in $4 \mathrm{~B}$. Runs executed in $4 \mathrm{~B}$ performed $1.7 \%$ slower with windows generated in $4 \mathrm{C}$ than with windows generated in $4 \mathrm{~B}$.

\section{Class Variance Reduction Problem}

MCNP4C generated cell-based weight windows more effectively than MCNP4B in this problem, as demonstrated in Fig. 6.1d. Windows generated by $4 \mathrm{C}$ outperformed $4 \mathrm{~B}$ windows by $45.4 \%$ when applied in $4 \mathrm{~B}$. When applied in $4 \mathrm{C}$, windows generated in $4 \mathrm{C}$ outperformed $4 \mathrm{~B}$ windows by $45.6 \%$.

\section{Oil Well Problem}

MCNP4C generated cell-based windows more effectively than MCNP4B in this particular problem, as demonstrated in Fig. 6.1e. Runs executed in $4 \mathrm{C}$ performed $16.3 \%$ better 
with windows generated in $4 \mathrm{C}$ than with windows generated in $4 \mathrm{~B}$. Runs executed in $4 \mathrm{~B}$ performed $16.4 \%$ better with windows generated in $4 \mathrm{C}$ than with windows generated in $4 \mathrm{~B}$.

\section{Mesh-Based Weight Windows \\ 1. Skyshine Problem}

The mesh-based window generator outperformed both cell-based importance and cellbased window techniques in $4 \mathrm{C}$ and $4 \mathrm{~B}$ by about a factor of 4 . The performance of the mesh varied only slightly based upon the initial guesses of cell importances, and geometry subdivision insignificantly affected the solution. This variation is shown in Fig. 6.2c, comparing the applied mesh-based window runs to a run with cell-based windows generated in 4C and applied in 4C. Performance is obviously a function of the mesh configuration. Sensitivity of performance to coarse grid location and the number of fine grids might be the subject of future investigations.

Meshes generated from runs expert-guessed importances and from simply defined, binary-valued importances produced similar figures of merit, indicating that a satisfactory mesh can be produced without any prior knowledge of the problem. The simply defined geometry performed only about $10 \%$ poorer than the expert-generated mesh, due to a more poorly converged mesh-generation run.

An additional concern surrounding mesh-based weight windows was whether high mesh weights caused by incomplete sampling of the geometry would force a weight cut-off game in those regions, limiting the effectiveness of the windows. A run (not shown) was performed in which a smoothed set of windows replaced the input weights for the complex, expert-guessed run. The results were identical, suggesting that the weight cut-off game was not a large burden on performance. The weight cut-off card was set to a conservative value of $-10^{-5}$ in both runs, however, so a thorough test must be performed at a larger value for more meaningful results.

\section{Fusion Problem}

The mesh-based window generator in $4 \mathrm{C}$ performed about $3.4 \%$ better than cell-based techniques in $4 \mathrm{C}$ for the second-generation runs when the mesh was generated in the detailed geometry using expert importances. The performance of the mesh varied according to the initial setup, as seen in Fig. 6.2b. The run performed in a simplified geometry (here 42 cells as opposed to 177) had a figure-of-merit $20-30 \%$ that of the run generated and applied using 
expert importances. To understand why, the meshes generated from the expert importance 177-cell initial run and the binary importance 177-cell initial run were tried on the 177 and 42cell geometries as shown in Fig. 6.3a. For either geometry the expert mesh is superior to the binary mesh, and for either mesh the simple geometry is better than the detailed geometry. From Fig. 6.3a we observe that the expert mesh, generated from a run with good importances, is better than the binary-generated mesh run which just had ones and zeros for importances. Also, the simple geometry using the binary-generated mesh outperforms the expert importance, complex geometry using the same mesh by $31.1 \%$. This speed-up can only be due to the less complicated cell make-up, as no weight-cutoff game was played in either run. A similar improvement of $28.4 \%$ was observed in the expert mesh when applied to the simple-geometry model and applied to the binary importance model.

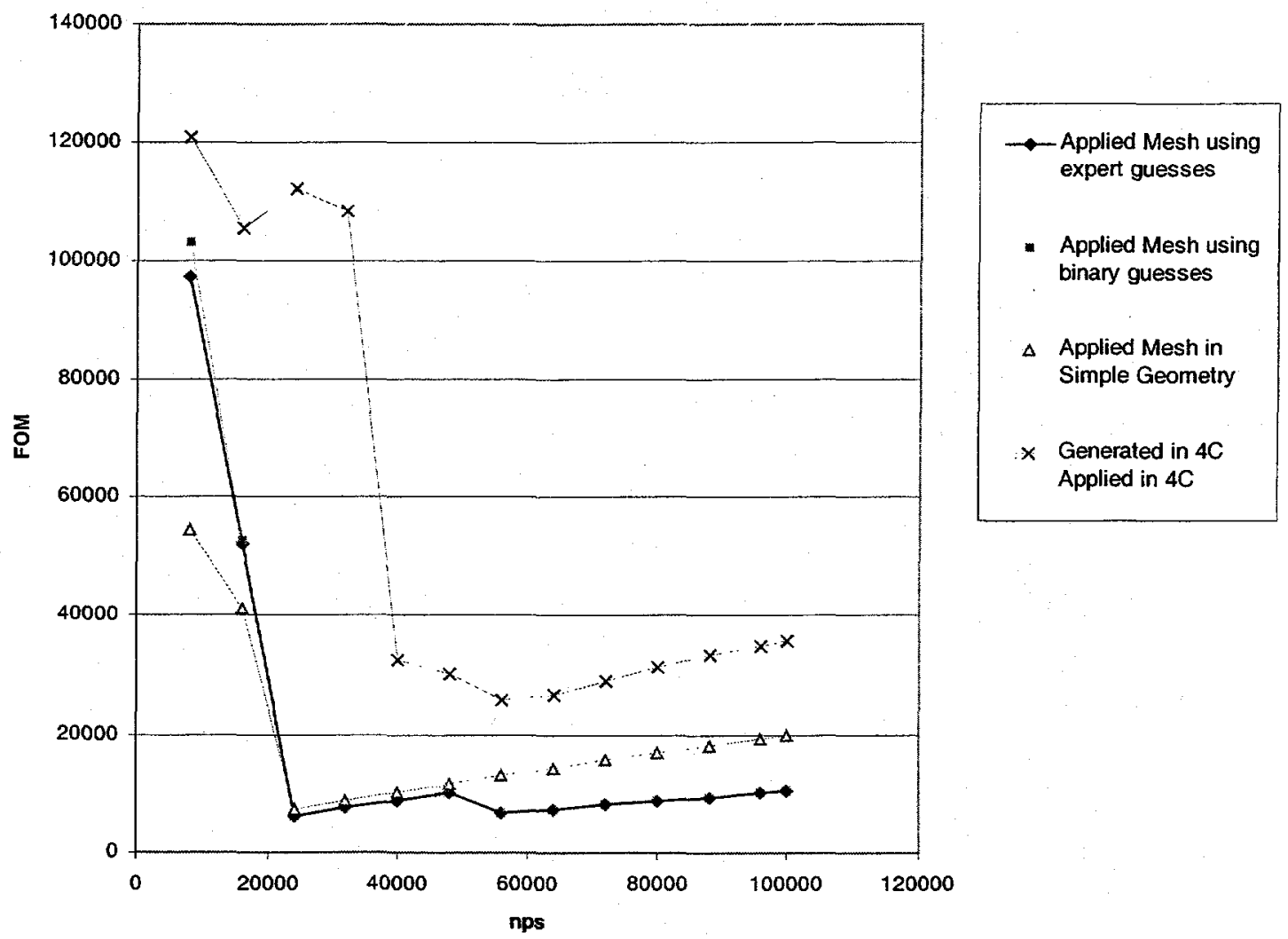

Fig. 6.2a: Air over ground problem. 

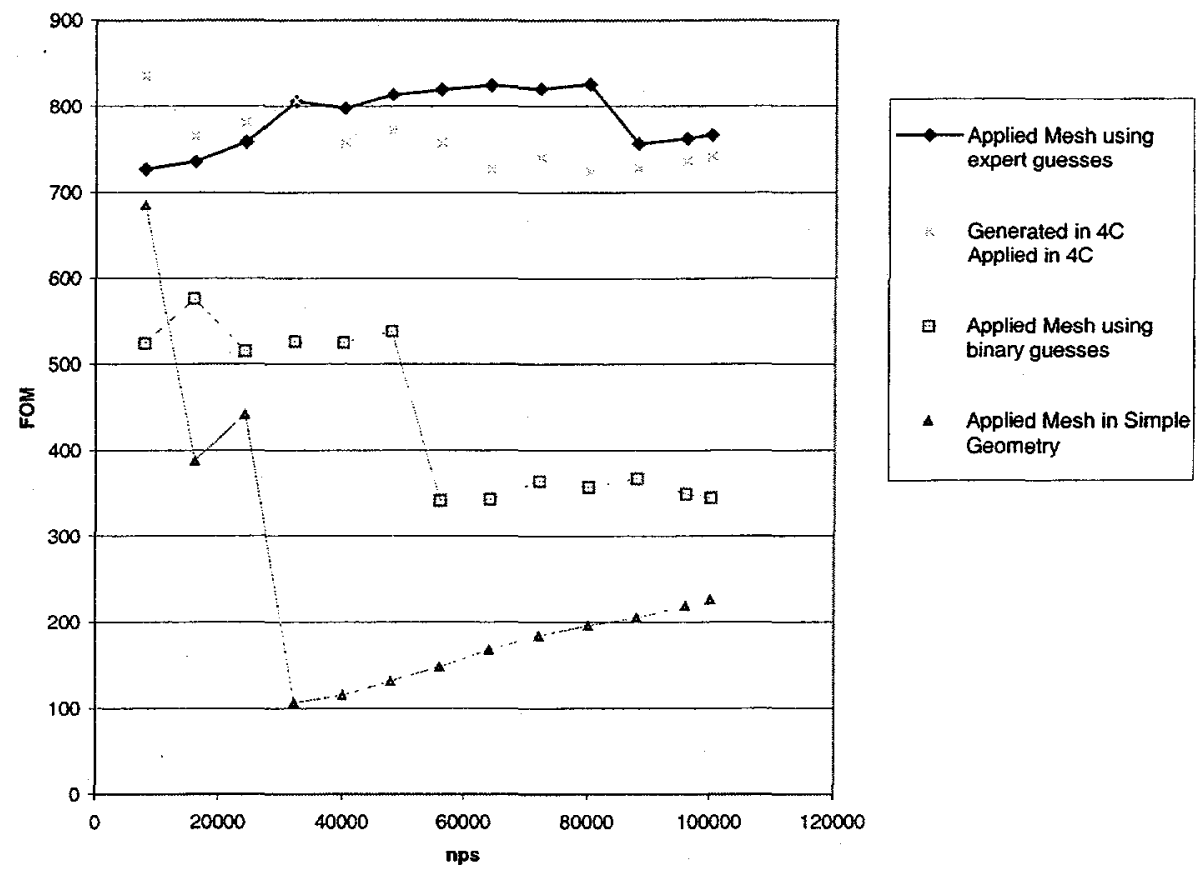

Fig. 6.2b: Fusion problem.

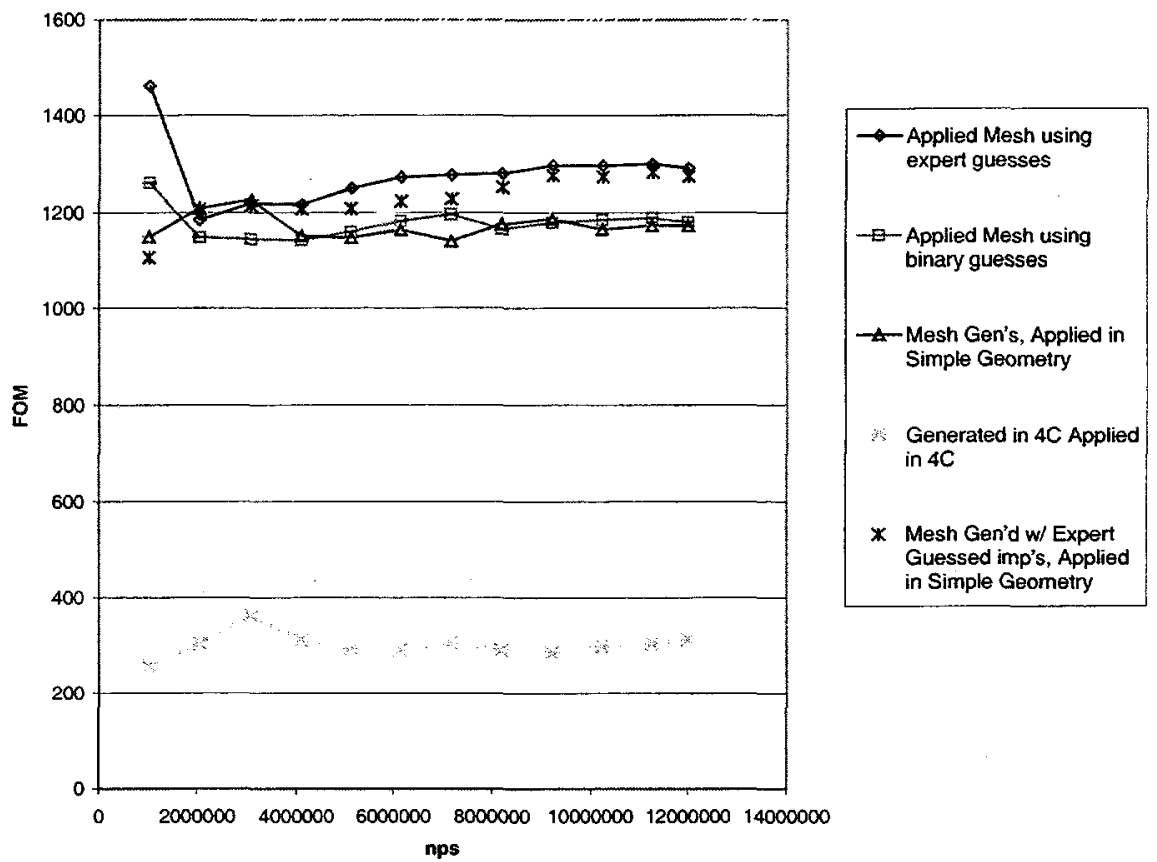

Fig. 6.2c: Skyshine problem. 


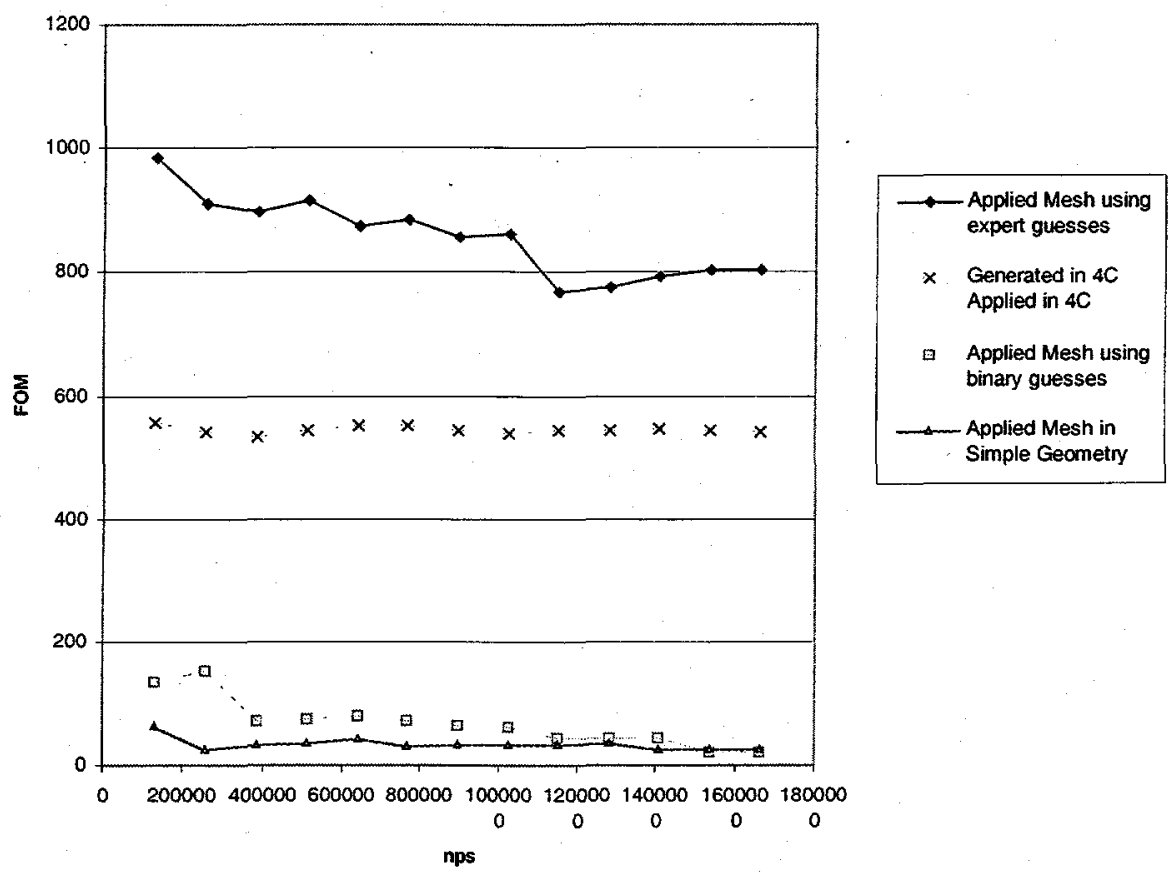

Fig. 6.2d: Class problem.

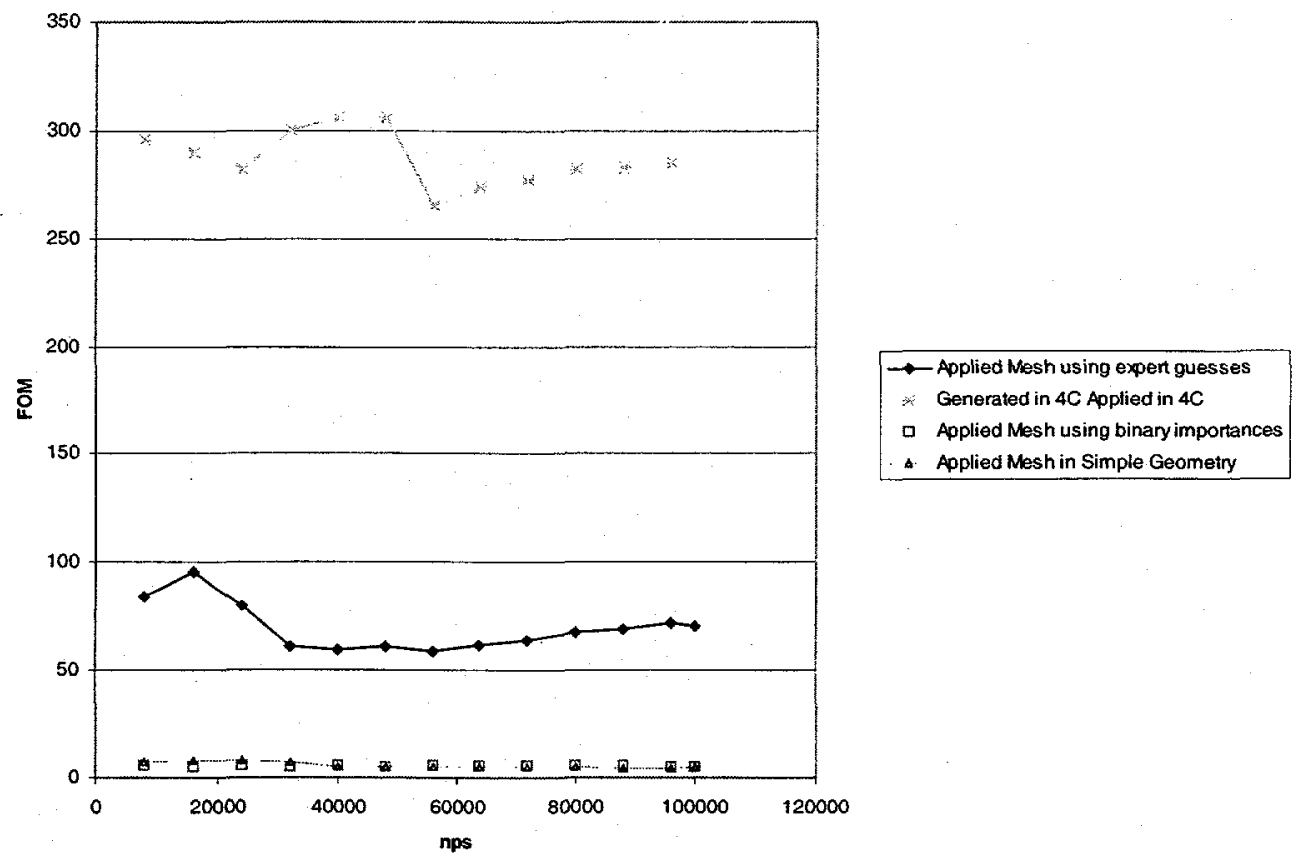

Fig. 6.2e: Oil well. 
Another investigation was performed to determine the performance of mesh-based weight windows in iteration. All three fusion models (detailed geometry with expert importance function, detailed geometry with binary importances, and simple geometry with binary importances) were run for five generations, resulting in the originally generated mesh and two successive improved meshes. Selected results are shown in Fig. 6.3b and indicate that after 2-3 generations, the mesh-based wiindows can equal or better the original expert, cellbased windows (Fig. 6.2b).

\section{Air Over Ground Problem}

From Fig. 6.2a it is observed that mesh-based windows generated by the simple geometry were comparable to those generated by the detailed geometry. Thus subdivision is not necessary on this problem. Windows generated from the complex model with binary initial importances are also as good as those generated using expert importances in detailed geometry. Again, the geometry subdivision proves unnecessary.

All calculations had convergence problems due to the source bias not matching the weight windows. In all calculations applying the windows, all source particles started below the window value. When poorly combined in this manner, the two techniques perform worse than either technique alone, in effect canceling out benefits while increasing computational overhead. (The advisability of using source biasing alone in such cases has been recommended by $H$. Lichtenstein. ${ }^{7}$ )

This failing points out the need for a simple method of renormalizing the windows to lower (or higher if required) values than originally generated. Note that to generate usable windows, the initial generating run had to be run almost to convergence. If there had been a mechanism for matching source bias to the generated windows or renormalizing the windows, then we speculate that windows could be used and iterated upon from shorter generating runs.

The poor match between generated windows and source bias implies that the expertguessed source bias and importances were far from ideal. Thus we further speculate that if there were a means of correctly adjusting generated windows with source bias, then the new weight window generator would give even better results than expert guesses rather than comparable answers. Even with the current limitations, the first iteration of runs applying the generated windows had a FOM 100 times better than the first iteration of the expert-guessed importances, which exhibited identical non-convergent behavior and at $10^{5}$ particles reached a figure-of-merit of 113 . 


\section{Class Variance Reduction Problem}

The expert-importance generated mesh performed $51.6 \%$ better than cell-based techniques in $4 \mathrm{C}$ in the second-generation runs. The mesh application runs using binary importances in the complex geometry and the simple geometry performed far worse than the cell-based techniques, as shown in Fig. 6.2d.

Upon iterating the mesh-based weight windows, a large improvement over the initial mesh application runs, which were far from converged, was observed in the binary importance and simple models. The simple model error was reduced from $86 \%$ to $0.9 \%$ in 5 generations, whereas the binary model error was reduced from $52 \%$ to $0.7 \%$. This success is shown in Fig. 6.3c. The results indicate that after enough generations, the mesh-based model betters the original expert, cell-based model. Noteworthy in these results is the apparent degradation of the simple model in the third iteration and the subsequent recovery in the fourth and fifth generations and the convergence of the simple and binary models despite large errors and small slopes in the generating run.

\section{Oil Well Problem}

The mesh-based window generator in $4 \mathrm{C}$ performed much poorer than cell-based techniques in $4 \mathrm{C}$ for the second-generation runs. The performance of the mesh varied according to the initial setup, as seen in Fig. 6.2e. The run performed in a simplified geometry had a much lower figure-of-merit than the run generated and applied using expert importances, but all mesh-based runs were outperformed by the cell-based run generated and applied in $4 \mathrm{C}$.

Another investigation was performed to determine the performance of mesh-based weight windows during iterations. All three models were run for five additional generations, resulting in the originally generated mesh and four successive improved meshes. The results are shown in Fig. 6.3d and indicate that after enough generations, the figure-of-merit for the meshbased model is within a factor of two of the original expert, cell-based model. Again, the generating runs were run to $20 \%$ relative error and iterated upon.

Originally a cylindrical mesh was used, yielding the poor results of Fig. 6.2c. Later, a rectangular mesh was used yielding the better results in Fig. 6.3d. The rectangular mesh is far faster than the cylindrical mesh and should be used preferentially. 


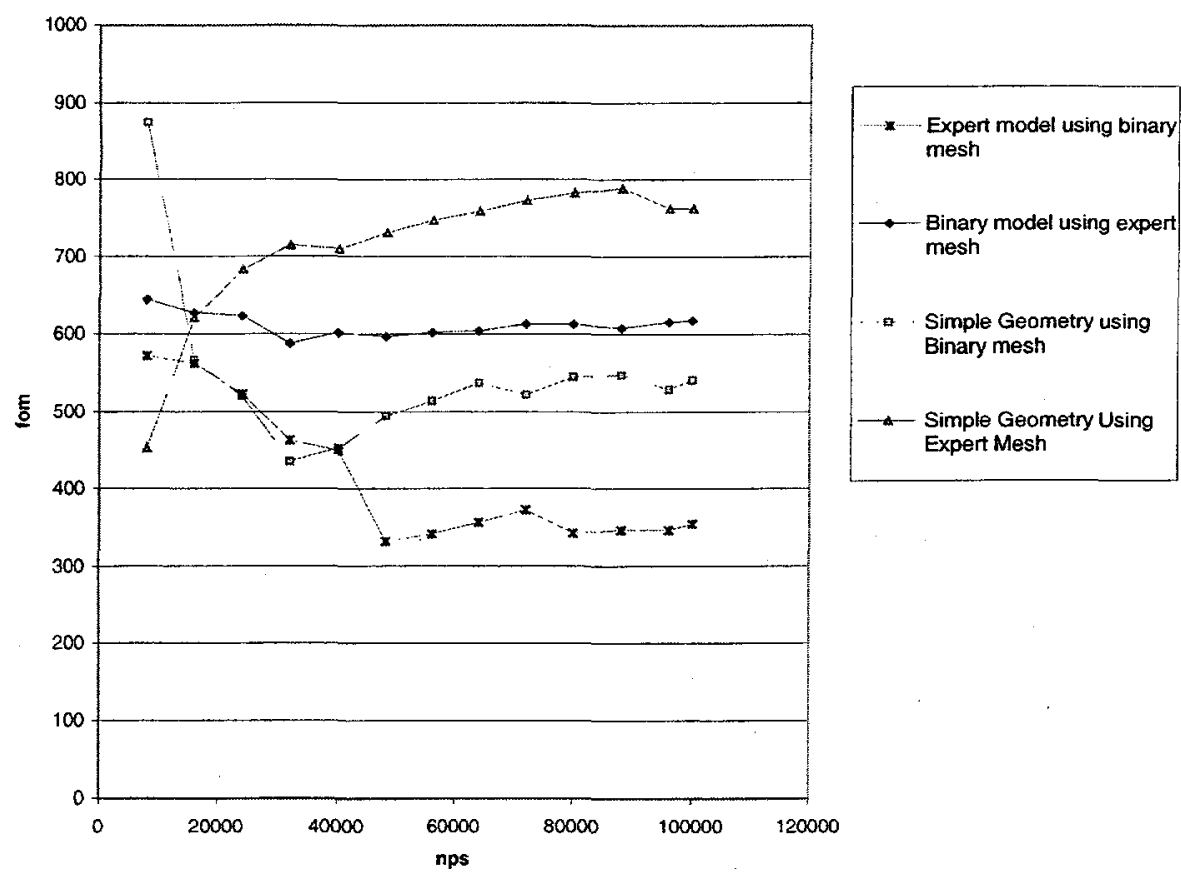

Fig. 6.3a: Fusion problem.

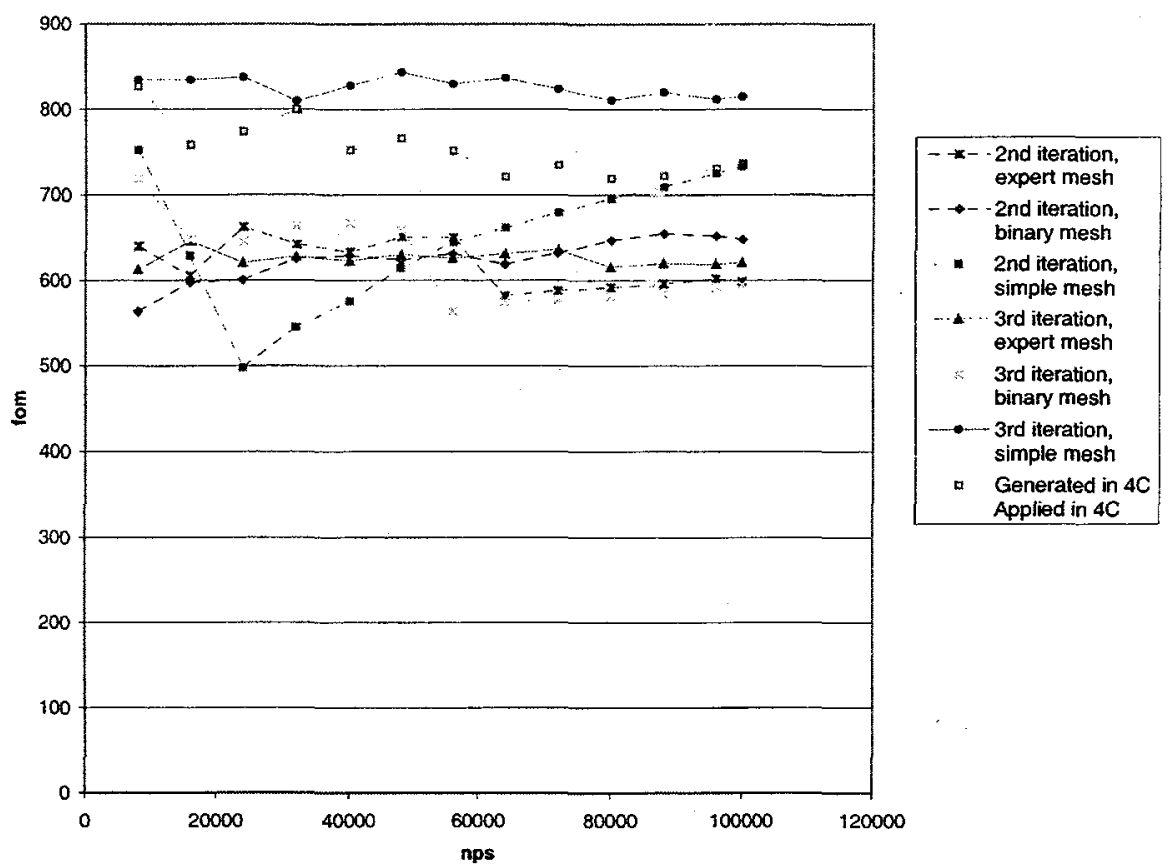

Fig. 6.3b: Fusion problem. 


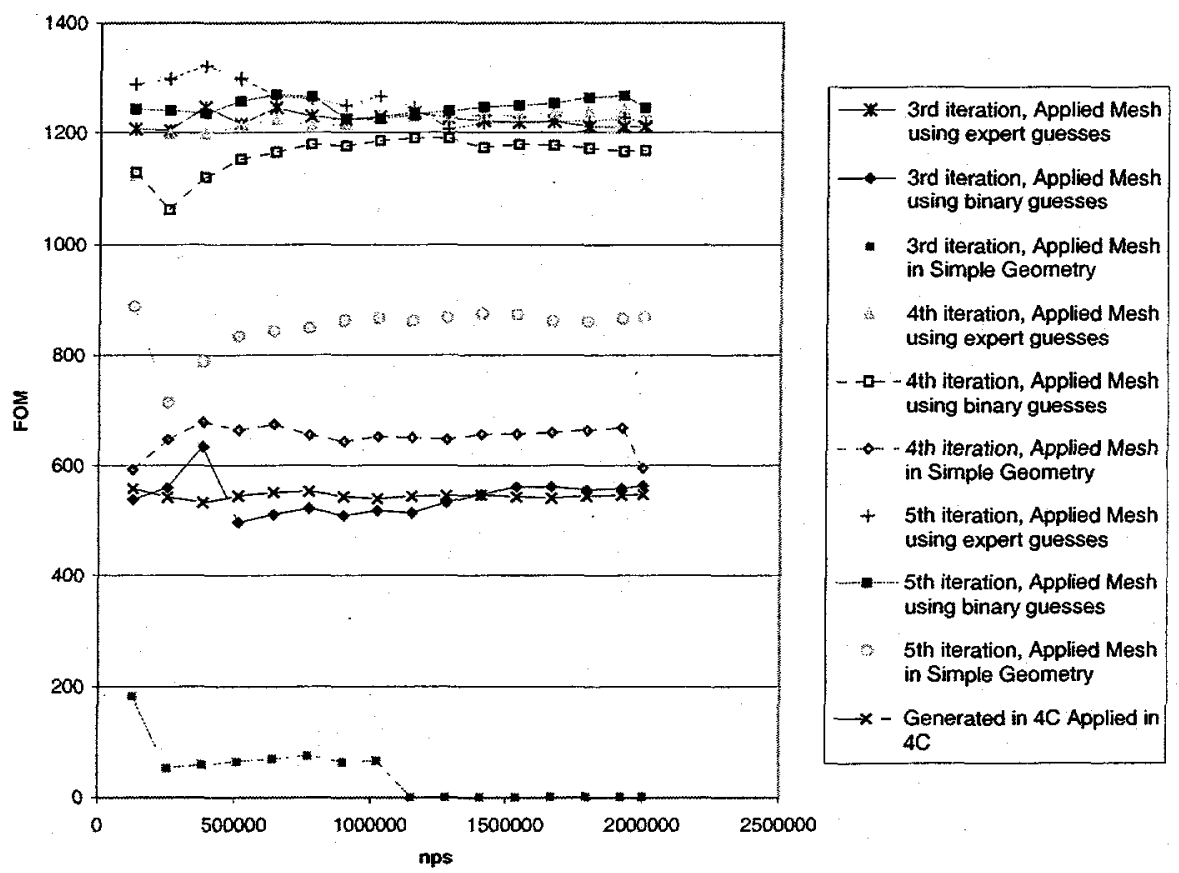

Fig. 6.3c: Class problem.

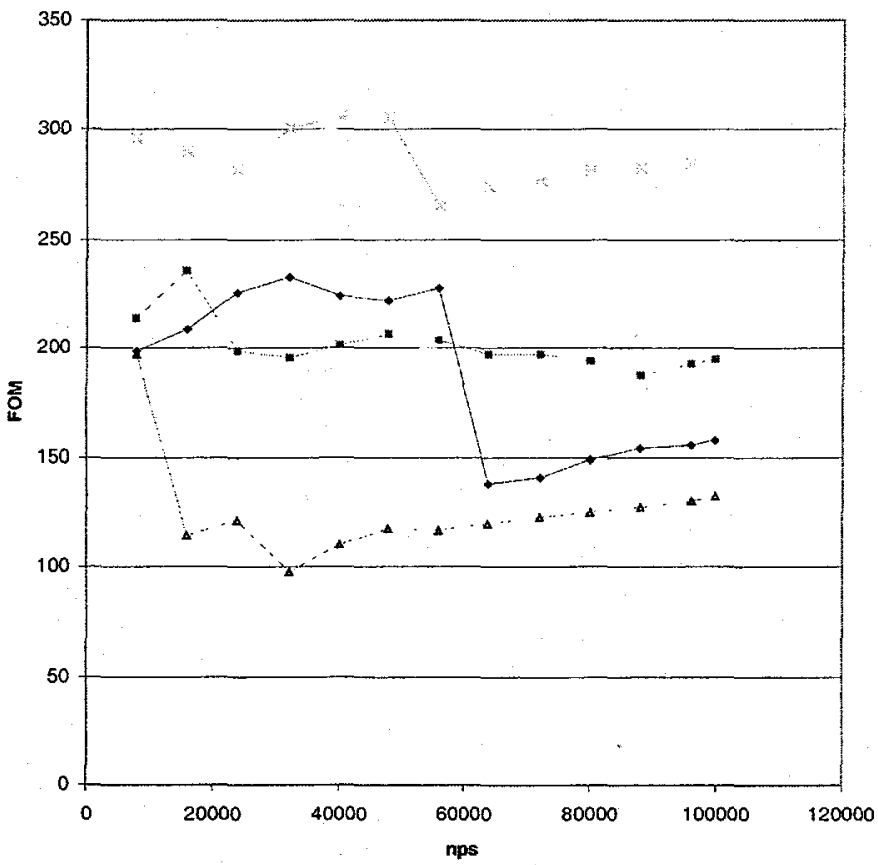

\begin{tabular}{|c|c|}
\hline & $\begin{array}{l}\text { Generated in } 4 C \\
\text { Applied in } 4 \mathrm{C}\end{array}$ \\
\hline & $\begin{array}{l}\text { Applied Mesh } \\
\text { using expert } \\
\text { guesses } \\
\text { Applied Mesh in } \\
\text { Simple Geometry }\end{array}$ \\
\hline & $\begin{array}{l}\text { Applied Mesh } \\
\text { using binary } \\
\text { guesses }\end{array}$ \\
\hline
\end{tabular}

Fig. 6.3d: Fifth iteration, oil well. 


\section{GUIDELINES}

Our experience with the MCNP4C weight windows and weight window generator leads us to the following recommended guidelines for their utilization.

Whether using cell-based or mesh-based generated weight windows, if the generated windows are poor they will not improve the figure-of-merit (FOM) for the calculation of interest. On the other hand, if the generating run is converged, then there is no need to utilize the generated windows because the answer will be good enough. We therefore suggest the following methodology to properly utilize the weight window generator.

\section{A. WHEN TO USE CELL-BASED OR MESH-BASED WINDOWS}

If the calculational geometry is finely divided into cells appropriate for variance reduction, then cell-based windows are adequate, faster, and easier to understand and utilize. MCNP will automatically print out a table of adjacent weight windows whose ratio differs by more than a factor of 4 making it easier to identify badly generated windows. These can then be adjusted manually. Cell-based windows can also be input in the INP file so that it is easier to keep track of which importance function was actually used for a given calculation.

We recommend the use of cell-based weight windows when the problem geometry is sufficiently subdivided so that the importance function does not differ by more than a factor of 4 from cell to cell. In reality, most problems are not sufficiently subdivided in geometry to effectively utilize cell-based weight windows.

We recommend the use of mesh-based weight windows when the importance function varies significantly within important geometric cells. Our experience is that a variation by more than a factor of 10 within an important geometric cell justifies either further subdividing the geometry for cell-based windows or using mesh-based weight windows. Thus the meshbased windows are recommended for most problems because further subdivision of a geometry for variance reduction is difficult. Generally the mesh-based windows have been observed to outperform the cell-based windows.

Note that the DXTRAN sphere cutoffs are utilized with cell-based weight windows and not mesh-based windows, which may affect your choice of cell- or meshed-based windows when using DXTRAN. 
Point detector contribution (PD card) and DXTRAN contribution (DXC card) roulette games work only for cells and not meshes. If these variance reduction games are needed, subdividing cells rather than utilizing meshes may be warranted.

\section{B. Guidelines for Specifying Superimposed Meshes.}

The MCNP4C mesh card specifies the mesh upon which weight windows will be generated. In subsequent runs utilizing the generated weight windows, this mesh is carried over.

We recommend that the superimposed mesh be slightly larger than the underlying problem. If it is not, then particles may still be in the problem but not be able to determine the appropriate weight window. A warning error will be issued, and there is no appropriate weight control.

Although the external mesh boundaries should not lie on problem surfaces, but extend beyond them, we have no recommendation for internal problem surfaces even though which mesh cell weight window is used when a particle crosses a problem surface will be determined by roundoff. We have observed no adverse effects whether the mesh lies on internal surfaces or is slightly offset.

Fine meshes should be spaced about 1 mean free path apart, unless finer spacing is required to get close to problem surface boundaries. We have tried "smart" meshes in which case we paid attention to the problem surfaces inside the mesh, and "dumb" meshes in which case the mesh was set up with no concern about the underlying geometry. The smart meshes provide better results, but the dumb meshes are generally not too bad. It may not be worth the effort to finely tune the meshes to the underlying geometry.

If the resulting mesh-based weight windows have lots of zeros, then the mesh is probably too fine so that good estimates cannot be made in all the mesh cells. If the resulting mesh-based weight windows have values that vary greatly between adjacent meshes, then the meshes are too coarse. It is difficult to assess the quality of the meshes by looking at the mesh file (WWOUT, WWONE, WWINP); a means of visualizing the mesh values would be helpful.

The rectangular xyz mesh is much more efficient than the cylindrical rz $\theta$ mesh. In the oil well logging benchmark problem with the off-center, non-rotationally symmetric tool, we could not get satisfactory results with the cylindrical mesh. Therefore, we recommend preferential use of the rectangular mesh. 


\section{PROCEDURE FOR GENERATING WEIGHT WINDOWS}

The weight window generator works by keeping track of the total weight passing through a given cell (in optional WWGE time or energy bins) and how much scores. The importance is the scoring weight divided by the total weight, and this is approximately the adjoint solution. The generated windows are the inverse, namely the total weight divided by the scoring weight normalized to the reference cell weight. If the scoring tally is poorly converged, then the generated weight windows will also be poorly converged. If the scoring tally is well converged, then there is probably not much point in generating a new set of weight windows.

We recommend using the weight window generator iteratively. Use a crude guess of the importance function to generate a set of windows, and then use these windows to generate better windows. Generally 2 - 4 generating runs are needed.

For the first weight window generator run we have the following recommendations:

In the first weight window generator run, generate windows on an easy tally. Suppose you want to calculate the response to a detector. In the first generator run, optimize on a simple tally, such as a surface tally, near the detector or in the direction of the detector. This optimization will get you an importance function that gets particles headed towards the detector. Then using this good importance function, you can optimize on the final tallies in the detector in subsequent generator runs. The tally for which you first generate windows should be a tally for which it is easy to get results, and not necessarily the final tally result you want, in order to make the generator problem run quickly.

In the first weight window generator run, use a single energy or time group (WWGE card). If you have many weight window energy or time groups on the WWGE card, then the estimates in each group will be more difficult to obtain and may produce a poor importance function. The weight window generator automatically gives you a single group set of generated windows (WWONE file) whenever you request multiple groups (WWOUT file). If the generated multigroup windows have lots of zeros (no window generator estimate made for the mesh or cell), then use the single group windows in the next iteration. Or you can do a short run with both the single group and multigroup windows and choose whichever gives the better figure-of-merit.

Run the weight window generator long enough to get a $10 \%-20 \%$ relative error for the reference tally of the generator (1st entry on WWG card.) If you get a lower relative error than 
$10 \%$, then you are probably better off doing an iteration with the new windows rather than generating them longer. If you get a higher relative error, then the windows may be garbage. If you have a high relative error you can do the following:

1. Run the generating run longer. This choice is usually poor because the importance function is probably not very good and you may never converge to a better relative error.

2. Use a better importance function if the information gained from this run is sufficient to guide you in choosing a better importance function. Unfortunately, coming up with a better choice is usually difficult.

3. Optimize on a simpler tally that is not the one you ultimately want, but gets particles to head towards more important regions.

Once you get better than a 10\% error for the tally you are interested in, you can use the windows generated in this calculation and stop iterating further. Or, if it appears that you still cannot achieve the desired accuracy and pass all the statistical checks in a reasonable amount of time, you can continue iterating, using multiple energy or time bins (WWGE card) to get more efficient weight windows in subsequent iterations.

If the windows in subsequent generation run iterations do not change much or do not improve the figure-of-merit much, you've probably generated the optimum windows for your WWGE choices. You should either stop iterating or try finer energy or time bins on your WWGE card.

If the figure-of-merit gets worse in subsequent generator iterations, go back to the generating run with the better figure-of-merit and run it longer (or change the importance function or reference tally) to generate better windows. The windows should improve the figure-of-merit in each subsequent iteration.

If you are using cell-based weight windows, be sure to check the OUTP file table that lists the ratio of generated windows from cell to cell. If the windows in adjacent cells vary by too much, you may need to iterate some more, subdivide your geometry, or change to meshbased weight windows.

With a good set of windows (less than $10 \%$ error on the reference tally in the generating run) you can now safely turn on additional variance reduction schemes such as the exponential transform to further improve problem performance. The exponential transform should not be used with a bad set of weight windows because you may have false convergence. Source 
energy bias is also better turned on only after the energy-dependent windows indicate the optimum target weights for the source cell energy bias. The same is true for source time bias, biasing of source cells if there are multiple source cells, and other source biases such as directional biasing.

When you have your final set of generated windows, you should consider turning off the generator to save the $20 \%-40 \%$ computational time penalty. Of if you have mesh-based windows, you may consider switching to a cell-based window generator just so the code prints out the adjoint solution for the reference tally as the new generated windows. If low-window values (high importances) are generated near problem boundaries, this may indicate your geometry was truncated and needs to be extended further. If important regions have a zero or high-window values, then these cells may be under sampled. The cell-based windows are not just a good importance function, but a good diagnostic tool as well.

We recommend that once you pass all statistical tests, run for $50 \%$ longer and see if you still pass them to ensure the calculation is completely converged.

\section{Summary of Recommendations}

1. Use mesh-based windows unless the problem geometry is sufficiently subdivided to use cell-based windows.

2. Use the weight window generator iteratively. In the first iteration, generate windows for an easier tally than the one you ultimately want and generally use only the single-group generated windows.

3. Run the weight window generator long enough to get a $10 \%-20 \%$ relative error for the reference tally of the generator before using those windows in a subsequent run.

4. Once you pass all statistical tests, run $50 \%$ longer.

\section{E. Guidelines for Using Weight Windows}

Our previous experience with weight windows and this study indicate the following guidelines for use of the weight window variance reduction technique once the windows are generated.

1. WWP Card Entries

There are 6 entries on the WWP card:

WWP $\mathrm{W}_{1} \mathrm{~W}_{2} \mathrm{~W}_{3} \mathrm{~W}_{4} \mathrm{~W}_{5} \mathrm{~W}_{6}$ 
with defaults

WWP 535000

These entries are:

$W_{1}$ upper weight window bound is $W_{1}$ times the lower bound specified on the WWN card.

$\mathrm{W}_{2}$ When rouletting, restore weight to $\mathrm{W}_{2}$ times the lower bound specified on the WWN card.

$\mathrm{W}_{3} \quad$ Never split or roulette more than $\mathrm{W}_{3}$ for 1 .

$\mathrm{W}_{4}$ Play weight window game at $\mathrm{W}_{4}=-1$ collision, $\mathrm{W}_{4}=1$ surfaces, or $\mathrm{W}_{4}=0$ both (default).

$\mathrm{W}_{5}=0$ Cell-based weight windows (default) $=1$ Convert importances to cell-based importances $=-1$ Read cell or mesh based windows from WWINP file.

$\mathrm{W}_{6}=0 \mathrm{WWE}$ bins are for energy (default) $=1 \mathrm{WWE}$ bins are for time.

We see no reason to change the defaults. Whether or not to use mesh-based windows $\left(W_{5}\right)$ is discussed in Section VII.A. Where to play the weight window game $\left(W_{4}\right)$ and when to use $\mathrm{W}_{5}=1$ is discussed below.

Weight windows are nearly always more effective than importances. If you use importances (because they are more intuitive), consider converting them to weight windows simply by adding the following WWP card:

WWP $5350 \mathrm{~W}_{5}$

The 5th entry converts the importance to weight windows with a lower weight bound of $\mathrm{W}_{5} / \mathrm{I}$ where $\mathrm{I}$ is the input importance for each cell. In shielding problems this simple conversion will usually improve efficiency by up to $20 \%$. If w0 is the average source weight, and $W_{1}$ is the value of the 1 st WWP entry, good values of $W_{5}$ are

$$
\mathrm{w} 0 / \mathrm{W}_{1}<\mathrm{W}_{5}<\mathrm{w} 0
$$

Generally $W_{5}=.5$ w0 or $W_{5}=.25 w 0$ are good values.

The weight window game can be played at surfaces, collisions, or both. The surfaceonly weight window is turned on by $W_{4}=1$ on the WWP card. The collision-only weight window is turned on by $\mathrm{W}_{4}=-1$ on the WWP card. The default is to play the weight window game at both cell surfaces and collisions, $\mathrm{W}_{4}=0$. 
Prior to MCNP4C, the surface-only game utilized the weight cutoff game at collisions which was disastrous unless the weight cutoff was chosen sufficiently low. As a result of this study, the surface-only weight window game now uses analog capture by default and does no weight checking if analog capture is turned off. We see no advantage in using surface-only weight windows unless the problem material is nearly purely scattering, in which case the surface-only window saves the effort to check the windows at scatters. However, in a pure scatterer, it may be advantageous to use the exponential transform, in which case the weights should be checked at each collision. With a mesh-based weight window, the surface-only checking may be a disaster since the weights will not be checked in the mesh except at problem surfaces. We therefore recommend against using the surface-only weight window.

The weight window game can also be played at collisions only. Prior to MCNP4C if importances were specified in addition to windows, surface splitting and roulette were played at surfaces if collision-only windows were also specified or the window of the cell being entered was zero. In MCNP4C, surface splitting and roulette is completely turned off if the weight window is turned on. We know of no advantages to using the collision-only window.

We recommend using the default weight-window game at both collisions and surfaces. 2. Importance Sampling and Weight Cutoff Game.

Prior to MCNP4C the weight window game was strongly affected by the weight cutoff game and importance splitting at surfaces. If the default weight cutoffs (CUT card) were used, results could be disastrous.

In MCNP4B importance splitting at surfaces occurred for:

1. collision-only windows;

2. whenever the window of the entering cell was zero;

3. inside DXTRAN spheres for cell-based windows only

In MCNP4C importance splitting at surfaces does not occur when weight windows are used.

In both MCNP4B and MCNP4C the DXTRAN weight cutoff game is played inside DXTRAN spheres at collisions for cell-based windows but not for mesh-based windows.

In MCNP4B the weight cutoff game was played with weight windows at collisions in the following circumstances when analog capture was not specified. 
1. surface-only windows, but not at surface sources;

2. whenever the window of the collision cell was zero, but not for the secondary particles produced at collisions;

3. for the 2 nd and subsequent forced collision particles in a cell if the forced collision parameter is positive and surface-only windows are specified.

In MCNP4C weight windows now follow the following rules:

1. For surface-only windows, analog capture is the default. If the weight cutoff game is specified there is no weight control or cutoff game at collisions.

2. If the window of the collision cell is zero, the weight cutoff game is played for both primary and secondary particles at collisions, but roulette is limited to 1for-2.

3. For the 2 nd and subsequent forced collision particles in a cell if the forced collision parameter is positive and surface-only windows are specified, then no further collisions are forced, and there is no further weight control.

These rules are complicated. In MCNP4B they were inconsistent. They may be stated more simply as follows:

In general, in MCNP4C, the rules are:

1. For zero windows (at a surface entering a zero-window cell or at collisions) the weight cutoff game is played at surfaces and collisions, but roulette is never more severe than 1-for-2. Otherwise, the weight cutoff game is not played.

2. Analog capture is the default for surface-only windows.

3. The DXTRAN weight cutoff game is played inside DXTRAN spheres for cellbased windows only.

MCNP4C will track MCNP4B if analog capture was specified or if the weight cutoff game had a weight so low it was not played. The surface-only weight window is different and significantly better. If the weight cutoff game is not adjusted by the user to be below the lowest weight window, MCNP4C gives good results while MCNP4B has disastrous results with severe roulette games.

Thus, we have the following recommendations for the weight cutoff game. In MCNP4B either all windows had to be nonzero, or analog capture had to be played, or the weight cutoff had to be set below the lowest weight window in the problem. Weight windows needed to be played at both surfaces and collisions, and all importances, if specified, should 
have been unity. These are still reasonable approaches in MCNP4C, but it is no longer disastrous if the default weight cutoff game is used now that there is a 1-for-2 weight cutoff game roulette limiter in zero window cells and surface-only windows use analog capture by default. Thus, in MCNP4C, the default CUT card is generally sufficient with cell- or meshbased weight windows; there are no known option combinations that lead to disaster.

\section{RECOMMENDATIONS FOR FUTURE MCNP DEVELOPMENT}

Mesh Visualization: It is presently very difficult to assess the quality of generated mesh-based weight windows. Do the values vary too much from mesh cell to mesh cell indicating poor convergence or too coarse of a mesh? Are there too many zeros (undertimed weight windows), particularly in important parts of the problem? Perhaps a warning or printout could be provided in the OUTP file. The best solution would be a means of plotting the superimposed mesh with the MCNP geometry plotter with a color scale for the mesh values or to be able to have three-dimensional mesh plots.

Smoothing: Perhaps zero windows and large variations in windows from mesh cell to mesh cell could be treated with a smoothing algorithm. We attempted to smooth mesh values manually, but our limited experience was that smoothing is both difficult and potentially ineffective. Any smoothing algorithm should be optimum and carefully assessed.

Mesh Extrapolation: An alternative to smoothing a mesh is to have the code, upon encountering a zero weight window in a mesh, use the last nonzero weight window. Unfortunately, such a scheme would be difficult to implement (was the last nonzero weight window for the same particle or track from the bank?) and would increase the bank size even when mesh-based windows are not used. Also, using the last nonzero window would override the present weight cutoff game (with a 1-for-2 split limiter added in MCNP4C) and not get rid of particles in truly unimportant parts of the problem geometry.

Normalization: In the air-over-ground problem, which had a strong spatial source bias, $100 \%$ of the source particles had weights below the windows. Though it is possible to renormalize the mesh by rerunning the generating run with a different source normalization value (3rd entry on the WWG card), it would be far more efficient to be able to renormalize an existing mesh on the subsequent run that uses it. We recommend an additional parameter on the WWP card to renormalize the mesh by a user-specified amount. Then source and other 
biases could be compensated for by renormalizing the mesh until as many source particles started above the mesh as below.

Automatic Source Bias: In many problems source spatial, energy, directional or time bias is desired. It would be very useful if MCNP could automatically bias the source so that source particles are born inside their weight windows. We presently have no idea how this could be done.

DXTRAN and detector contributions. Presently the DXTRAN contribution card (DXC) and detector contribution card (PDn) are very useful when certain problem regions are unlikely to make significant contributions to DXTRAN or detector tallies. When simplified geometries are used with large cells, which is now made possible by the mesh-based weight windows, the (cell-based) DXC and PD cards are no longer useful because the importance of contributing to the DXTRAN or detector varies too much over the cell. It would be useful if MCNP could automatically play the DXC and PDn games when the mesh-based weight window is used. How could this be done? Let $\mathrm{j}$ be the mesh index where the highest DXTRAN or detector score is made. Let $\mathrm{k}$ be the mesh index where the source or collision event occurs. Let $\mathrm{W}_{\mathrm{j}}$ and $\mathrm{W}_{\mathrm{k}}$ be the corresponding weight window lower bounds in mesh cells $\mathrm{j}$ and $\mathrm{k}$. Let $\mathrm{i}$ be the cell of the collision or source event. Then, if the DXC or PDn entry for cell $i$ is negative, let the DXC/PDn roulette game be played if the DXTRAN or detector pseudoparticle weight (without attenuation)

$$
\mathrm{W}=\mathrm{W}_{\mathrm{o}} * \mathrm{p}(\mu) / 2 * \pi * \mathrm{R} * * 2
$$

is less than

$$
\mathrm{W}<\mathrm{W}_{\mathrm{j}} / \mathrm{W}_{\mathbf{k}} * \mathrm{~W}_{\mathrm{a}}
$$

where $\mathrm{W}_{\mathrm{a}}$ is the average weight scoring to the DXTRAN sphere or detector. Roulette could be limited to 1 for 10 or 1 for 100 maximum. Perhaps there is a better algorithm. Any algorithm would require careful assessment.

Testing: The superimposed mesh capability needs to be tested with lattices/repeated structures, criticality problems, and time-dependent weight windows.

Implemented recommendations. As a result of this study, the following features have already been added to MCNP4C:

1. a 1-for-2 splitting limiter for the weight cutoff game in meshes or cells with zero weight windows. The MCNP4B unlimited roulette game frequently caused false convergence unless the weight cutoff was set very low, in which case the 
benefits of a weight cutoff game in unimportant regions with zero windows was lost.

2. analog capture is the default when using surface-only weight windows.

3. The PROBID identification is written to WWONE and WWOUT files so that when they are used in subsequent problems as the WWINP file, you can tell which run created the weight windows utilized. For cell-based windows read from a WWINP file, PRINT TABLE 20 is always turned on so that you know which weight windows you are using.

4. The following MCNP4B subtlety has been added back into MCNP4C: When cell-based weight windows are turned on, collided parts of a forced collision play analog capture in DXTRAN spheres if the DXTRAN weight cutoffs are zero.

\section{CONCLUSIONS}

\section{A. Utilization of Weight Windows}

Whether cell-based weight windows are generated in MCNP4B or MCNP4C or elsewhere, the utilization of them in MCNP4C is comparable to that in MCNP4B. In the fusion problem, MCNP4B was $6 \%$ better; in the air-over ground problem, MCNP4C was $5 \%$ better; in the oil well problem, MCNP4C was $12 \%$ better. These differences are small and may be caused by other new MCNP4C features.

\section{B. Generation of Weight Windows}

MCNP4C generates cell-based weight windows more effectively than MCNP4B. In the five problems examined, regardless of where the windows were generated, MCNP4C outperformed MCNP4B by

$67 \%$ in the skyshine problem

$15 \%$ in the fusion problem

$46 \%$ in the class variance reduction problem

$16 \%$ in the oil well problem.

In the air over ground problem, both MCNP4B and MCNP4C generated windows were comparable in performance only because the source spatial bias hid the relative performance. 


\section{Mesh-Based Windows Can Outperform Cell-Based Windows}

Mesh-based windows can outperform both cell-based importances and cell-based windows. In the skyshine problem, they were $10 \%$ better and in the class variance reduction problem, they were $52 \%$ better. However, they were only $50 \%$ as good in the oil well problem with a rectangular mesh and much worse with a cylindrical mesh. They were comparable in the fusion problem. They were also comparable in the air-over-ground problem whose results were inconclusive because of the source biasing. Perhaps a better choice of mesh would have improved the oil well problem results. Clearly, it is possible to outperform expert-developed cell-based windows with mesh-based windows in many cases.

Of course, it is also possible to do much worse if meshes are chosen improperly, cylindrical rather than rectangular geometry is chosen, inappropriately (oil well problem), and windows are insufficiently converged. The recommendations of Section VIII may make meshbased windows easier to use, but expert judgement is still required.

\section{Subdividing Geometries for Importances Is No Longer Needed}

Generally, use of the mesh-based weight windows makes it no longer necessary to subdivide geometries for variance reduction. With sufficient iterations, the mesh-based windows in a simple geometry outperformed expert-devised cell-based windows in the fusion and class problems. Reasonable performance was achieved with mesh-based windows applied to a simple geometry for the other problems.

We believe it is no longer necessary to subdivide geometries extensively for variance reduction because mesh-based weight windows can be used.

\section{REFERENCES}

1. J. F. Briesmeister, Ed., "MCNP-A General Monte Carlo N-Particle Transport Code, Version 4B," Code Manual LA-12625-M, Version 4B, Los Alamos National Laboratory, 1997.

2. L. Liu and R. P. Gardner, "A Geometry-Independent Fine-Mesh-Based Monte Carlo Importance Generator," Nucl. Sci. Eng, 125, 188-195 (1997). 
3. T. M. Evans and J. S. Hendricks, "An Enhanced Geometry-Independent Mesh Weight Window Generator for MCNP," 1998 Radiation Protection and Shielding Division Topical Conference on Technologies for the New Century, Sheraton Music City, Nashville, TN, Vol. 1, pg. 165 (April 1998).

4. Daniel J. Whalen, D. A. Cardon, J. L. Uhle, and J. S. Hendricks, "MCNP: Neutron Benchmark Problems," LA-12212, Los Alamos National Laboratory, 1991

5. Daniel J. Whalen, D. E. Hollowell, and J. S. Hendricks, "MCNP: Photon Benchmark Problems," LA-12196, Los Alamos National Laboratory, 1991

6. T. E. Booth, "A Sample Problem for Variance Reduction in MCNP," LA-10363-MS (June 1985).

7. Henry Lichtenstein, "Monte Carlo Importance Sampling for the MCNP General Source," Proceedings of ANS Topical Meeting on Radiation Protection and Shielding, North Falmouth, MA, Vol. 1, p. 427-31 (April 1996). 


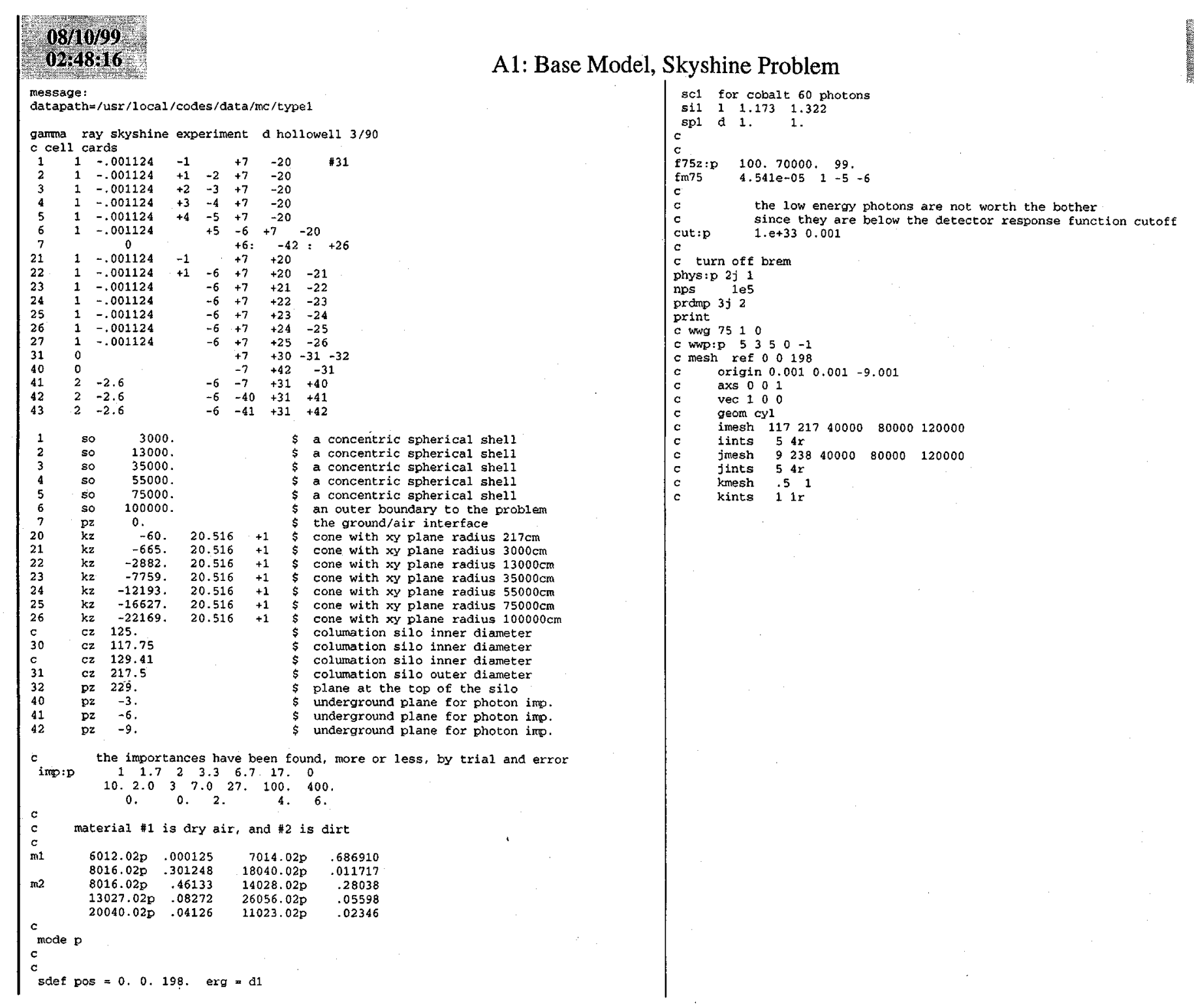



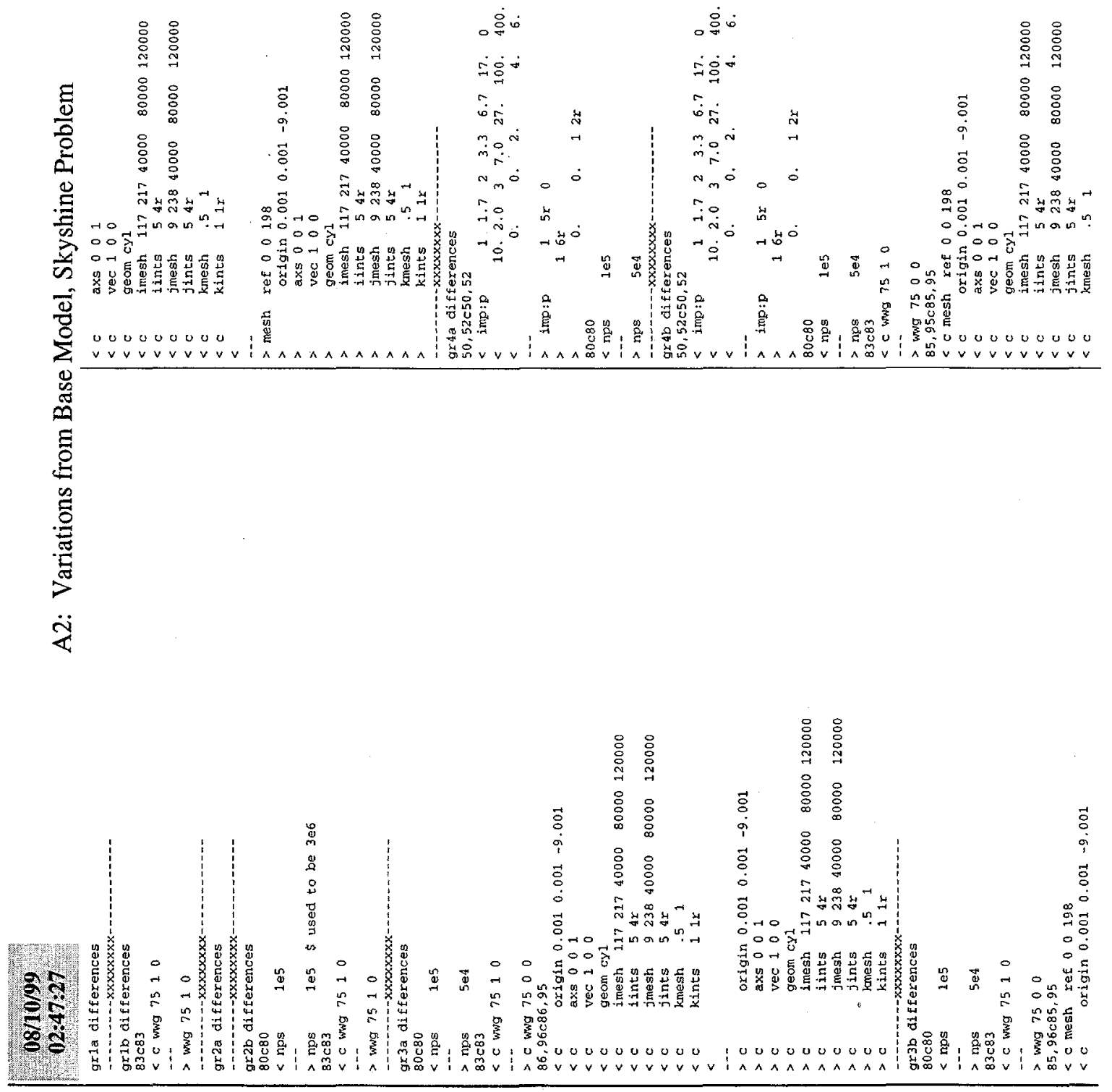


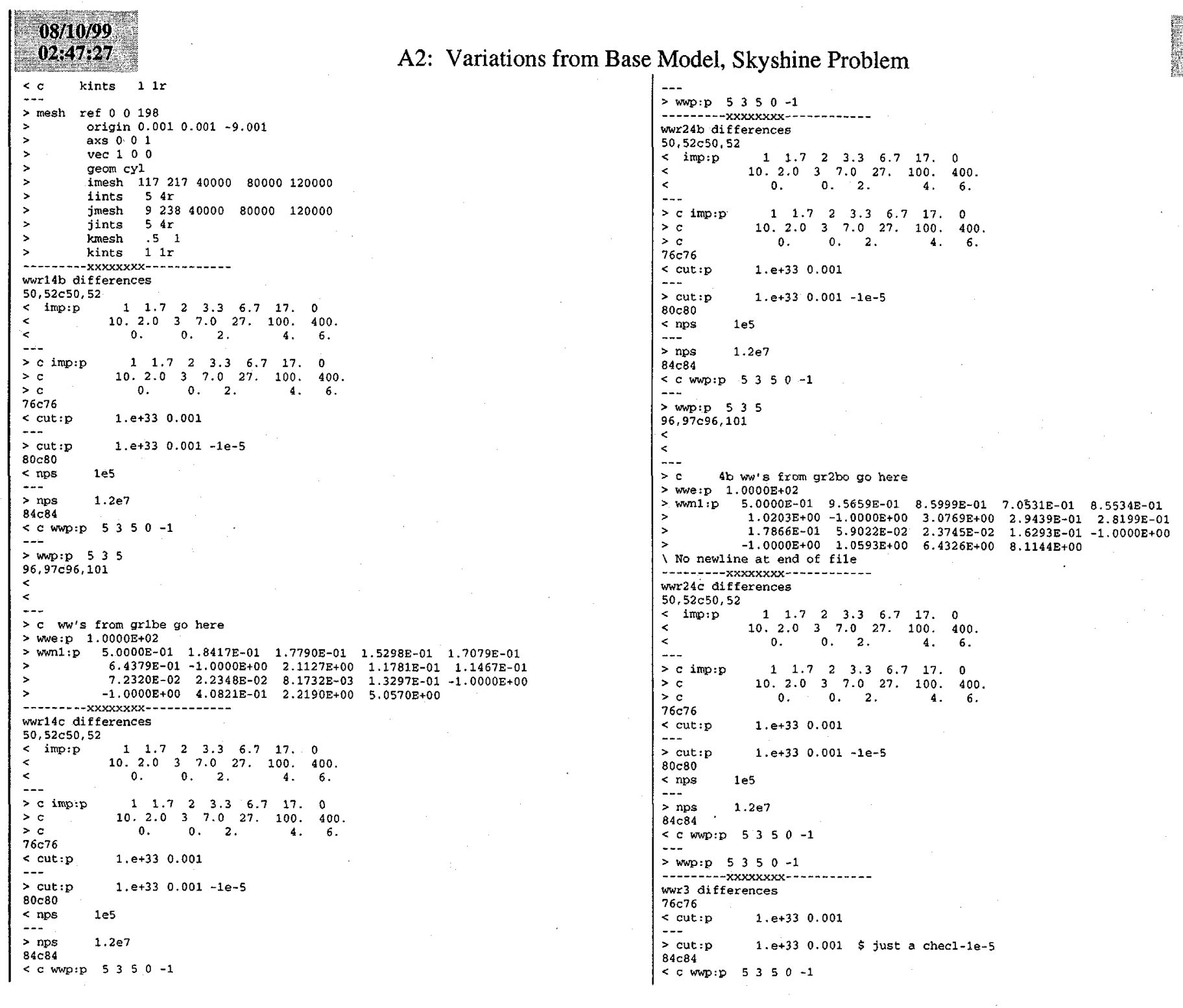


3 waxp: 5535

wort differences

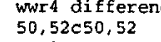

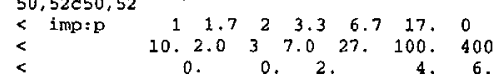

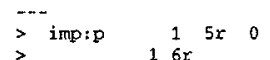

$\begin{array}{lcll}3 & 16 x & 0 . & \\ 2 & 0 . & 12 x\end{array}$

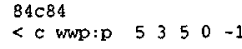

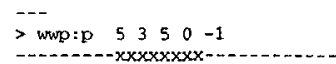

A2: Variations from Base Model, Skyshine Problem

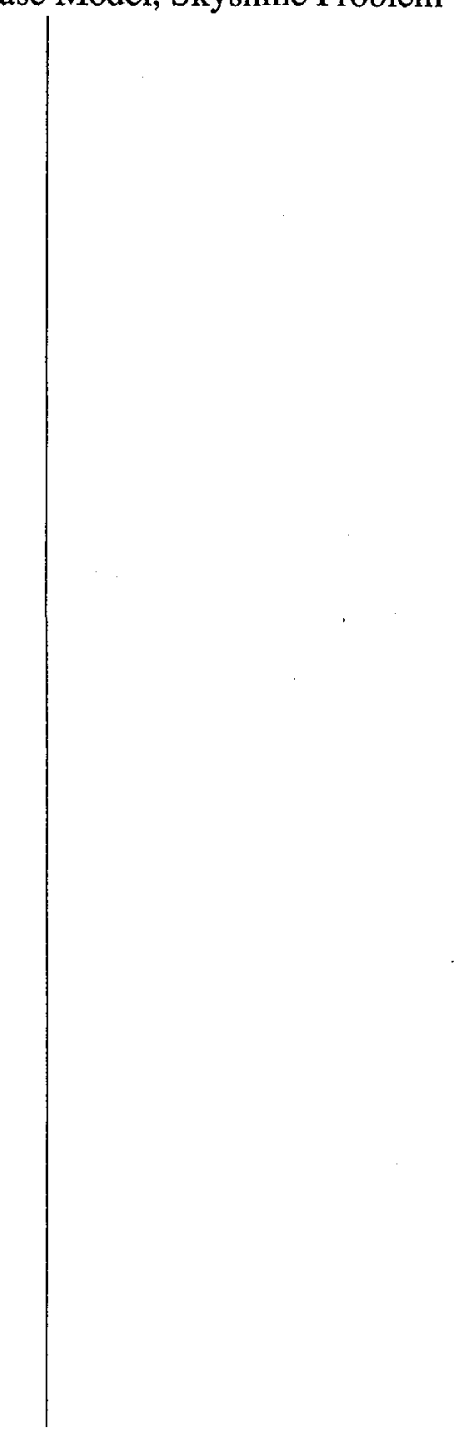


Table A3: Explanation of Runs Performed in Assessment

\begin{tabular}{|c|c|c|}
\hline Run & Explanation & Code Run \\
\hline Gr1a & Expert importances, no wwg, no ww used. & MCNP4C \\
\hline Gr1b & $\begin{array}{l}\text { Same as grla, but cell-based ww's } \\
\text { generated. }\end{array}$ & MCNP4C \\
\hline Gr2a & Expert importances, no wwg, no ww used. & MCNP4B \\
\hline Gr2b & $\begin{array}{l}\text { Same as gr2a, but cell-based ww's } \\
\text { generated. }\end{array}$ & MCNP4B \\
\hline Gr3a & $\begin{array}{l}\text { Expert importances, complex geometry, no } \\
\text { wwg, no ww used. }\end{array}$ & MCNP4C \\
\hline Gr3b & $\begin{array}{l}\text { Same as gr3b, but mesh-based ww's } \\
\text { generated. }\end{array}$ & MCNP4C \\
\hline Gr4a & $\begin{array}{l}\text { Binary importances, complex geometry, no } \\
\text { wwg, no ww used. }\end{array}$ & MCNP4C \\
\hline Gr4b & $\begin{array}{l}\text { Same as gr4a, but mesh-based ww's } \\
\text { generated. }\end{array}$ & MCNP4C \\
\hline Gr5a & $\begin{array}{l}\text { Binary importances, simple geometry, no } \\
\text { wwg, no ww used. }\end{array}$ & MCNP4C \\
\hline Gr5b & $\begin{array}{l}\text { Same as gr5a, but mesh-based ww's } \\
\text { generated. }\end{array}$ & MCNP4C \\
\hline Wwr14b & Applies cbww generated in gr $1 \mathrm{~b}$ & MCNP4B \\
\hline Wwr14C & Applies cbww generated in gr1b & MCNP4C \\
\hline Wwr24b & Applies cbww generated in gr2b & MCNP4B \\
\hline Wwr24C & Applies cbww generated in gr2b & MCNP4C \\
\hline WWr3 & Applies mbww generated in gr3b & MCNP4C \\
\hline Wwr4 & Applies mbww generated in gr $4 \mathrm{~b}$ & MCNP4C \\
\hline Wwr5 & Applies mbww generated in gr5b & MCNP4C \\
\hline
\end{tabular}


 \\ A4: Simplified Model, Skyshine Problem -gr5b}

message:
datapath=/usr/local/codes/data/mic/type

gannia ray skyshine experiment a hollowell $3 / 90$

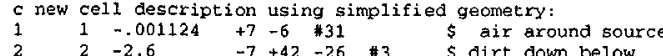

$\begin{array}{llllll}3 & 0 & -7 & +42 & -26 & \text { as }\end{array}$

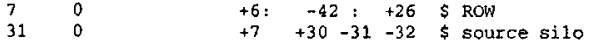

6 so $100000 . \quad \$$ an outer boundary to the problem

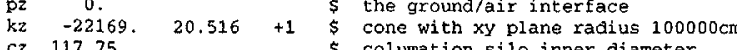

c2 117.75 $\$$ colunation silo inner diameter

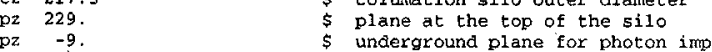

c the importances have been found, more or less, by trial and exror

c material $\$ 1$ is dry air, and $\# 2$ is dirt

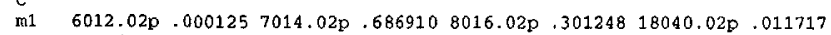

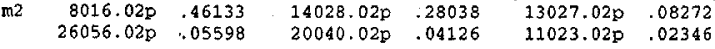

mode $\mathrm{p}$

sdef pos $=0.0 \cdot 198$, erg $=d 1$

Sc1 for cobalt 60 photon

sp1 d 1.1731 . 1 .

the ring detectors are set up to give dose, which will

f75z:p 100. 70000. 99 .

$\begin{array}{lll}c & \text { the low energy photons are not worth the bother } \\ c & \end{array}$

since they are below the detector response function cutot

nps $5 e 4$

print sed

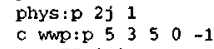

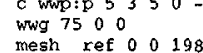

$\begin{array}{lllll} & \\ \text { origin } 0.001 & 0.001 & -9.001\end{array}$

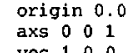

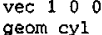

iriesh $11721740000 \quad 80000120000$

iints 5 4r

$\begin{array}{lll}\text { jesh } & 9 & 238 \\ \text { jints } & 54 & 4 r \\ \text { kmesh } & 5 & \end{array}$

knesh is 


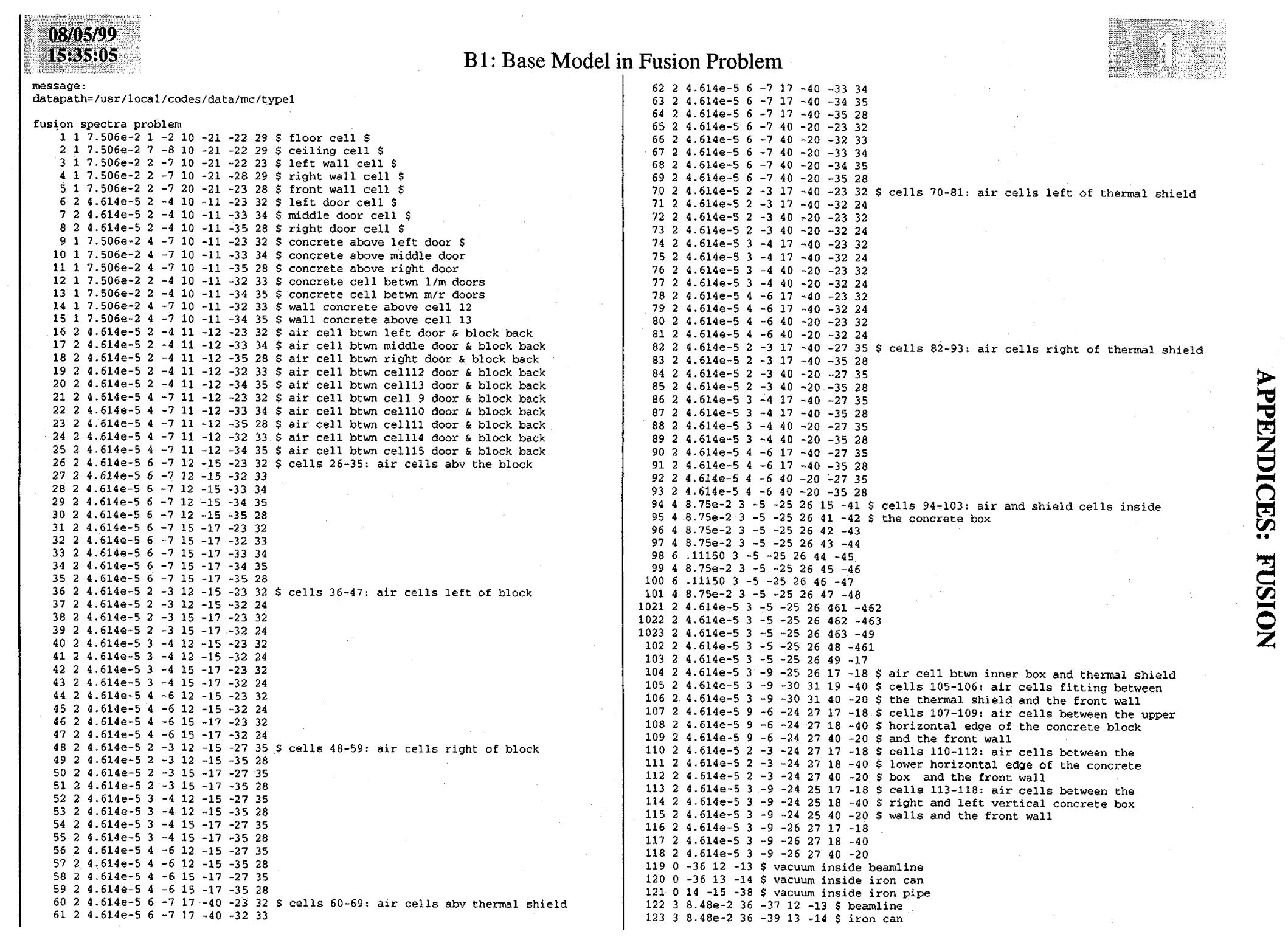


B1: Base Model in Fusion Problem

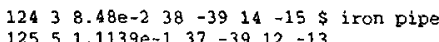

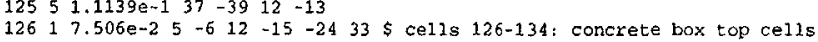

$12717.506-255-6.12-15-243$

278
129

$12917.506 e-25-615-45-2433$

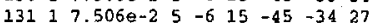

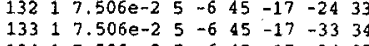

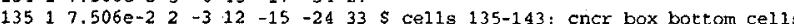

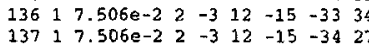

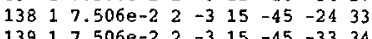

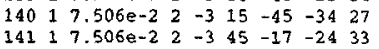

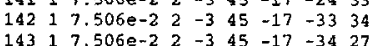

$144417.5066-2-24253-5012-15 \$$ s cel1s 144-149: concrete box left

$14517.506-2-24253-5015-45 \$$ vertical wall cells

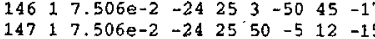

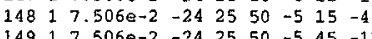

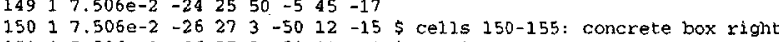

$15117.506 e-2-26273-5015-45 \&$ vertical wall cells

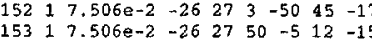

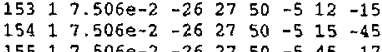

$15617.506 e-23-5-2526 \quad 3912-51$ \& cel1s 156-164: inner concrete box cel1s

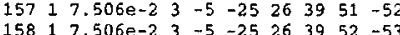

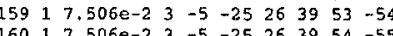

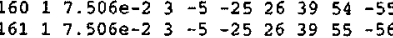

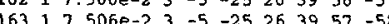

$16417.506 e-23-5-25263958-15$

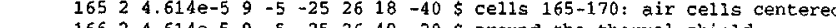

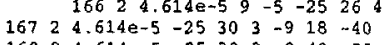

$16824.6140-5-25303-940-20$

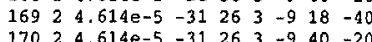

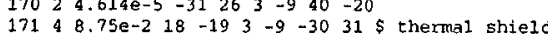

$1720-1$ \& void cell below the concrete roon

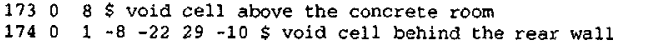

1

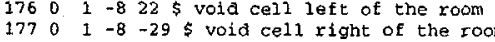

$1 \mathrm{pzz}-91.44$

$2 \mathrm{pz} 05$ upper floor plane

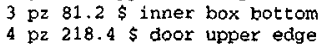

$4 \mathrm{pz}^{2} 21.4 \mathrm{~s} . \mathrm{s}$ door upper edge
$5 \mathrm{pz} 253.92 \mathrm{~s}$ inner box top

$7 \mathrm{pz} 495.30$ \& ceiling plane

$8 \mathrm{p2} 586.74$ \& ceiling plane (upper)

$10 \mathrm{pz} 23.60$ s upper thermal shield edge
$10 \mathrm{py}-29.21$ \$ rear wall plane (rear)

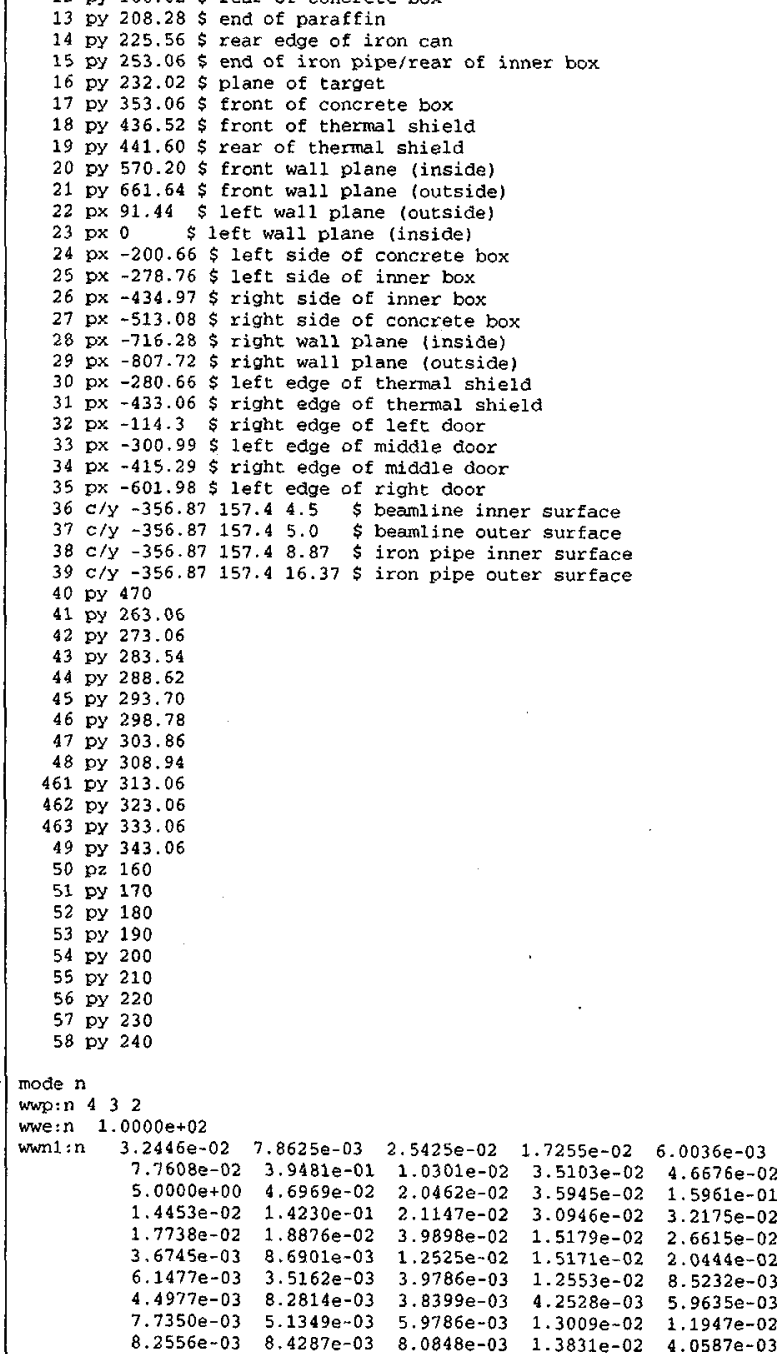


B1: Base Model in Fusion Problem

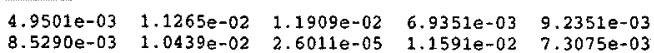

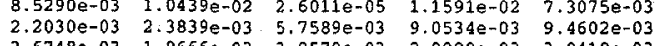
$\begin{array}{llllll}3,6748 \mathrm{e}-03 & 1.9666 \mathrm{e}-03 & 3.0570 \mathrm{e}-03 & 2.09900-03 & 3.9418 \mathrm{e}-03\end{array}$

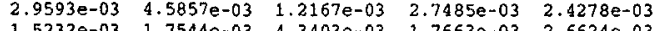

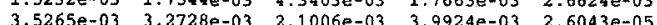
$\begin{array}{llllll}2.1373 \mathrm{e}-03 & 2.5724 \mathrm{e}-03 & 1.2843 \mathrm{e}-03 & 1.0302 \mathrm{e}-03 & 1.4356 \mathrm{e}-03\end{array}$

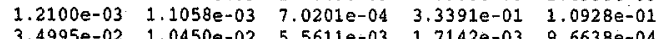

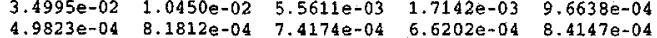
$\begin{array}{lllllll}5.8902 \mathrm{e}-04 & 6.0071 \mathrm{e}-04 & 3.2920 \mathrm{e}-04 & 8.1447 \mathrm{e}-04 & 1.0684 \mathrm{e}-03\end{array}$ $\begin{array}{lllllll}8.0835 e-04 & 1.3830 \mathrm{e}-03 & 1.3101 \mathrm{e}-03 & 1.2927 \mathrm{e}-03 & 1.5245 \mathrm{e}-03\end{array}$

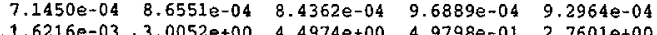

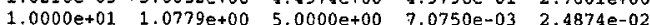
$\begin{array}{llllll}3.7824 e-02 & 5.4701 e-03 & 4.2745 e+00 & 5.0000 e+00 & 1.5644 e-03\end{array}$

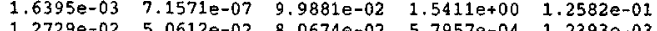
$\begin{array}{lllll}2.9755 \mathrm{e}-03 & 1.9004 \mathrm{e}-01 & 01.4316 \mathrm{e}-01 & 6.2365 \mathrm{e}-04 & 2.6084 \mathrm{e}-01\end{array}$ $\begin{array}{llllll}2.0931 \mathrm{e}-01 & 7.5104 \mathrm{e}-04 & 3.2267 \mathrm{e}+00 & 1.9934 \mathrm{e}-01 & 1.9722 \mathrm{e}-03\end{array}$ $\begin{array}{llllll}2.0724 e-01 & 6.8996 e-02 & 2.0353 e-03 & 3.92011-01 & 1.2993 e+00\end{array}$ $\begin{array}{lllll}5.0000 \mathrm{e}+00 & 1.6933 \mathrm{e}+00 & 2.9015 \mathrm{e}-04 & 3.4540 \mathrm{e}-04 & 5.7251 \mathrm{e}-04\end{array}$ $7.5752 \mathrm{e}-04 \quad 3.1696 \mathrm{e}-04-1.0000 \mathrm{e}+00-1.0000 \mathrm{e}+00-1.0000 \mathrm{e}+00$

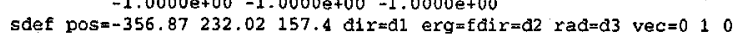

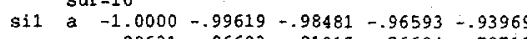

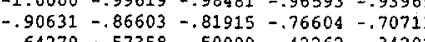

$\begin{array}{rrrrr}.64279 & -.5758 & -.50000 & -.42262 & -.34202 \\ .25882 & -.17365 & -.08716 & .00000 & .08716\end{array}$

\begin{tabular}{llllll}
.17365 & .25882 & .34202 & .42262 & .50000 \\
\hline
\end{tabular}

$\begin{array}{rrrrr}.57358 & .64279 & .70711 & .76604 & .81915 \\ .8603 & .90631 & .93969 & .96593 & .98481\end{array}$

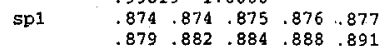

.879 .882 .884 .888 .891

.919 .924 .930 .935 .941

.996 .952 .957 .962 .9467

.991 .994 .996 .998 .999

ds2 q $\quad-.99619180-.98481175-.96593170-.93962165 \quad-.90631160$

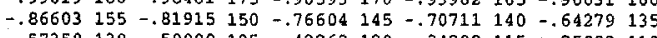

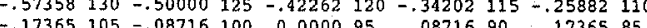

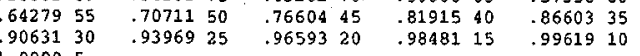

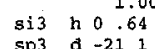

$\begin{array}{llll}\text { sp3 } & \text { a } & -21 & 1 \\ \text { sis } & \text { h } & 15.106 & 15.110\end{array}$

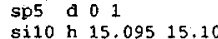

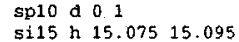

sp15 a 011 .

$\begin{array}{llll}\text { sp20 d } 0 & \text { l } \\ \text { sizs h } & 15.015 & 15.049\end{array}$

$\begin{array}{llll}\text { sp25 } & \text { a } & 0 & 1 \\ \text { si } & \text { h } & 14.974 & 15.015\end{array}$

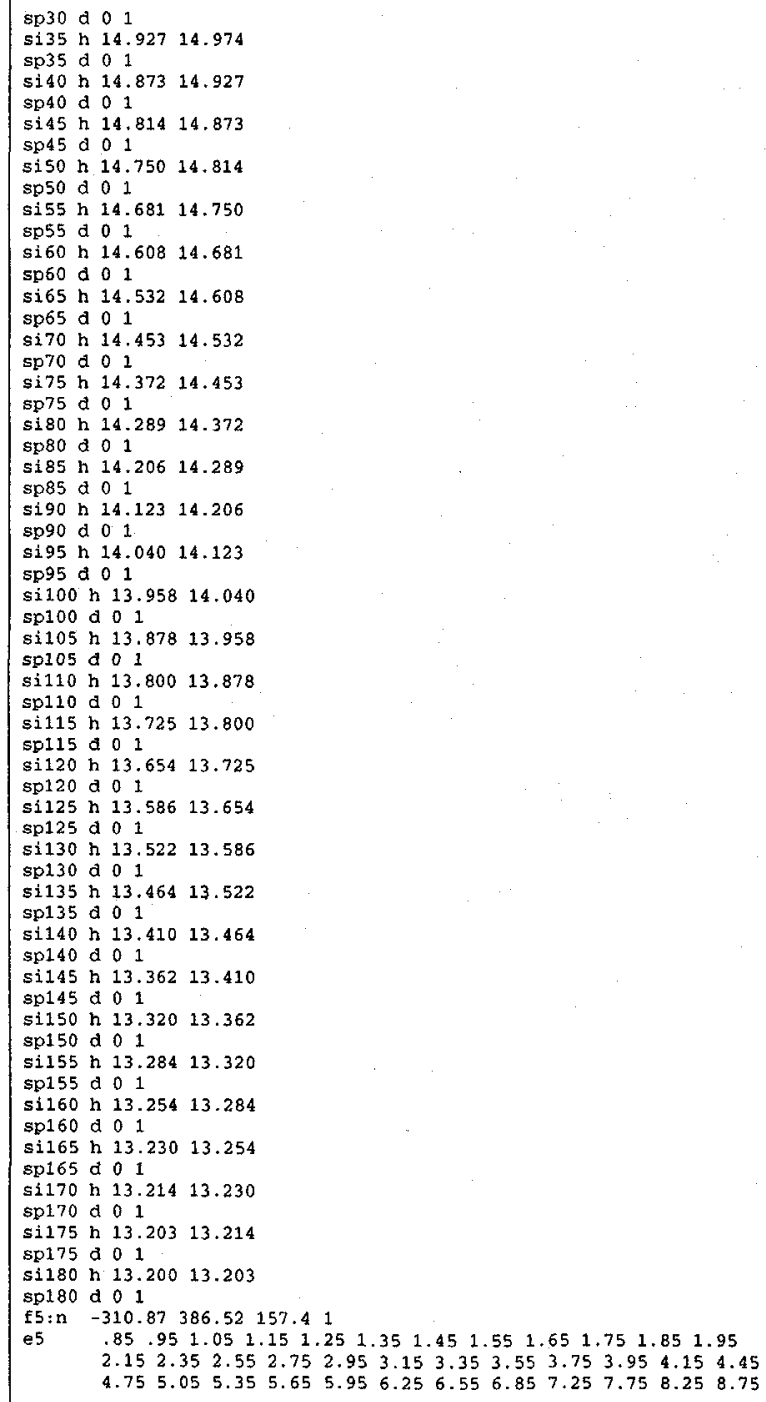


$9.25 \quad 9.75 \quad 10.25 \quad 10.75 \quad 11.25 \quad 11.75 \quad 12.5513 .3514 .15 \quad 14.95$

em5 $\begin{gathered}1 \\ \text { ens }\end{gathered}$

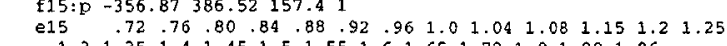

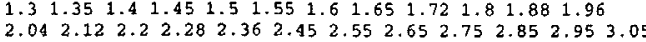

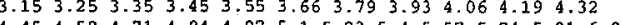

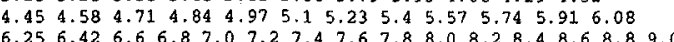

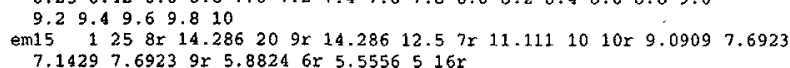

cut:n $1 \mathrm{e} 33.850-1 \mathrm{e}-5-1 \mathrm{e}-5 \$$ ignore neutrons below the detector response $\begin{array}{lllll}0 \text { wwg } & 51210 & -310.87 & 386.52 & 157.4\end{array}$

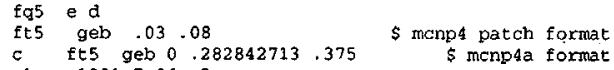

m1 $10017.86 \mathrm{e}-3$

$80164.39 \mathrm{e}-2$

$\begin{array}{ll}11023 & 1.05 e-3 \\ 12000 & 1.40 \theta-4\end{array}$

$13027 \quad 2.39 \mathrm{e}-3$
14000
$1.58 \mathrm{e}-2$

19000
20000
$2.902 \mathrm{e}-4$

$260003.10 \mathrm{e}-4$

m3 $26000 \quad 8.48 \mathrm{e}-2$

$250551.770-3$

6.000 $6.02 \mathrm{e}-2$

$\begin{array}{r}28000 \\ 7014 \quad 3.63 e-3 \\ \hline\end{array}$

$8016 \quad 9.74 \mathrm{e}-6$

$6000 \quad 3.338 \mathrm{e}-2$

$\begin{array}{ll}8016 & 1.125 \mathrm{e}-2 \\ 3006 & 5.565 \mathrm{e}-4\end{array}$

$30076.944 \mathrm{e}-3$

m6 $\quad 10017.13 \mathrm{e}-2$

$\begin{array}{rl}5010 & 4.87 e-4 \\ 5011 & 1.97 e-3\end{array}$

print

nps 1 es 


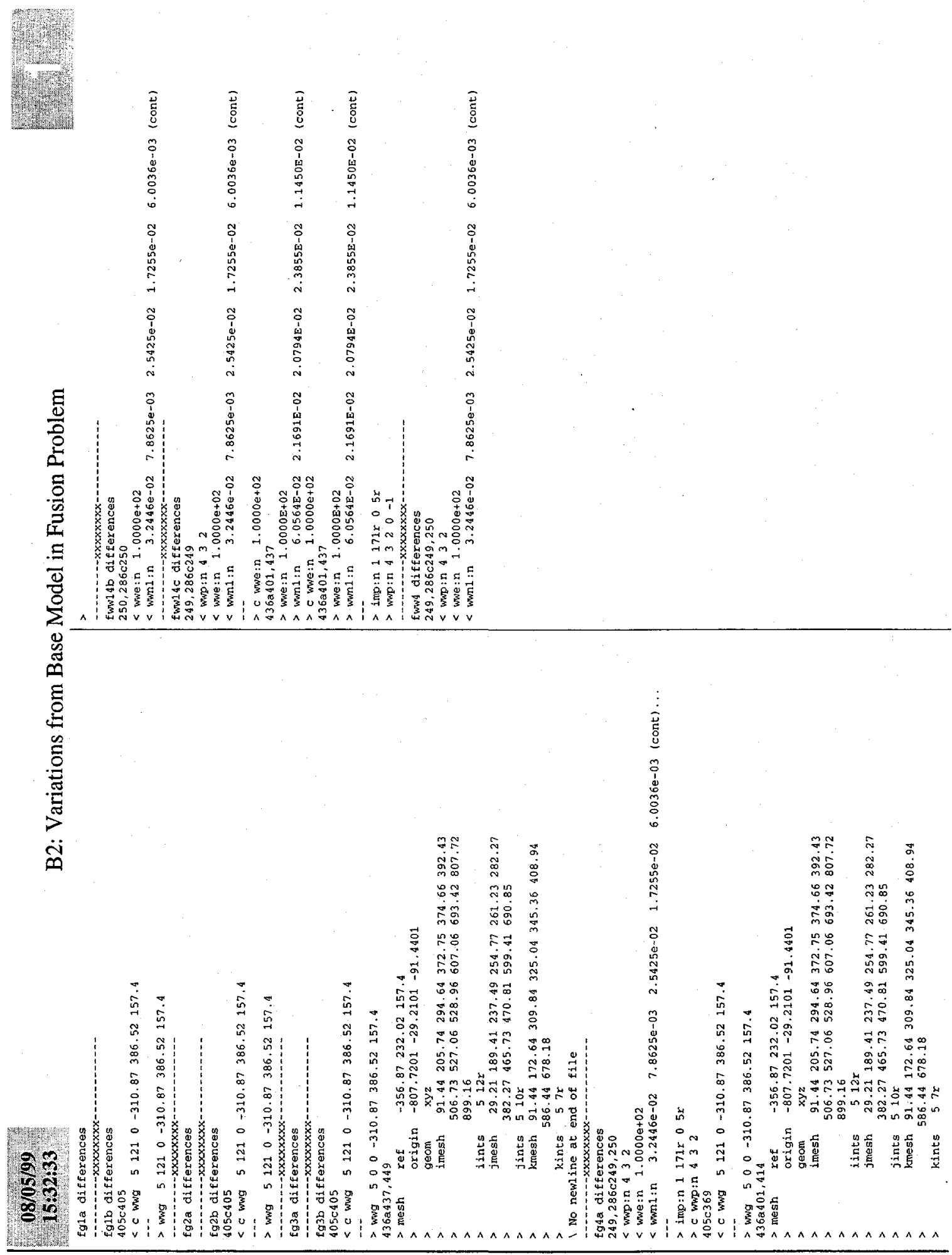


Table B3: Explanation of Runs Performed in Assessment

\begin{tabular}{|c|c|c|}
\hline Run & Explanation & Code Run \\
\hline Fgla & Expert importances, no wwg, no ww used. & $\mathrm{MCNP} 4 \mathrm{C}$ \\
\hline Fg1b & $\begin{array}{l}\text { Same as Fg1a, but cell-based ww's } \\
\text { generated. }\end{array}$ & MCNP4C \\
\hline Fg2a & Expert importances, no wwg, no ww used. & MCNP4B \\
\hline $\mathrm{Fg} 2 \mathrm{~b}$ & $\begin{array}{l}\text { Same as Fg2a, but cell-based ww's } \\
\text { generated. }\end{array}$ & MCNP4B \\
\hline Fg3a & $\begin{array}{l}\text { Expert importances, complex geometry, no } \\
\text { wwg, no ww used. }\end{array}$ & MCNP4C \\
\hline Fg3b & $\begin{array}{l}\text { Same as Fg3b, but mesh-based ww's } \\
\text { generated. }\end{array}$ & MCNP4C \\
\hline Fg4a & $\begin{array}{l}\text { Binary importances, complex geometry, no } \\
\text { wwg, no ww used. }\end{array}$ & MCNP4C \\
\hline Fg4b & $\begin{array}{l}\text { Same as Fg4a, but mesh-based ww's } \\
\text { generated. }\end{array}$ & MCNP4C \\
\hline Fg5a & $\begin{array}{l}\text { Binary importances, simple geometry, no } \\
\text { wwg, no ww used. }\end{array}$ & MCNP4C \\
\hline Fg5b & $\begin{array}{l}\text { Same as Fg5a, but mesh-based ww's } \\
\text { generated. }\end{array}$ & MCNP4C \\
\hline Fww14b & Applies cbww generated in Fg1b & MCNP4B \\
\hline Fww14C & Applies cbww generated in Fg1b & MCNP4C \\
\hline Fww24b & Applies cbww generated in Fg2b & MCNP4B \\
\hline Fww24C & Applies cbww generated in Fg2b & MCNP4C \\
\hline Fww3 & Applies mbww generated in Fg3b & MCNP4C \\
\hline Fww4 & Applies mbww generated in Fg4b & MCNP4C \\
\hline Fww5 & Applies mbww generated in Fg5b & MCNP4C \\
\hline
\end{tabular}



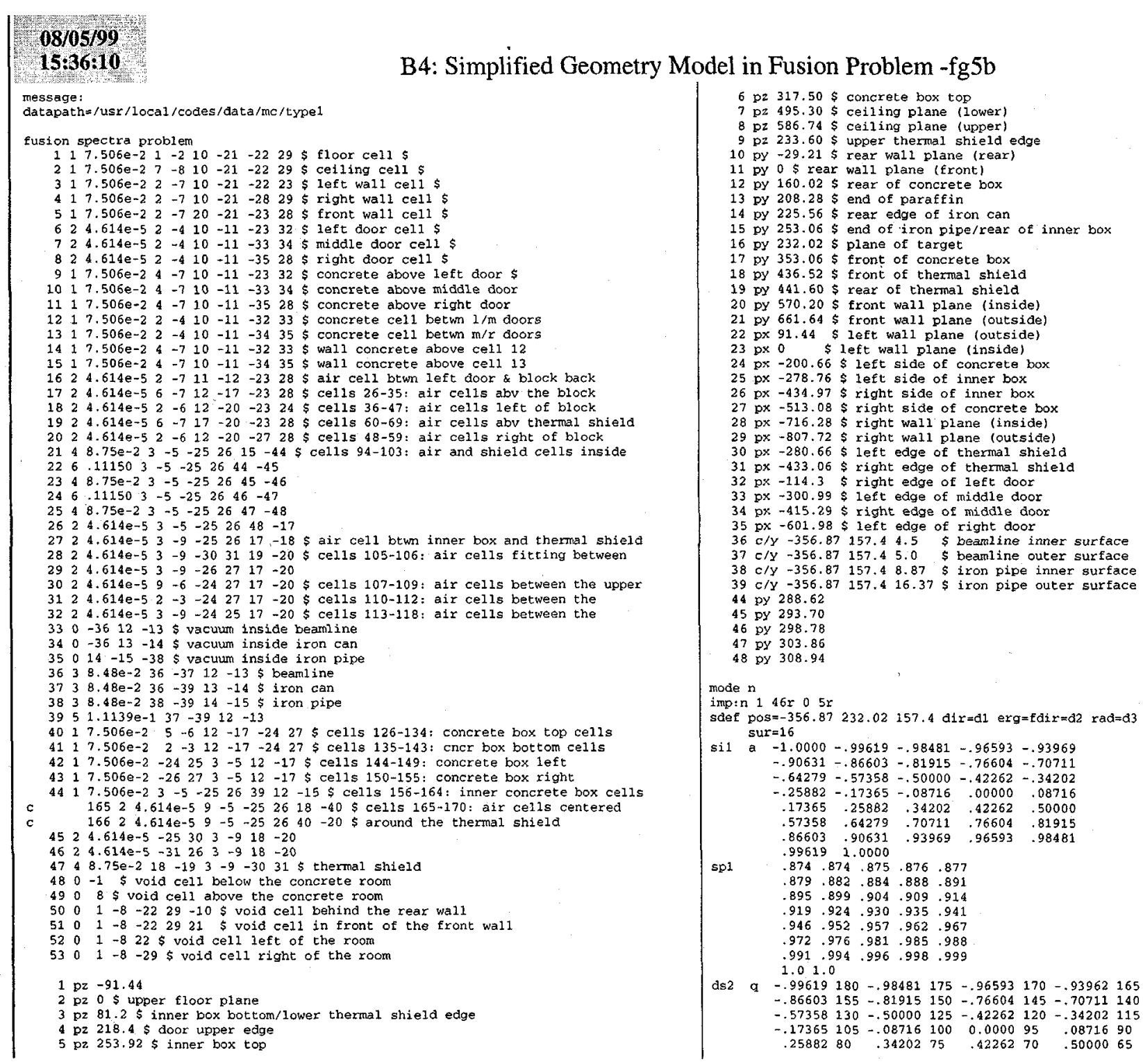

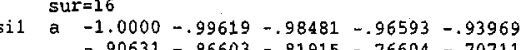

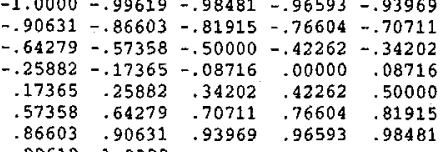

sp

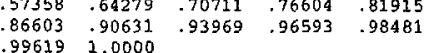

$8.879 .874 .875 \cdot 876 \cdot 877$

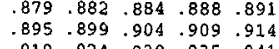
.919 .924 .930 .935 .941
.946 .952 .957 .962 .967 $.946 .952 .957 .962 .967)$

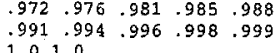

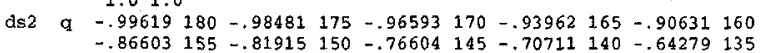

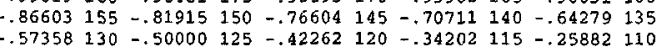

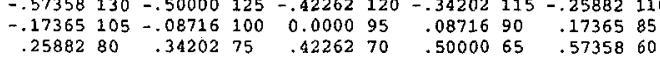




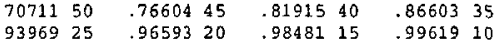

(2)

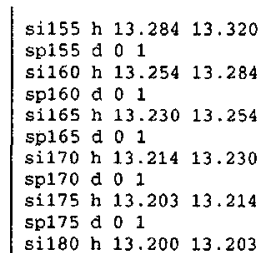




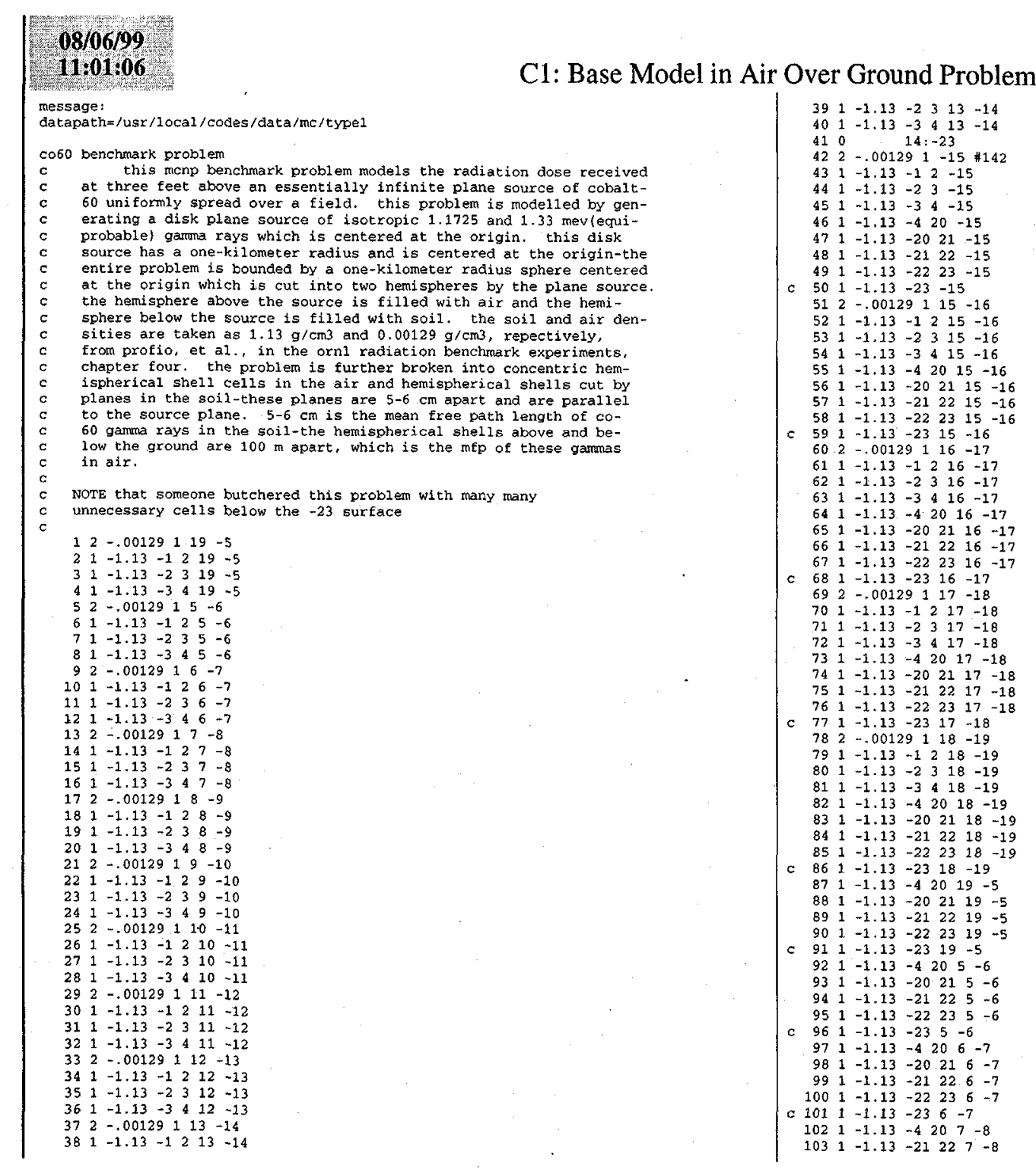




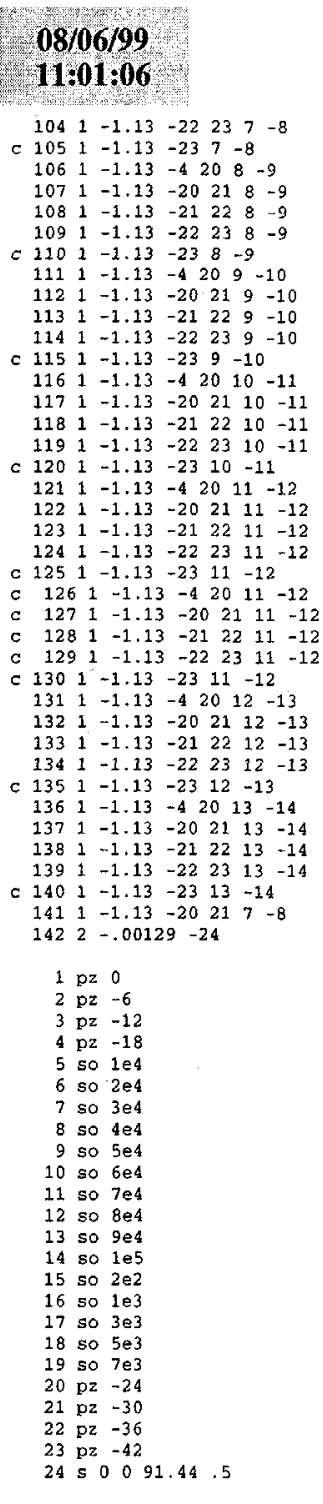

\section{C1: Base Model in Air Over Ground Problem}

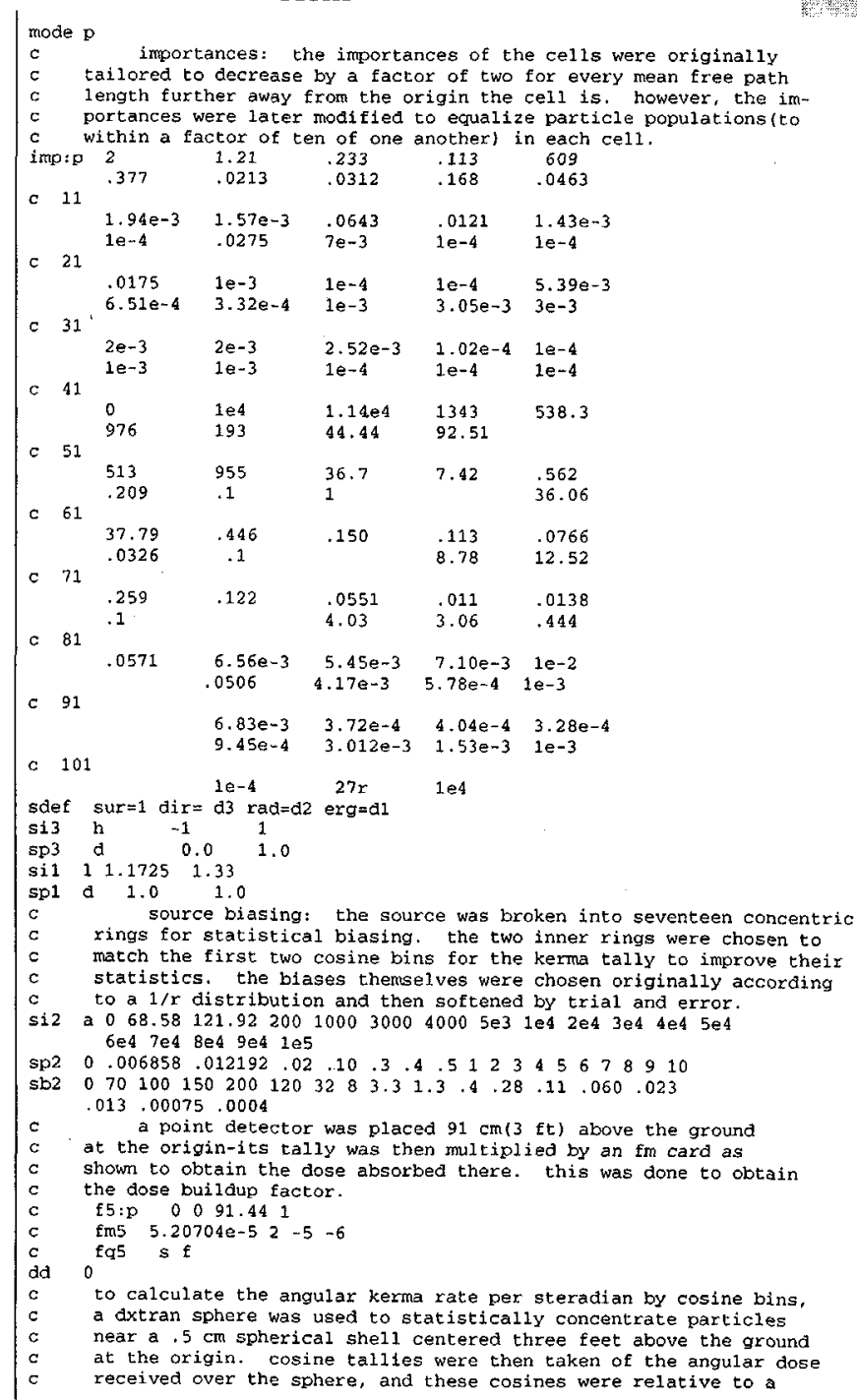




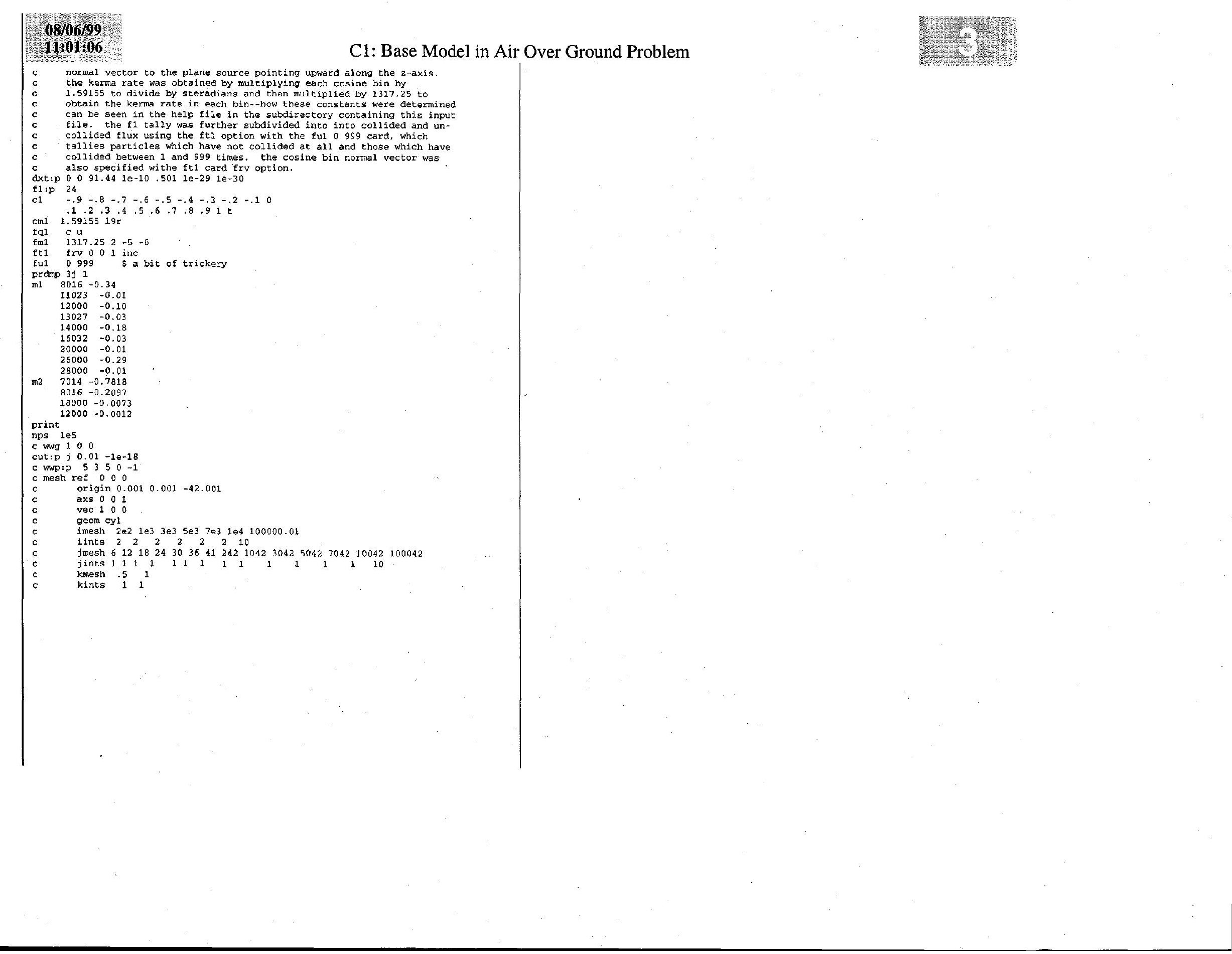


ag1a differences

aglo differences

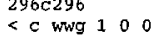

$>$ wug 1420

agza differences

agrb differences

$<<c$ wwg 100

$>$ wwg 1420

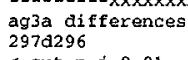

$<$ cut: $:$; $0.01-1 e-18$

$2963 \mathrm{~b}$ differences

$\begin{array}{lll} & \end{array}$

$>$ invg 1 lll

$299,3099298,308$

$<c$ mesh reft 0 o 000

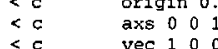

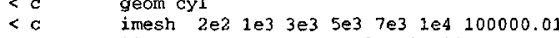

$<c \quad$ ints $22^{2} 2_{2} 2_{2} 2^{2} 10$

$<\mathrm{c} \quad$ jmesh 6121824303641242104230425042704210042100042

$\begin{array}{llll}<c & \text { knesh } & -5 & 1 \\ << & k i n n s & -1 & 1\end{array}$

3 mesh ref 000

$>$ origin $0.0010 .001-42.001$

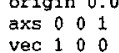

veom cyl

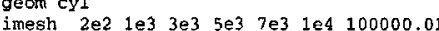

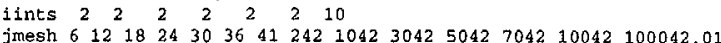

Jmesh $61218243036412421042 \quad 304250427042 \quad 1004210$ kmesh .5

ag4a differences

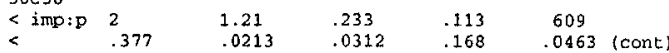

$>$ imp:p 1390010

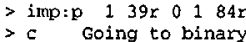

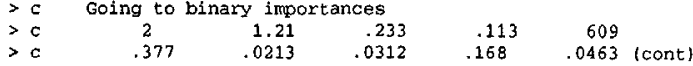

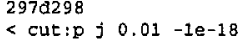

agdb differences

C2: Variations from Base Model, Air Over Ground -ag1a

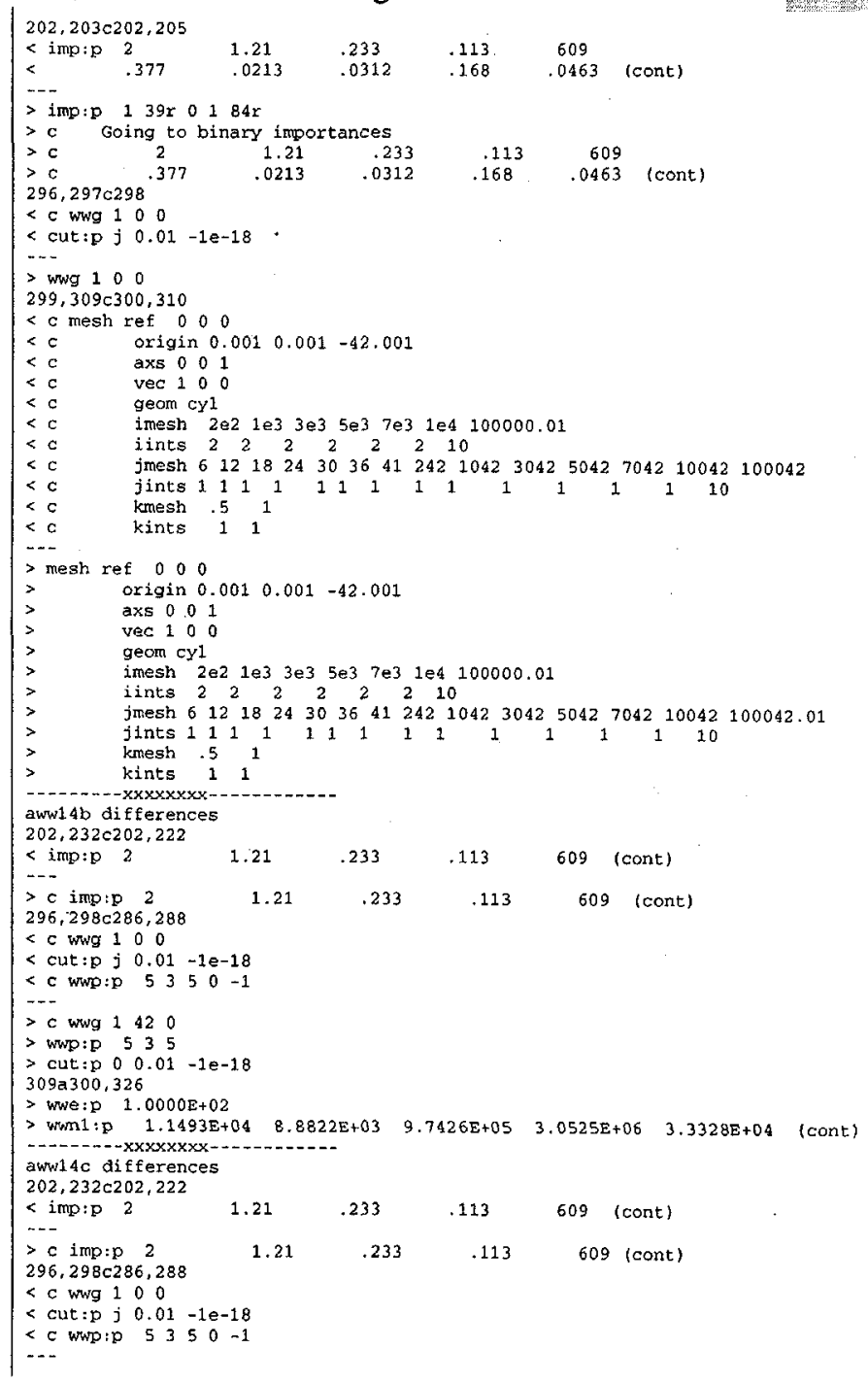




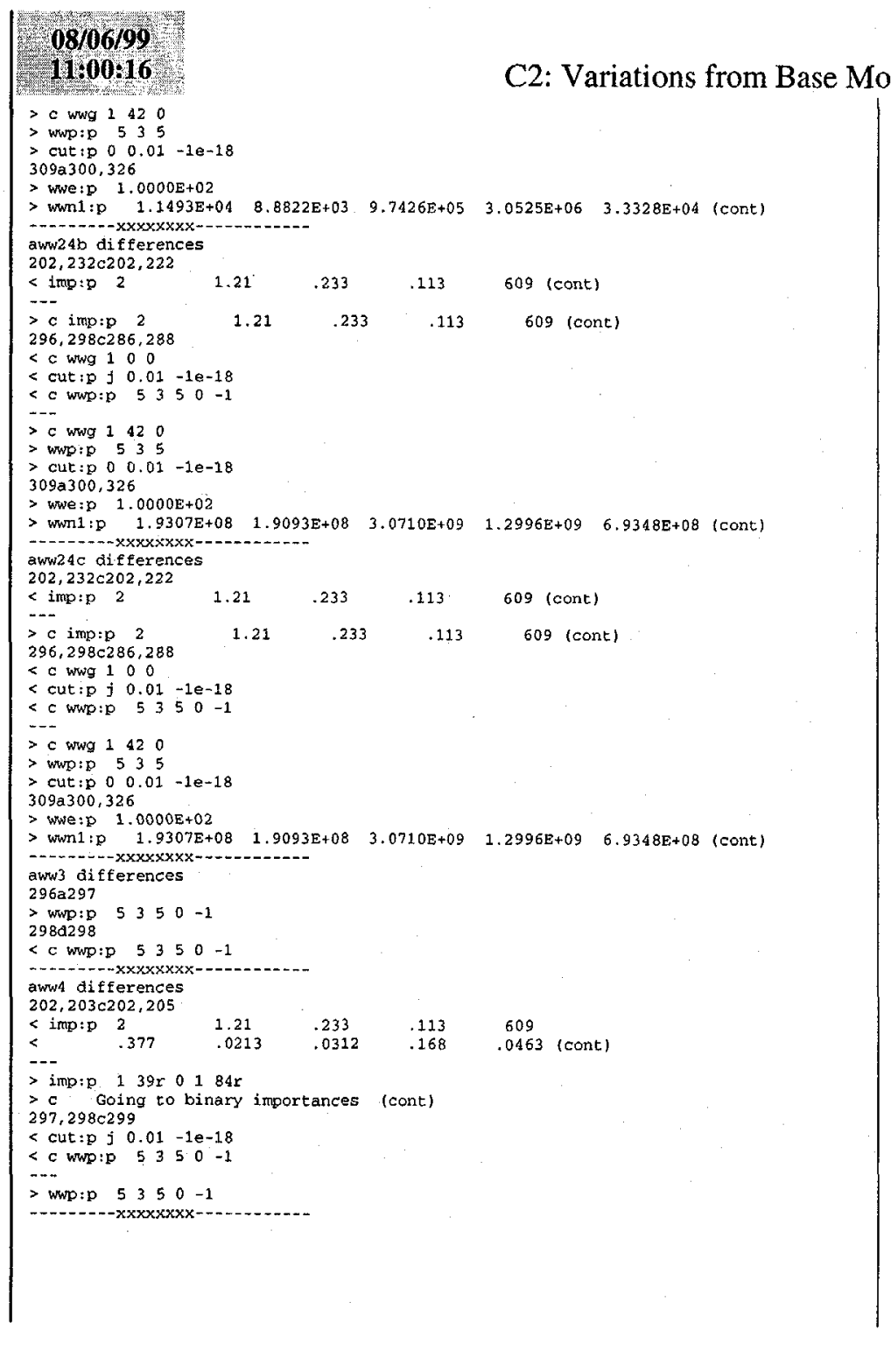


Table C3: Explanation of Runs Performed in Assessment

\begin{tabular}{|c|c|c|}
\hline Run & Explanation & Code Run \\
\hline Ag1a & Expert importances, no wwg, no ww used. & $\mathrm{MCNP} 4 \mathrm{C}$ \\
\hline Ag1b & $\begin{array}{l}\text { Same as Ag1a, but cell-based ww's } \\
\text { generated. }\end{array}$ & MCNP4C \\
\hline Ag2a & Expert importances, no wwg, no ww used. & MCNP4B \\
\hline Ag2b & $\begin{array}{l}\text { Same as Ag2a, but cell-based ww's } \\
\text { generated. }\end{array}$ & MCNP4B \\
\hline Ag3a & $\begin{array}{l}\text { Expert importances, complex geometry, no } \\
\text { wwg, no ww used. }\end{array}$ & MCNP4C \\
\hline Ag3b & $\begin{array}{l}\text { Same as Ag3b, but mesh-based ww's } \\
\text { generated. }\end{array}$ & $\mathrm{MCNP} 4 \mathrm{C}$ \\
\hline Ag4a & $\begin{array}{l}\text { Binary importances, complex geometry, no } \\
\text { wwg, no ww used. }\end{array}$ & MCNP4C \\
\hline Ag4b & $\begin{array}{l}\text { Same as Ag4a, but mesh-based ww's } \\
\text { generated. }\end{array}$ & MCNP4C \\
\hline Ag5a & $\begin{array}{l}\text { Binary importances, simple geometry, no } \\
\text { wwg, no ww used. }\end{array}$ & MCNP4C \\
\hline Ag5b & $\begin{array}{l}\text { Same as Ag5a, but mesh-based ww's } \\
\text { generated. }\end{array}$ & $\mathrm{MCNP} 4 \mathrm{C}$ \\
\hline Aww14b & Applies cbww generated in Ag1b & MCNP4B \\
\hline Aww14C & Applies cbww generated in Ag1b & MCNP4C \\
\hline Aww24b & Applies cbww generated in Ag2b & MCNP4B \\
\hline Aww24C & Applies cbww generated in Ag2b & MCNP4C \\
\hline Aww3 & Applies mbww generated in Ag3b & $\mathrm{MCNP} 4 \mathrm{C}$ \\
\hline Aww4 & Applies mbww generated in Ag4b & $\mathrm{MCNP} 4 \mathrm{C}$ \\
\hline Aww5 & Applies mbww generated in Ag5b & MCNP4C \\
\hline
\end{tabular}




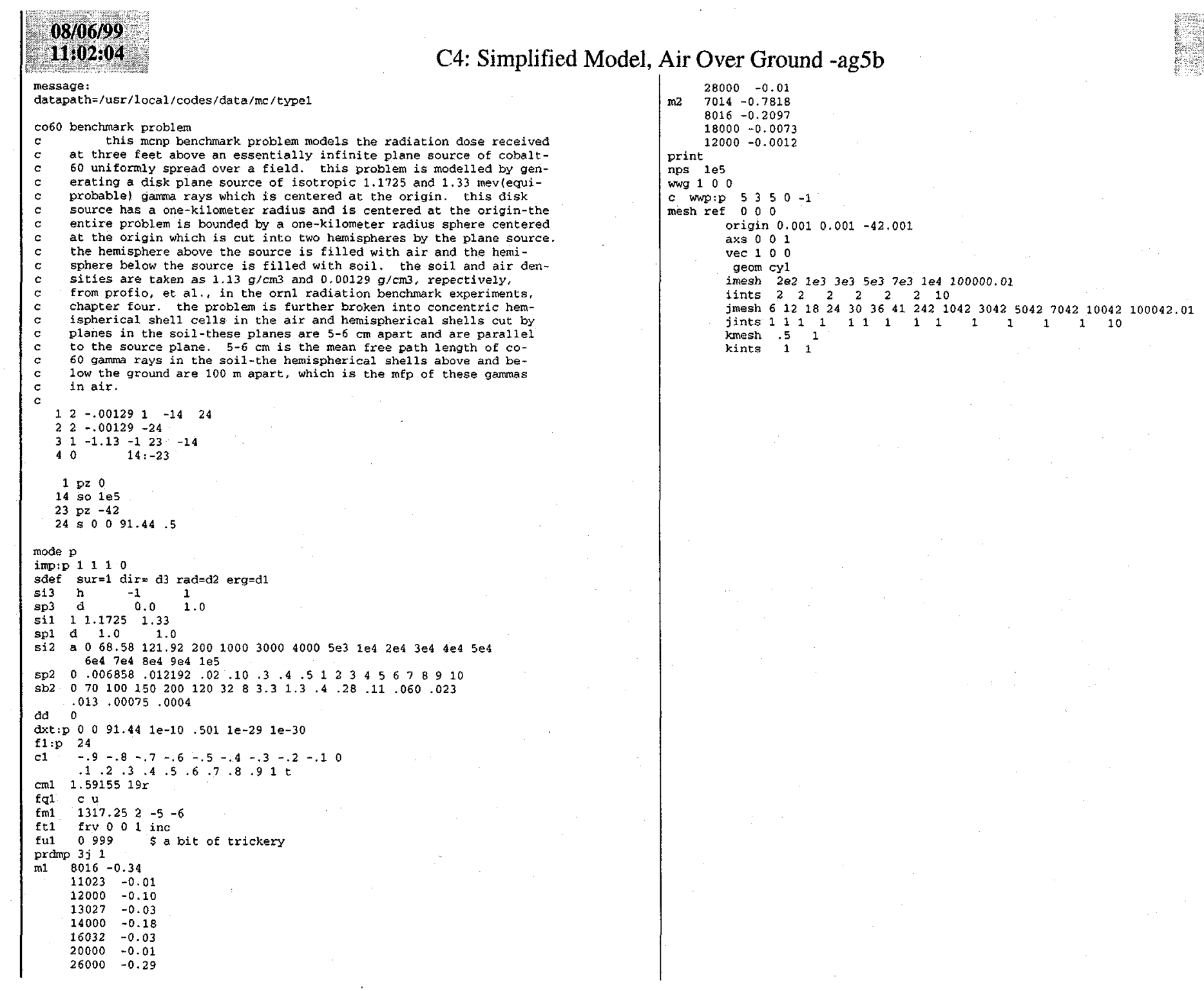


message:
datapath $=$ /usr/local/codes/data/mc/typel

testprob12 $==>>$ porosity tool model

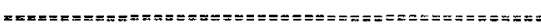

$\begin{array}{lll}==\Rightarrow>> & \text { run } & : \text { probl2 } \\ ==>>> & \text { tool } & \text { genexic porosity tool }\end{array}$

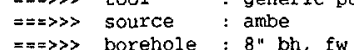

$=\Rightarrow \Rightarrow>>$ borehole $: 8 "$ bh, fw
$=\Rightarrow \Rightarrow>>$ formation $: 20 \mathrm{pu}$ limestone, $\mathrm{tw}$

$==\Rightarrow \gg>$ detector : he-3 at 4 atomospheres

$=\Rightarrow>>>$ near : 1 "odx3" at $7.5 "$ centerline from source

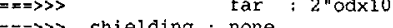
$=\Rightarrow>>>$ sonde : solid iron

$===>>$ weights : xtrapt/diffusion

="=>>> generate weights using wep patch with factor of 2.0 to far det $==\geq>>$ physics

$==\$>>>(a, b)$ added for water

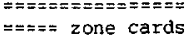

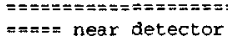

作

$1 \quad 1-0.000$

$\begin{array}{lll}-1 & +13 \quad-14\end{array}$

$\$$ det_n

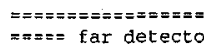

$\begin{array}{lllllll}2 & 1 & -0.000502 & -2 & +16 & -19\end{array}$

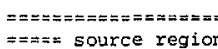

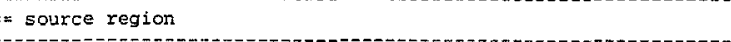

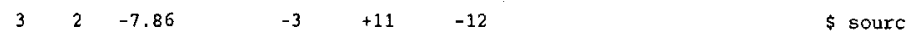

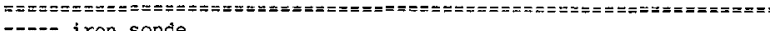

$\rightarrow=m=$ iron sonde

\begin{tabular}{|c|c|c|c|c|c|c|}
\hline 4 & $2 \quad-7.86$ & -3 & +10 & -11 & & $\$$ sonde \\
\hline 5 & & & +12 & -13 & & \\
\hline 6 & -7.86 & & & & -14 & \\
\hline$?$ & $2 \quad-7.86$ & -3 & +14 & -15 & & $\$$ sonde \\
\hline 8 & -7.86 & -3 & +15 & -16 & & sonde \\
\hline & -7.86 & +2 & -3 & +16 & -17 & sonde \\
\hline 10 & -7.86 & +2 & -3 & +17 & -18 & sonde \\
\hline 11 & $\begin{array}{l}-7.86 \\
--7.86\end{array}$ & $\begin{array}{l}+2 \\
-3\end{array}$ & -3 & $\begin{array}{l}+18 \\
-20\end{array}$ & -19 & sonde \\
\hline $\begin{array}{l}12 \\
13\end{array}$ & $\begin{array}{l}-7.86 \\
-7.86\end{array}$ & $\begin{array}{l}-3 \\
-3\end{array}$ & $\begin{array}{l}+19 \\
+20\end{array}$ & $\begin{array}{l}-20 \\
-21\end{array}$ & & sonde \\
\hline $\begin{array}{l}13 \\
14\end{array}$ & $\begin{array}{ll}2 & -7.86 \\
2 & -7.86\end{array}$ & $\begin{array}{l}-3 \\
-3\end{array}$ & $\begin{array}{l}+20 \\
+21\end{array}$ & $\begin{array}{l}-21 \\
-22\end{array}$ & & $\begin{array}{l}\$ \text { sonde } \\
\$ \text { sonde }\end{array}$ \\
\hline
\end{tabular}




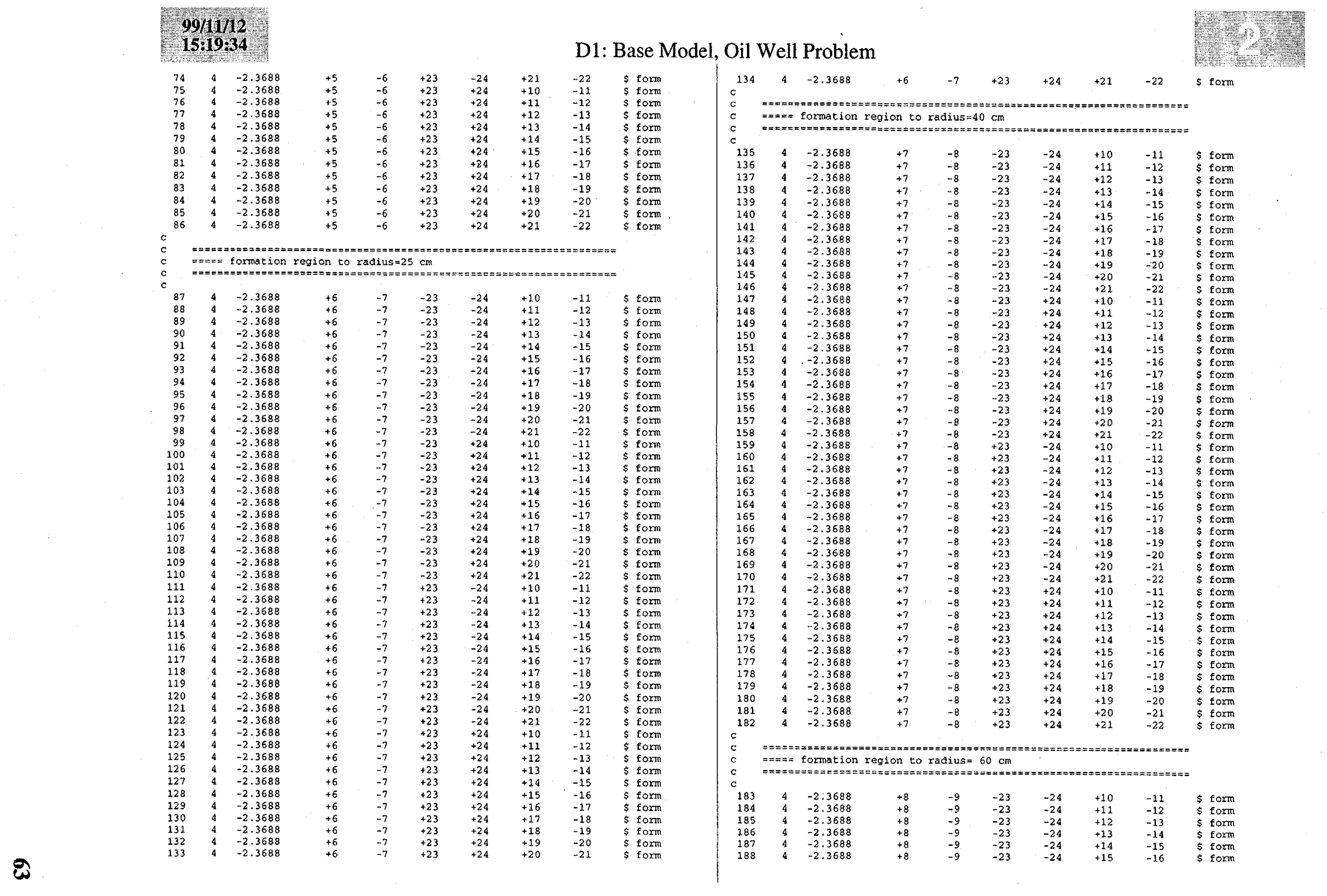




\section{$99 / 11 / 12$}

15.194

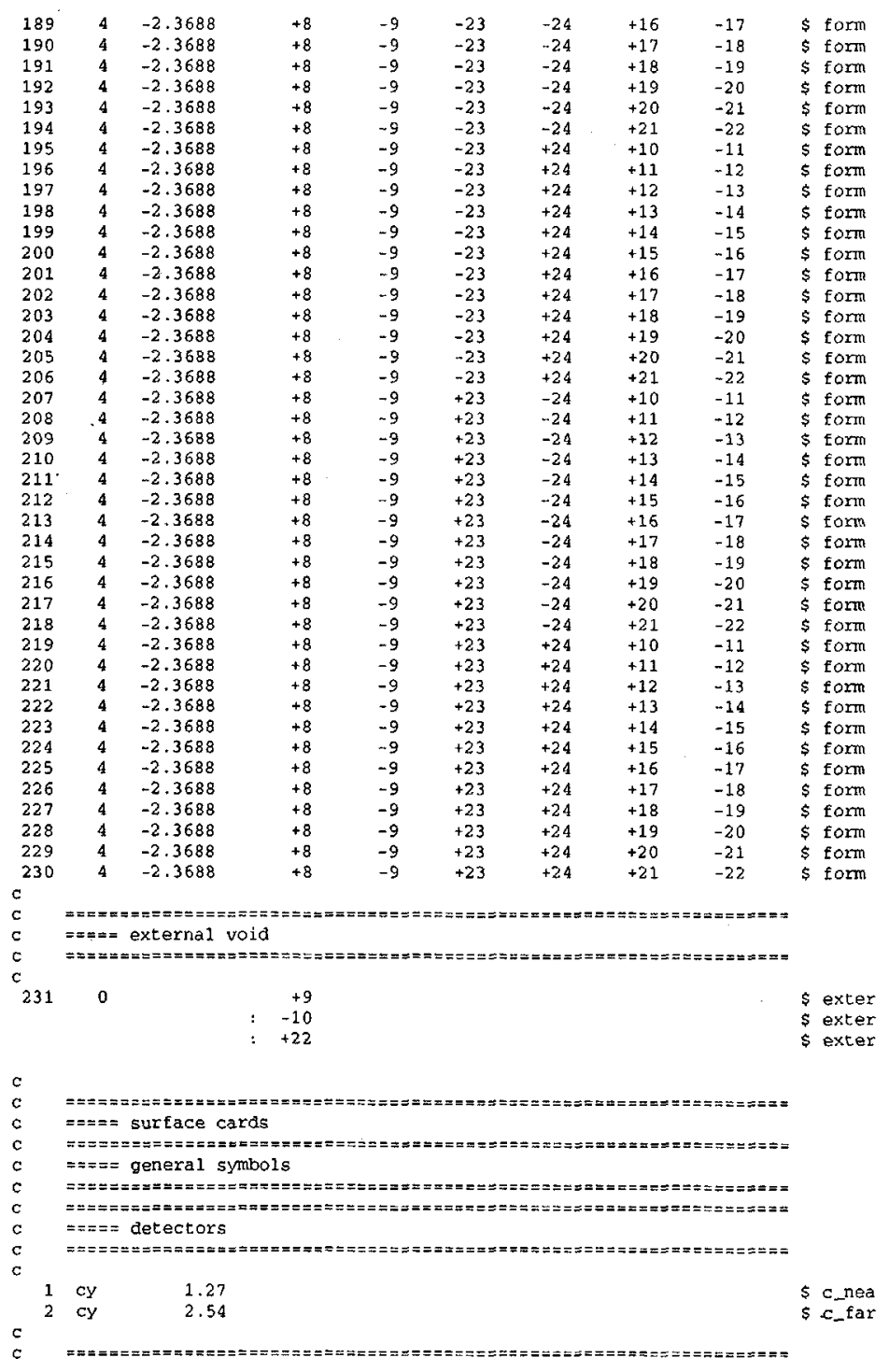

\section{D1: Base Model, Oil Well Problem}

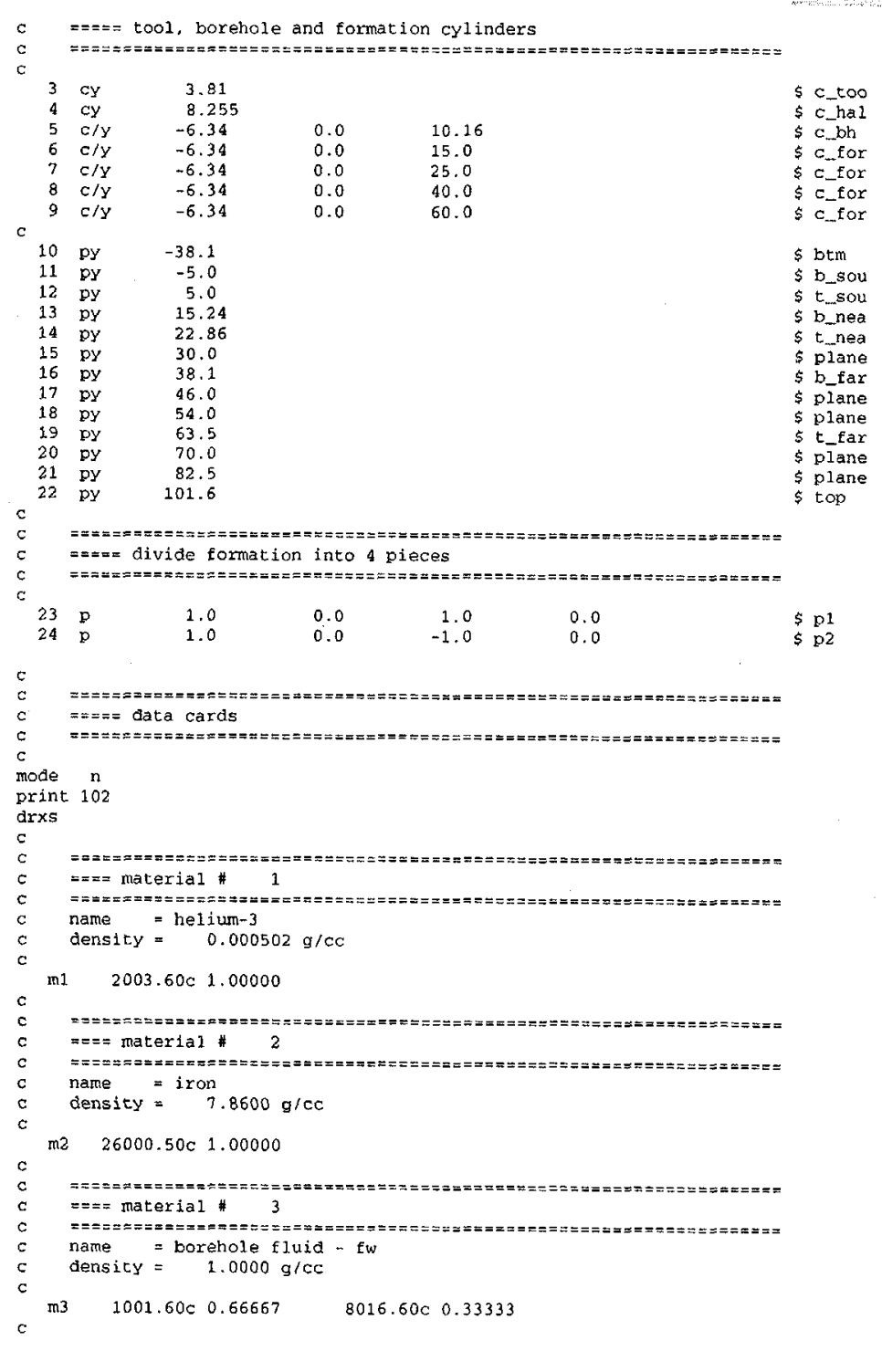




\section{D1: Base Model, Oil Well Problem}

e44 $\quad 0.1 e-6 \quad 0.41 e-6 \quad 10.6 e-6 \quad 101 e-6 \quad 1.5 e-3 \quad 26 e-3 \quad .492 .7 \quad 12.2 \quad 17.3$ $\begin{array}{llll}e m 44 & 19 r \\ f m 44 & 1.0023 e-04 & 1 & 103\end{array}$

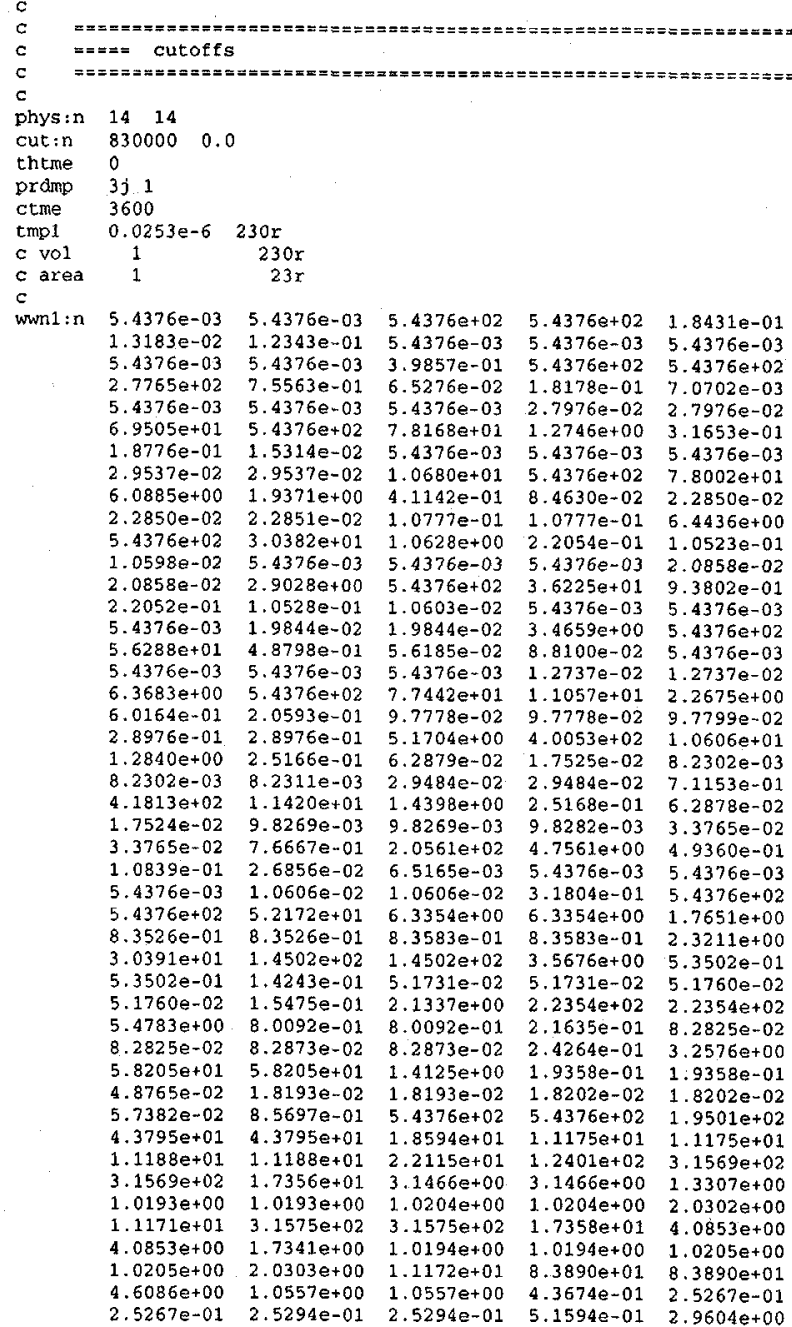


$\begin{array}{cccccc}1.9247 \mathrm{e}-02 & 1.1756 \mathrm{e}-02 & 1.9036 \mathrm{e}-03 & 4.5802 \mathrm{e}-04 & 4.2660 \mathrm{e}-04\end{array}$ $\begin{array}{llllll}4.6101 e-04 & 2.0273 e-03 & 9.2488 \mathrm{e}-03 & 4.5802 \mathrm{e}-04 & 4.26600 \mathrm{e}-04 \\ 1.5880+00 & 3.2581 & 1.5880 \mathrm{e}+00\end{array}$ $\begin{array}{llllll}1.5880 \mathrm{e}+00 & 3.2581 \mathrm{e}-01 & 5.6523 \mathrm{e}-02 & 8.4317 \mathrm{e}-02 & 6.3782 \mathrm{e}-03 \\ 7.9420 \mathrm{e}-04 & 7.6414 \mathrm{e}-04 & 7.9513 \mathrm{e}-04 & 9.9312 \mathrm{e}-03 & 9.9312 \mathrm{e}\end{array}$ $\begin{array}{llllll}1.3818 \mathrm{e}+00 & 1.5880 \mathrm{e}+00 & 1.5880 \mathrm{e}+00 & 1.5880 \mathrm{e}+00 & 3.2129 \mathrm{e}-01\end{array}$ $\begin{array}{llllll}2.0132 \mathrm{e}-01 & 1.9183 \mathrm{e}-02 & 3.7223 \mathrm{e}-03 & 3.3823 \mathrm{e}-03 & 3.7288 \mathrm{e}-03\end{array}$ $\begin{array}{lllll}4.2937 \mathrm{e}-02 & 4.2937 \mathrm{e}-02 & 1.5880 \mathrm{e}+00 & 1.5880 \mathrm{e}+00 & 1.5880 \mathrm{e}+00 \\ 1.5880 \mathrm{e}+00 & 8.6552 \mathrm{e}-01 & 2.2900 \mathrm{e}-01 & 5.6212 \mathrm{e}-02 & 1.6773 \mathrm{e}-02\end{array}$ $1.6773 \mathrm{e}-02-1.6965 \mathrm{e}-02 \quad 6.29314$ $\begin{array}{llllll}1.5880 \mathrm{e}+00 & 1.5880 \mathrm{e}+00 & 7.0903 \mathrm{e}-01 & 1.1152 \mathrm{e}-01 & 4.3747 \mathrm{e}-02\end{array}$ $\begin{array}{llllll}9.0062 e-03 & 2.5991 \mathrm{e}-03 & 2.5991 \mathrm{e}-03 & 2.6214 \mathrm{e}-03 & 2.1023 e-02\end{array}$ $\begin{array}{ccccc}2.1023 \mathrm{e}-02 & 6.2600 \mathrm{e}-01 & 1.5880 \mathrm{e}+00 & 1.5880 \mathrm{e}+00 & 6.0060 \mathrm{e}-01 \\ 1.1429 \mathrm{e}-01 & 4.4277 \mathrm{e}-02 & 9.2444 \mathrm{e}-03 & 2.1392 \mathrm{e}-03 & 2.1392 \mathrm{e}-03\end{array}$ $\begin{array}{ll}-03 & 2.1392 e-03 \\ -01 & 1.5880 e+00\end{array}$ $\begin{array}{llllll}1.5880 \mathrm{e}+00 & 2.5971 \mathrm{e}-01 & 4.7687 \mathrm{e}-02 & 1.9363 \mathrm{e}-02 & 4.1038 \mathrm{e}-03\end{array}$ $\begin{array}{lllllll}1.0309 \mathrm{e}-03 & 1.0309 \mathrm{e}-03 & 1.0374 \mathrm{e}-03 & 8.5303 \mathrm{e}-03 & 8.5303 \mathrm{e}-03\end{array}$

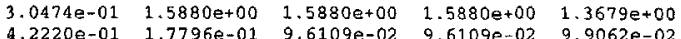
$\begin{array}{cccccc}3.0572 \mathrm{e}-01 & 3.0572 \mathrm{e}-01 & 1.5880 \mathrm{e}+00 & 1.5880 \mathrm{e}+00 & 1.5880 \mathrm{e}+00 \\ 1.0978 \mathrm{e}+00 & 1.7900 \mathrm{e}-01 & 5.2549 \mathrm{e}-02 & 2.0479 \mathrm{e}-02 & 1.1504 \mathrm{e}-02\end{array}$ \begin{tabular}{lllll}
$1.1504 \mathrm{e}-02$ & $1.1829 \mathrm{e}-02$ & $4.5590 \mathrm{e}-02$ & $2.0459 \mathrm{e}-02$ & $1.1504 \mathrm{e}-02$ \\
\hline & $1.590 \mathrm{e}-02$ & $7.0268 \mathrm{e}-01$
\end{tabular} $\begin{array}{lllll}1.5880 \mathrm{e}+00 & 1.5880 \mathrm{e}+00 & 1.1712 \mathrm{e}+00 & 1.7892 \mathrm{e}-01 & 5.2624 \mathrm{e}-02\end{array}$ $\begin{array}{lll}2.0222 \mathrm{e}-02 & 1.28023 \\ 4.8261 \mathrm{e}-02 & 7.432\end{array}$ $\begin{array}{llllll}8.2036 \mathrm{e}-02 & 2.3525 \mathrm{e}-02 & 8.7609 \mathrm{e}-03 & 1.0469 \mathrm{e}-03 & 4.0469 \mathrm{e}-03\end{array}$ $\begin{array}{lllll}4.14880+00 & 1.51880 \mathrm{e}+00 & 1.8180 \mathrm{e}-02 & 3.0805 \mathrm{e}-01 & 1.5880 \mathrm{e}+00 \\ 1.5880+00 & 1.5880 \mathrm{e}+00 & 1.5880 \mathrm{e}+00\end{array}$ $\begin{array}{lllll}1.4073 \mathrm{e}+00 & 1.4073 \mathrm{e}+00 & 1.4452 \mathrm{e}+00 & 1.4452 \mathrm{e}+00 & 1.5830 \mathrm{e}+00\end{array}$ $\begin{array}{llllll}1.5880 e+00 & 1.5880 \mathrm{e}+00 & 1.5880 \mathrm{e}+00 & 1.5880 \mathrm{e}+00 & 7.5695 \mathrm{e}-01\end{array}$ $\begin{array}{llllll}7.5695 \mathrm{e}-01 & 2.9543 \mathrm{e}-01 & 1.0399 \mathrm{e}-01 & 1.0399 \mathrm{e}-01 & 1.0656 \mathrm{e}-01 \\ 1.0656 \mathrm{e}-01 & 3.5910 \mathrm{e}-01 & 1.5920 \mathrm{e} & 1.5980 \mathrm{e}-0 & 1.5600 \mathrm{e}\end{array}$ $1.58800+00 \quad 1.11490+00$

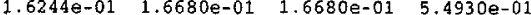
$\begin{array}{lllll}1.5880 \mathrm{e}+00 & 1.5880 \mathrm{e}+00 & 1.5880 \mathrm{e}+00 & 2.7938 \mathrm{e}-01 & 2.7938 \mathrm{e}-01\end{array}$ $\begin{array}{lllll}1.1265 e-01 & 3.7097 e-02 & 3.7097 e-02 & 3.7806 e-02 & 3.7806 e-02\end{array}$ $\begin{array}{lllll}1.5880 \mathrm{e}+00 & 1.5880 \mathrm{e}+00 & 1.5880 \mathrm{e}+00 & 1.5880 \mathrm{e}+00 & 1.588 \mathrm{e}+00\end{array}$ $\begin{array}{lllll}1.5880 \mathrm{e}+00 & 1.5880 \mathrm{e}+00 & 1.5880 \mathrm{e}+00 & 1.5880 \mathrm{e}+00 & 1.5880 \mathrm{e}+00\end{array}$ $\begin{array}{lllll}1.5880 e+00 & 1.5880 e+00 & 1.5880 e+00 & 1.5880 e+00 & 1.5880 e+00\end{array}$ $\begin{array}{lllll}1.5880 \mathrm{e}+00 & 1.5880 \mathrm{e}+00 & 1.5880 \mathrm{e}+00 & 1.5880 \mathrm{e}+00 & 1.5880 \mathrm{e}+00\end{array}$ $\begin{array}{lllll}1.5880 \mathrm{e}+00 & 1.5880 \mathrm{e}+00 & 1.5880 \mathrm{e}+00 & 1.5880 \mathrm{e}+00 & 1.5880 \mathrm{e}+00\end{array}$ $\begin{array}{lllll}1.5880 \mathrm{e}+00 & 1.5880 \mathrm{e}+00 & 1.5880 \mathrm{e}+00 & 1.5880 \mathrm{e}+00 & 1.5880 \mathrm{e}+00\end{array}$ $\begin{array}{lllll}1.5880 \mathrm{e}+00 & 1.5880 \mathrm{e}+00 & 1.5880 \mathrm{e}+00 & 1.1394 \mathrm{e}+00 & 6.7161 \mathrm{e}-01 \\ 6.7161 \mathrm{e}-01 & 6.9171 \mathrm{e}-01 & 5.9171 \mathrm{e}-01 & 1.565 \mathrm{e}+00 & 1.580 \mathrm{e}\end{array}$ $6.7161 \mathrm{e}-01$

$\begin{array}{lllll}5.6850 \mathrm{e}-01 & 5.6850 \mathrm{e}-01 & 7.4392 \mathrm{e}-01 & 7.4392 \mathrm{e}-01 & 7.4392 \mathrm{e}-01\end{array}$ $2 \quad 2.6799 \mathrm{e}-02$

$\begin{array}{lllll}1.7728 \mathrm{e}-01 & 5.0000 \mathrm{e}-01 & 5.0000 \mathrm{e}-01 & 5.0000 \mathrm{e}-01 & 5.0000 \mathrm{e}-01\end{array}$ 


\section{D1: Base Model, Oil Well Problem}

$\begin{array}{ccccc}5.0000 e-01 & 5.0000 e-01 & 5.0000 e-01 & 5.0000 e-01 & 5.0000 e-01\end{array}$

$\begin{array}{ccccc}5.0000 e-01 & 5.0000 e-01 & 5.00000 e-01 & 5.0000 e-01 & 5.0000 e-01 \\ 5.0000 e-01 & 5.0000 e-01 & 5.0000 e-01 & 5.000 e-01 & 5.0000 e-01\end{array}$

$\begin{array}{ccccc}5.0000 e-01 & 5.0000 e-01 & 5.0000 e-01 & 5.0000 e-01 & 5.0000 e-01\end{array}$

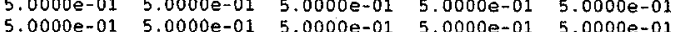

$\begin{array}{ccccc}5.0000 e-01 & 5.0000 e-01 & 5.0000 e-01 & 5.0000 e-01 & 5.0000 e-01\end{array}$

$\begin{array}{llllll}5.0000 e-01 & 5.0000 e-01 & 5.0000 e-01 & 5.0000 e-01 & 5.0000 e-01\end{array}$

$\begin{array}{llllll}5.0000 e-01 & 5.0000 e-01 & 5.0000 e-01 & 5.0000 e-01 & 5.0000 e-01\end{array}$

$\begin{array}{cccccc}6.5593 \mathrm{e}-01 & 6.5593 \mathrm{e}-01 & 6.5593 \mathrm{e}-01 & 6.5593 \mathrm{e}-01 & 2.0210 \mathrm{e}-01 \\ 7.8339 \mathrm{e}-02 & 2.9105 \mathrm{e}-02 & 1.6076 \mathrm{e}-02 & 1.0422 \mathrm{e}-02 & 9.6449 \mathrm{e}-03\end{array}$

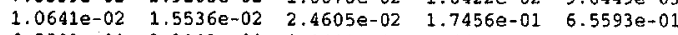

$\begin{array}{ccccc}6.5593 \mathrm{e}-01 & 2.3103 \mathrm{e}-01 & 1.0401 \mathrm{e}-01 & 4.6624 \mathrm{e}-02 & 2.3474 \mathrm{e}-02 \\ 1.1987 \mathrm{e}-02 & 1.1445 \mathrm{e}-02 & 1.2216 \mathrm{e} & 1.9814 \mathrm{e}-02 & 1.0814 \mathrm{e}-02\end{array}$

$\begin{array}{lllll}1.3353 \mathrm{e}-01 & 6.5593 \mathrm{e}-01 & 6.5593 \mathrm{e}-01 & 3.6752 \mathrm{e}-01 & 1.5445 \mathrm{e}-01\end{array}$

$\begin{array}{lllll}7.4292 \mathrm{e}-02 & 3.8532 \mathrm{e}-02 & 2.1708 \mathrm{e}-02 & 2.0162 \mathrm{e}-02 & 2.2221 \mathrm{e}-02\end{array}$

$\begin{array}{lllll}4.1354 \mathrm{e}-02 & 4.1334 \mathrm{e}-02 & 2.2691 \mathrm{e}-01 & 6.5593-01 & 6.5593 \mathrm{e}-01\end{array}$

$\begin{array}{llllll}4.0502 \mathrm{e}-02 & 4.1381 \mathrm{e}-02 & 7.5969 \mathrm{e}-02 & 7.5969 \mathrm{e}-02 & 3.053 \mathrm{e}-02\end{array}$

$\begin{array}{ccccc}6.5593 \mathrm{e}-01 & 6.5593 \mathrm{e}-01 & 2.6989 \mathrm{e}-01 & 1.1432 \mathrm{e}-01 & 5.5863 \mathrm{e}-02\end{array}$

$\begin{array}{lllll}3.0300 \mathrm{e}-02 & 1.6086 \mathrm{e}-02 & 1.6086 \mathrm{e}-02 & 1.6399 \mathrm{e}-02 & 3.3423 \mathrm{e}-02 \\ 3.3423 \mathrm{e}-02 & 1.7551 \mathrm{e}-01 & 6.5593 \mathrm{e}-01 & 6.5593 \mathrm{e}-01 & 2.6243 \mathrm{e}\end{array}$

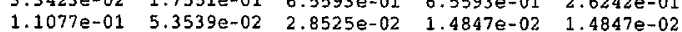

$\begin{array}{lllll}1.5151 \mathrm{e}-02 & 3.1281 \mathrm{e}-02 & 3.1281 \mathrm{e}-02 & 1.6684 \mathrm{e}-01 & 6.5593 \mathrm{e}-01\end{array}$

$\begin{array}{lllll}6.0373 \mathrm{e}-01 & 1.9382 \mathrm{e}-01 & 7.4164 \mathrm{e}-02 & 3.4342 \mathrm{e}-02 & 1.8415 \mathrm{e}-02\end{array}$

$\begin{array}{lllll}1.1271 \mathrm{e}-02 & 1.1271 \mathrm{e}-02 & 1.1454 \mathrm{e}-02 & 2.1263 \mathrm{e}-02 & 2.1263 \mathrm{e}-02 \\ 1.1919 \mathrm{e}-01 & 6.5593 \mathrm{e}-01 & 6.5593 \mathrm{e}-01 & 6.5593 \mathrm{e}-01 & 3.911 \mathrm{e}-01\end{array}$

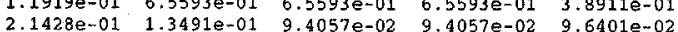

$\begin{array}{llllll}1.6281 \mathrm{e}-01 & 1.6281 \mathrm{e}-01 & 6.3185 \mathrm{e}-01 & 6.5593 \mathrm{e}-01 & 6.5593 \mathrm{e}-01\end{array}$

$\begin{array}{llllll}1.9118 \mathrm{e}-01 & 1.5444 \mathrm{e}-01 & 8.1239 \mathrm{e}-02 & 4.9417 \mathrm{e}-02 & 3.5943 \mathrm{e}-02\end{array}$

$\begin{array}{ccccc}3.5943 \mathrm{e}-02 & 3.6887 \mathrm{e}-02 & 6.5540 \mathrm{e}-02 & 6.5540 \mathrm{e}-02 & 2.7761 \mathrm{e}-01 \\ 6.5593 \mathrm{e}-01 & 6.5593 \mathrm{e}-01 & 3.7687 \mathrm{e}-01 & 1.4780 \mathrm{e}-01 & 7.6900 \mathrm{e}-02\end{array}$

4.6030e-02 $3: 2707 \mathrm{e}-02 \quad 3.2707 \mathrm{e}-02 \quad 3.3596 \mathrm{e}-02 \quad 6.1201 \mathrm{e}-02$

$\begin{array}{lllll}6.1201 \mathrm{e}-02 & 2.6451 \mathrm{e}-01 & 6.5593 \mathrm{e}-01 & 6.5593 \mathrm{e}-01 & 2.5556 \mathrm{e}-01\end{array}$

$\begin{array}{lllll}1.0329 \mathrm{e}-01 & 5.3342 \mathrm{e}-02 & 3.2002 \mathrm{e}-02 & 2.1341 \mathrm{e}-02 & 2.1341 \mathrm{e}-02\end{array}$

$\begin{array}{lllll}2.1865 \mathrm{e}-02 & 3.9569 \mathrm{e}-02 & 3.9569 \mathrm{e}-02 & 1.7524 \mathrm{e}-01 & 6.5593 \mathrm{e}-01 \\ 6.5593 \mathrm{e}-01 & 6.5593 \mathrm{e}-01 & 6.5593 \mathrm{e}-01 & 6.5593 \mathrm{e}-01 & 6.5593 \mathrm{e}\end{array}$

$4.4861 \mathrm{e}-01 \quad 4.4861 \mathrm{e}-01 \quad 4.5836 \mathrm{e}-01 \quad 4.5836 \mathrm{e}-01 \quad 6.5593 \mathrm{e}-01$

$\begin{array}{ccccc}6.5593 \mathrm{e}-01 & 6.5593 \mathrm{e}-01 & 6.5593 \mathrm{e}-01 & 6.5593 \mathrm{e}-01 & 4.4258 \mathrm{e}-01\end{array}$

$\begin{array}{llllll}4.4258 \mathrm{e}-01 & 2.2366 \mathrm{e}-01 & 1.3216 \mathrm{e}-01 & 1.3216 \mathrm{e}-01 & 1.3562 \mathrm{e}-01 \\ 1.3562 \mathrm{e}-01 & 2.569 \mathrm{e} & 6.5593 \mathrm{e}-01 & 6.5593 \mathrm{e}-01 & 0.5593 \mathrm{e}\end{array}$

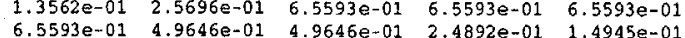

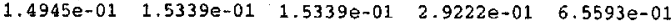

$\begin{array}{lllll}6.5593 \mathrm{e}-01 & 6.5593 \mathrm{e}-01 & 6.5593 \mathrm{e}-01 & 2.6836 \mathrm{e}-01 & 2.6836 \mathrm{e}-01\end{array}$

$\begin{array}{lllll}1.3444 \mathrm{e}-01 & 7.8026 \mathrm{e}-02 & 7.8026 \mathrm{e}-02 & 7.9840 \mathrm{e}-02 & 7.9840 \mathrm{e}-02 \\ 1.5446 \mathrm{e} & 6.5593-01 & 6.5593 \mathrm{e} & 6.5593-01 & 6.5593 e-01\end{array}$

$\begin{array}{ccccc}6.5593 \mathrm{e}-01 & 5.5593 \mathrm{e}-01 & 6.5593 \mathrm{e}-01 & 6.5593 \mathrm{e}-01 & 6.5593 \mathrm{e}-01 \\ 6 & 6.5593 \mathrm{e}-01 & 6.5593 \mathrm{e}-01 & 6.5593 \mathrm{e}-01\end{array}$

$6.5593 \mathrm{e}-01 \quad 6.5593 \mathrm{e}-01 \quad 6.5593 \mathrm{e}-01 \quad 6.5593 \mathrm{e}-01 \quad 6.5593 \mathrm{e}-01$

$\begin{array}{llllll}6.5593 \mathrm{e}-01 & 6.5593 \mathrm{e}-01 & 6.5593 \mathrm{e}-01 & 6.5593 \mathrm{e}-01 & 6.5593 \mathrm{e}-01\end{array}$

$\begin{array}{lllll}6.5593 e-01 & 6.5593 \mathrm{e}-01 & 6.5593 \mathrm{e}-01 & 6.5593 \mathrm{e}-01 & 6.5593 \mathrm{e}-01\end{array}$

$\begin{array}{llllll}6.5593 \mathrm{e}-01 & 6.553 \mathrm{e}-01 & 6.5593 \mathrm{e}-01 & 6.5593 \mathrm{e}-01 & 6.5593 \mathrm{e}-01 \\ 6.5593 \mathrm{e}-01 & 6.5593 \mathrm{e}-01 & 6.5593 \mathrm{e}-01 & 6.5593 \mathrm{e}-01 & 6.5593 \mathrm{e}-01\end{array}$

$6.5593 \mathrm{e}-01 \quad 6.5593 \mathrm{e}-01 \quad 6.5593 \mathrm{e}-01 \quad 6.5593 \mathrm{e}-01 \quad 6.5593 \mathrm{e}-01$

$\begin{array}{lllll}6.5593 \mathrm{e}-01 & 6.5593 \mathrm{e}-01 & 6.5593 \mathrm{e}-01 & 6.5593 \mathrm{e}-01 & 5.5474 \mathrm{e}-01 \\ 5.5474 \mathrm{e}-01 & 5.6948 \mathrm{e}-01 & 5.6948 \mathrm{e}-01 & 6.5593 \mathrm{e}-01 & 6.5593 \mathrm{e}-01\end{array}$

wwg $\quad 4400$

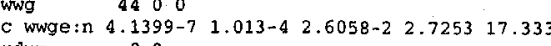

rdum 0.8

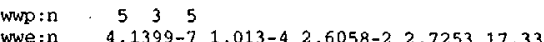

nesh

$\begin{array}{lllll}\text { ref } & 0 & 0 & & \\ \text { origin } & 0.001 & -38.101 & 0.001\end{array}$

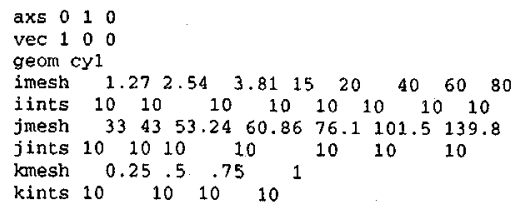


D2: Variations From Base Model, Oil Well Problem

ogla differences

$0 g 1 \mathrm{~b}$ differences

$\begin{array}{llllll}< & c \text { wwg } & 44 & 3 & 0 \\ \text { <c wwge:n } & 4.1399-7 & 1.023-4 & 2.5058-2 & 2.7253 & 17.33\end{array}$

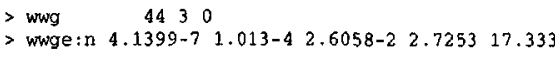

og2a differences

$0 \mathrm{~g} 2 \mathrm{~b}$ differences

$\begin{array}{llllll}<C & \text { wwg } & 44 & 3 & 0 \\ \text { \& } w w g e: n & 4.1399-7 & 1.013-4 & 2.6058-2 & 2.7253 & 17.333\end{array}$

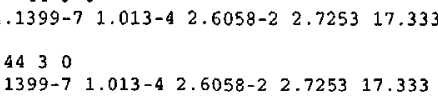

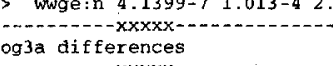

og $3 \mathrm{~b}$ differences

$708 c 708$
$<\mathrm{CWWg} \quad 4430$

$>$ WWg
$714,724 \mathrm{c} 714,724$

$<c$ mesh ref 0000

$\begin{array}{lllll} & c\end{array}$

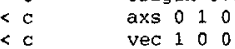

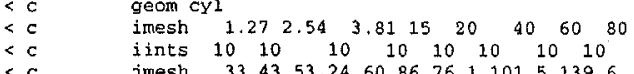

jmesh $3343 \quad 53.2460 .8676 .1101 .5139 .6$

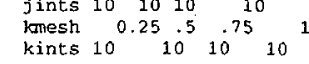

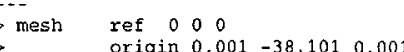

$\begin{array}{llll}\text { axs } & 0 & 1 & 0 \\ \text { vec } & 1 & 0 & 0\end{array}$

$\begin{array}{lllllllll}\text { geom cyl } & \\ \text { imesh } & 1.27 & 2.54 & 3.81 & 15 & 20 & 40 & 60 & 80\end{array}$

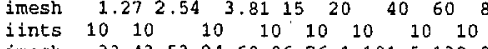

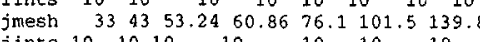

$\begin{array}{lllll}j \text { ints } & 10 & 10 & 10 & 10 \\ \text { kmesh } & 0 & 25 & 5 & 75\end{array}$

kints 10 (10 10 10 10

og4a differences

$463 a 464$

$>$ imp: $1229 \mathrm{x}$

< wwn1:n $5.4376 \mathrm{e}-03 \quad 5.4376 \mathrm{e}-03 \quad 5.4376 \mathrm{e}+02 \quad 5.4376 \mathrm{e}+02 \quad 1.8431 \mathrm{e}-01$ (cont

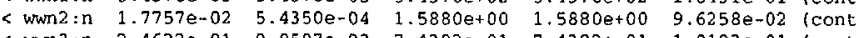

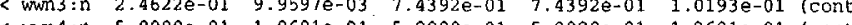

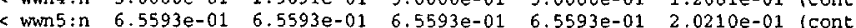
$711,7120477,478$

$\begin{array}{lcccccc}<\text { \&wp:n } & 5 & 3 & 5 & & & \\ <\text { wwe :n } & 4.1399-7 & 1.013-4 & 2.5058-2 & 2.7253 & 17.333\end{array}$

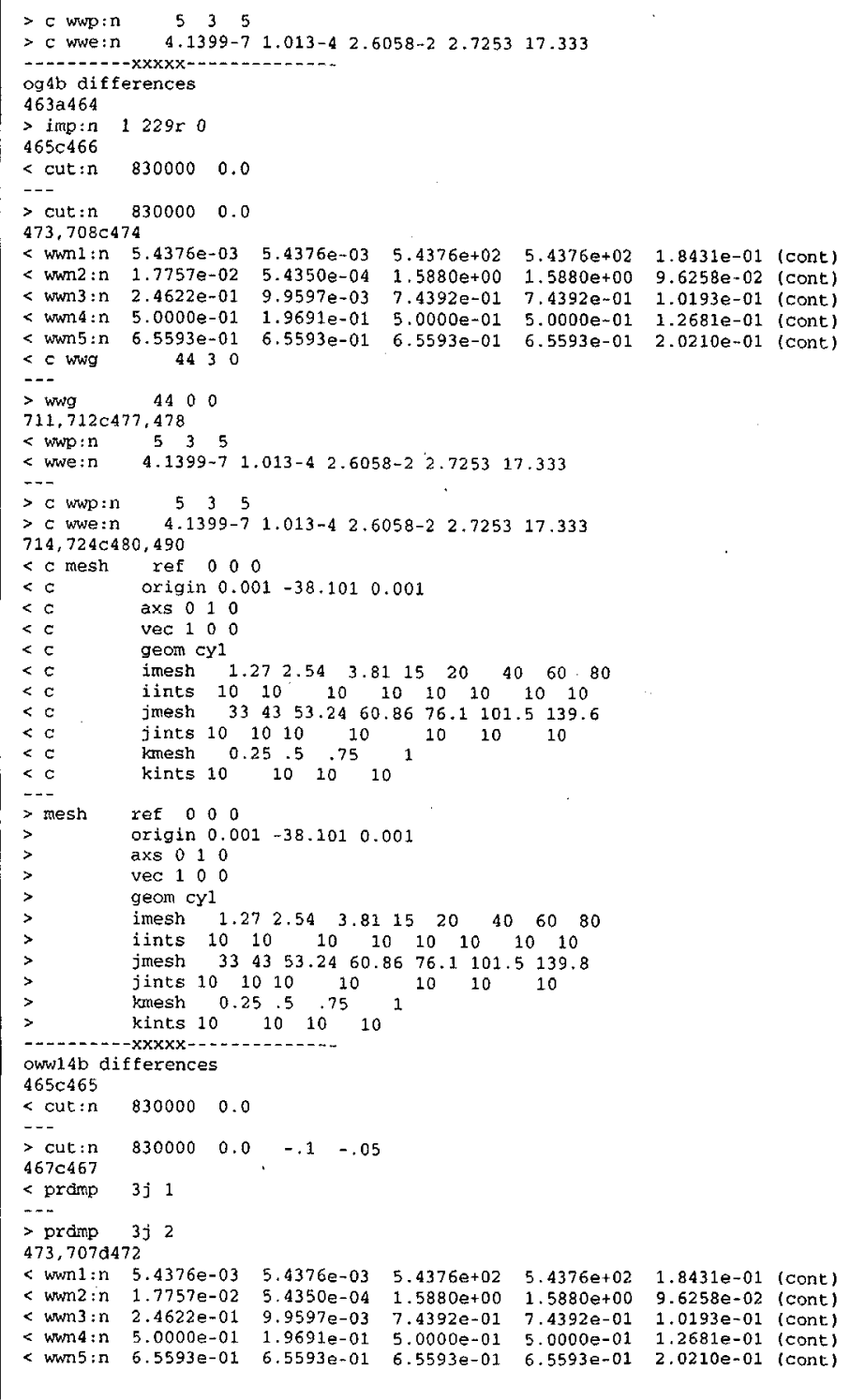




\section{$99 / 11112$}

15:47:06

$712,713 \times 477$

$\begin{array}{llllll}<\text { we:n } & 4.1399-7 & 1.013-4 & 2.6058-2 & 2.7253 & 17.333\end{array}$

$>$ nps 1 e5

origin $0.001-38.101 \quad 0.001$

-.-

$724 a 489,724$

origin $0.001-38.0010 .001$

Wwe:n $\quad 4,1399 \mathrm{E}-07 \quad 1.0130 \mathrm{E}-04 \quad 2.6058 \mathrm{E}-02 \quad 2.7253 \mathrm{E}+00 \quad 1.7333 \mathrm{E}+01$

$\begin{array}{lllllll}3 \text { wWn } 1: n & 2.8361 \mathrm{E}-01 & 1.2133 \mathrm{E}-04 & 0.0000 \mathrm{E}+00 & 0.0000 \mathrm{E}+00 & 1.6678 \mathrm{E}+01 & \text { (cont) }\end{array}$

$>$ wwm $2: n \quad 1.3004 \mathrm{E}-01 \quad 2.6945 \mathrm{E}-04 \quad 4.4455 \mathrm{E}+01 \quad 0.0000 \mathrm{E}+00 \quad 8.1770 \mathrm{E}-01$ (cont)

$\begin{array}{llllll} & \end{array}$

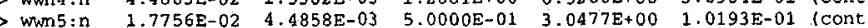

oww14c differences

$465 c 465$
$<$ cut:n $\quad 830000 \quad 0.0$

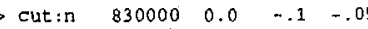

$467 c 467$
$<$ prdmp $\quad 3 j 1$

$>$ prdmp $3 j$

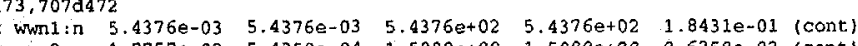

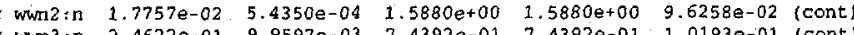
$\begin{array}{lllllll}\text { < wwn4:n } & 5.0000 \mathrm{e}-01 & 1.9691 \mathrm{e}-01 & 5.0000 \mathrm{e}-01 & 5.0000 \mathrm{e}-01 & 1.2681 \mathrm{e}-01 & \text { (cont) } \\ \text { < wwm5 } & 6.559 \mathrm{e}-01 & 6.5593 \mathrm{e}-01 & 6.5593 \mathrm{e}-01 & 6.5593 \mathrm{e}-01 & 2.0210 \mathrm{e}-01 & \text { (cont) }\end{array}$

< wwe:n 4.1399-7 $1.013-4 \quad 2.6058-2 \quad 2.7253 \quad 17.333$

$>$ wwe:n $4.1399 \mathrm{E}-07 \quad 1.0130 \mathrm{~B}-04 \quad 2.6058 \mathrm{E}-02 \quad 2.7253 \mathrm{E}+00 \quad 1.7333 \mathrm{E}+01$

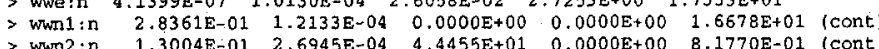

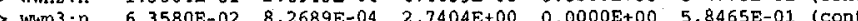

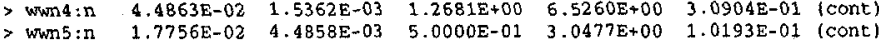

oww24b difference

$465 \mathrm{c} 465 \quad 830000 \quad 0.0$

cut: $\quad 830000 \quad 0.0$

$\begin{array}{lllll}>\text { cut } ! n & 830000 & 0.0 & -.1 & -.05\end{array}$

$<$ prdmp $3 j 1$

$>$ pramp $3 j 2$

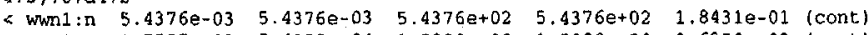

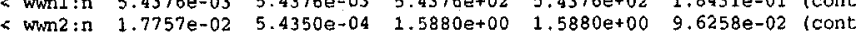

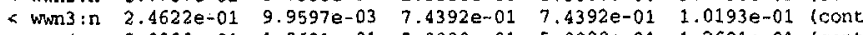

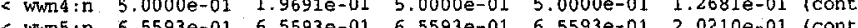

$712,713 \mathrm{C} 477{ }_{4.1399-7} 1.013-4 \quad 2.6058-2 \quad 2.7253 \quad 17.333$

$<$ wwe:n
$715 \mathrm{c} 479$ origin $0.001-38.1010 .001$

$>c$ origin $0.001-38.0010 .001$ (a)

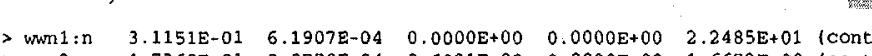

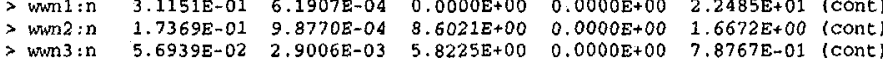
$\begin{array}{lllllll}>\text { wwm } 4: \mathrm{n} & 9.3729 \mathrm{E}-02 & 4.8202 \mathrm{E}-03 & 3.4337 \mathrm{E}+00 & 2.4721 \mathrm{E}-01 & 1.085 \mathrm{E}+00 & \text { (cont }\end{array}$

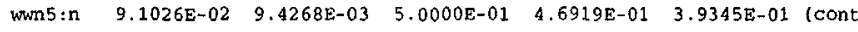
oww2 $4 \mathrm{c}$ differences

$465 c 465$

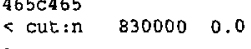

$\begin{array}{lllll}>\text { cut: } n & 830000 & 0.0 & -.1 & -.05\end{array}$

$<$ prdmp $3 j 1$

$>$ prdmp $3 j 2$
473,7070472

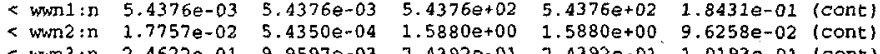
$\begin{array}{lllllll}<\text { wwin } 3: n & 2.4622 \mathrm{e}-01 & 9.9597 \mathrm{e}-03 & 7.4392 \mathrm{e}-01 & 7.4392 \mathrm{e}-01 & 1.0193 \mathrm{e}-01 & \text { (cont) } \\ <\text { <wn } 4: n & 5.0000 \mathrm{e}-01 & 1.9691 \mathrm{e} \times 01 & 5.0000 \mathrm{e}-01 & 5.0000 \mathrm{e}-01 & 1.2681 \mathrm{e}-01 & \text { (cont) }\end{array}$

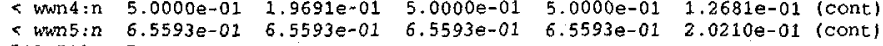

$\begin{array}{llllll}712,713 c 477 & \\ \text { swe:n } & 4.1399-7 & 1.013-4 & 2.6058-2 & 2.7253 & 17.333\end{array}$

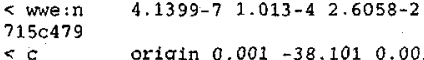

(a)

$>c$ origin $0.001-38.0010 .001$

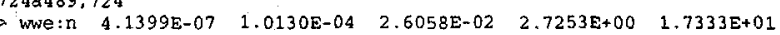

> wwn $1: \mathrm{n} \quad 3.1151 \mathrm{E}-01 \quad 6.1907 \mathrm{E}-04 \quad 0.0000 \mathrm{E}+00 \quad 0.0000 \mathrm{E}+00 \cdot 2.2485 \mathrm{E}+01$ (cont)

$\begin{array}{lllllll}>\text { wwm } 2: \mathrm{n} & 1.7369 \mathrm{E}-01 & 9.8770 \mathrm{E}-04 & 8.6021 \mathrm{E}+00 & 0.0000 \mathrm{E}+00 & 1.6672 \mathrm{E}+00 \text { (cont) }\end{array}$

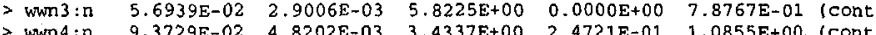

$\begin{array}{lllllll}>\text { wwn }: n & 9.3729 \mathrm{E}-02 & 4.8202 \mathrm{E}-03 & 3.4337 \mathrm{E}+00 & 2.47218-01 & 1.0855 \mathrm{E}+00 & \text { (cont) } \\ >\mathrm{wWn} 5: \mathrm{n} & 9.1026 \mathrm{E}-02 & 9.4268 \mathrm{E}-03 & 5.0000 \mathrm{E}-01 & 4.6919 \mathrm{E}-01 & 3.9345 \mathrm{E}-01 & \text { (cont) }\end{array}$

oww3 dif ferences

$=$ imp:n $1229 \mathrm{r}$

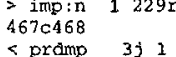

2 pramp $3 j$
$473,707 d 43$

Cwmin1:n $5.4376 \mathrm{e}-03 \quad 5.4376 \mathrm{e}-03 \quad 5.4376 \mathrm{e}+02 \quad 5.4376 \mathrm{e}+02 \quad 1.8431 \mathrm{e}-01$ (cont)

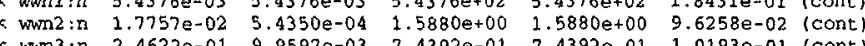
\& wrm $3: n$ 2.4622e-01 $9.9597 \mathrm{e}-03 \quad 7.4392 \mathrm{e}-01 \quad 7.4392 \mathrm{e}-01 \quad 1.0193 \mathrm{e}-01$ (cont

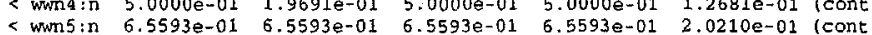
$711,712 \mathrm{c} 477,478$

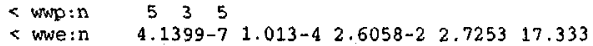

$>$ wup: : $\quad \begin{array}{llllll}5 & 3 & 5 & 0 & -1\end{array}$

$\begin{array}{llllll}>\text { c wwe:n } & 4.1399-7 & 1.013-4 & 2.6058-2 & 2.7253 & 17.333\end{array}$

$\begin{array}{llll}2 & 0 \\ <c & \text { origin } 0.001 & -38.101 & 0.001\end{array}$

$>$ origin $0.001-38.001 \quad 0.001$

oww4 differences

$\rightarrow$ imp:n $1229 \times$

$467 c 468$
4 promp $3 \mathrm{j} 1$ 
D2: Variations From Base Model, Oil Well Problem

$>$ prdmp $3 j 2$

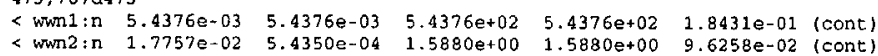

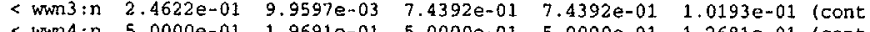

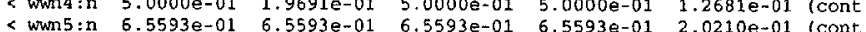

$711,712 \mathrm{C} 477,478$

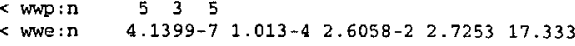

$>$ wup: : $\quad \begin{array}{llllll}5 & 3 & 5 & 0 & -1\end{array}$

$\begin{array}{llllllll}>c \text { wwe:in } & 4.1399-7 & 1.013-4 & 2.6058-2 & 2.7253 & 17.333\end{array}$

$\underset{<c}{715 c 481}$ origin $0.001-38.1010 .001$ $>c \quad$ origin $0.001-38.0010 .001$ 
Table D3: Explanation of Runs Performed in Assessment

\begin{tabular}{|c|c|c|}
\hline Run & Explanation & Code Run \\
\hline Og1a & Expert importances, no wwg, no ww used. & MCNP4C \\
\hline Og1b & $\begin{array}{l}\text { Same as Og1a, but cell-based ww's } \\
\text { generated. }\end{array}$ & MCNP4C \\
\hline Og2a & Expert importances, no wwg, no ww used. & MCNP4B \\
\hline Og2b & $\begin{array}{l}\text { Same as Og2a, but cell-based ww's } \\
\text { generated. }\end{array}$ & MCNP4B \\
\hline Og3a & $\begin{array}{l}\text { Expert importances, complex geometry, no } \\
\text { wwg, no ww used. }\end{array}$ & MCNP4C \\
\hline Og3b & $\begin{array}{l}\text { Same as Og3b, but mesh-based ww's } \\
\text { generated. }\end{array}$ & MCNP4C \\
\hline Og4a & $\begin{array}{c}\text { Binary importances, complex geometry, no } \\
\text { wwg, no ww used. }\end{array}$ & MCNP4C \\
\hline Og4b & $\begin{array}{l}\text { Same as Og4a, but mesh-based ww's } \\
\text { generated. }\end{array}$ & MCNP4C \\
\hline Og5a & $\begin{array}{l}\text { Binary importances, simple geometry, no } \\
\text { wwg, no ww used. }\end{array}$ & MCNP4C \\
\hline Og5b & $\begin{array}{c}\text { Same as Og5a, but mesh-based ww's } \\
\text { generated. }\end{array}$ & MCNP4C \\
\hline Oww14b & Applies cbww generated in Og1b & MCNP4B \\
\hline Oww14C & Applies cbww generated in Og1b & $\mathrm{MCNP4C}$ \\
\hline Oww24b & Applies cbww generated in Og2b & MCNP4B \\
\hline Oww24C & Applies cbww generated in Og2b & MCNP4C \\
\hline Oww3 & Applies mbww generated in Og3b & MCNP4C \\
\hline Oww4 & Applies mbww generated in $\mathrm{Og} 4 \mathrm{~b}$ & MCNP4C \\
\hline Oww5 & Applies mbww generated in Og5b & MCNP4C \\
\hline
\end{tabular}


usr/loca1/codes/data/mic/type

D4: Simplified Model, Oil Well Problem

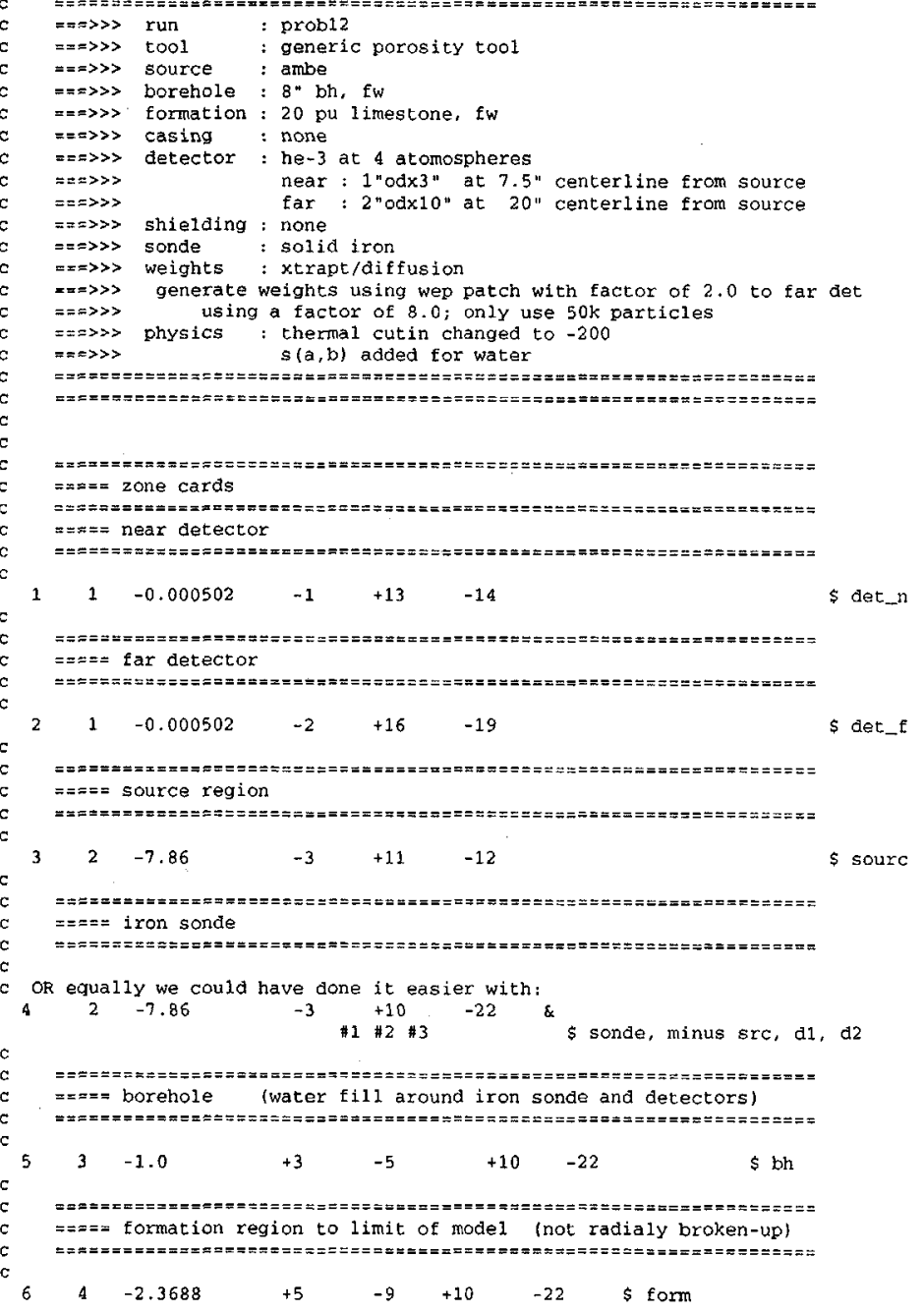


D4: Simplified Model, Oil Well Problem

$===$ material \#

name $=$ helium-3
density $=0.000502 \mathrm{~g} / \mathrm{cc}$

m1 2003.6001 .00000

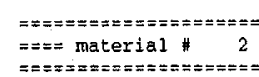

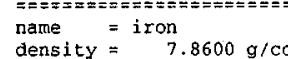

$\mathrm{m} 2 \quad 26000.50 \mathrm{C} 1.00000$

$=\leq=\leq=\leq=\leq x= \pm== \pm== \pm=$
$= \pm==$ material \# 3

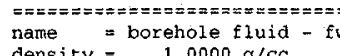

$3001.600 \quad 0.66667$

$8016.600 \quad 0.33333$

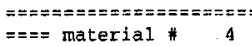

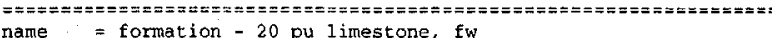

dense formation -20 pu limestone, fw

$\begin{array}{lllll}\mathrm{m} 4 & 1001.60 c & 0.15675 \quad 6012.50 c & 0.15298\end{array}$

$8016.600 \quad 0.53730$

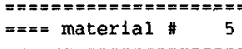

name = fornation -1 pu limestone, fw

density $=2.6939 \mathrm{~g} / \mathrm{cc}$

$\mathrm{m5} 1001.6000 .00818$

$6012.50 c 0.19755$

$8016.60 c 0.59673$

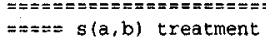

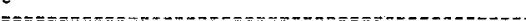

me3 lwtr

1 intr.01
iwtr.01

mes lwer.01t

$== \pm=$ neutron source $\Rightarrow$ ambe neutron source

$0.0 \quad 1.000 .00000 .5$

sil

$\begin{array}{lllllllll}\text { sair } & 0.0 & 1.0 & 0.0 & 0.6 & 0.5 \\ \text { cel }=3 & \text { wgt }=1 & \text { erg }=\text { d } 1 & \text { dir }=d 2 & \text { vec }= & 0.0 & 1.0 & 0.0\end{array}$

$\begin{array}{llllll}1110900 & .0026125 & .0408000 & .0673800 & .0865170 \\ .1227700 & .1356900 & .1499600 & .1647300\end{array}$

$\begin{array}{lllll}1831600 & .2024200 & .2237100 & .2427400 & .2732400\end{array}$

\begin{tabular}{rrrrrr}
.4978700 & .5337300 & .3683300 & .4076200 & .4504900 \\
\hline & 55300 & .6031000 & .6720600 & .7427400
\end{tabular}

$\begin{array}{rrrrr}.8208500 & .9071800 & 1.002600 & 1.108000 & 1.224600\end{array}$

$\begin{array}{llllll}1.353400 & 1.495700 & 1.653000 & 1.826800 & 2.019000 \\ 2.231300 & 2.465000 & 2.725300 & 3.01900 & 3.328700\end{array}$

$\begin{array}{lllll}3.678800 & 4.065700 & 4.493300 & 4.965900 & 5.488100 \\ 6.055300 & 6.703200 & 7.408200 & 8.187300 & 9.048400\end{array}$

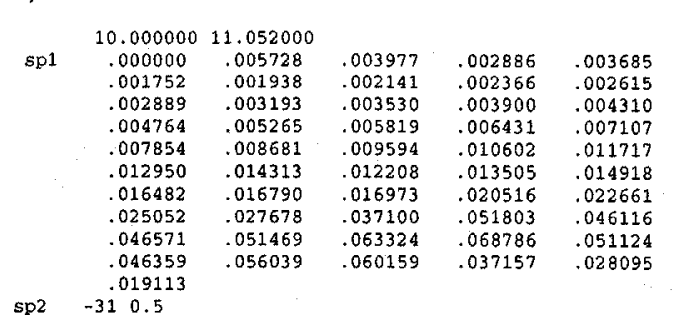

$= \pm= \pm * x=z= \pm=z$
$== \pm=$ tallies

fqo e $f$

$\mathrm{C}$
$\mathrm{f} 44: \mathrm{n} \quad 2$

fC44 neutron tota1 reaction rate in cells 1 (near) and 2 (far)

em44 1 9r

$\begin{array}{lll}\text { c } & \\ \text { phys : } n & 14 & 14\end{array}$

$\begin{array}{lll}\text { cut::n } & 830000 & 0.0 \\ \text { unn:n } & 150 & 0\end{array}$

$\begin{array}{llll}\operatorname{limp:n} & 1 & 5 \times 0 & 0 \\ \text { thtme } & 0 & 0\end{array}$

prdmp $3 j 1$

$\begin{array}{lll}\text { tmpl } & 0.0253 e-6 & 6 x \\ c \text { vol } & 1 & 230\end{array}$

$\begin{array}{llr}\text { C vol } & 1 & 230 r \\ \text { c area } & 1 & 23 r\end{array}$

$\begin{array}{lllllll}c & \\ \text { www } & 44 & 0 & 0\end{array}$

c wwge:n $4.1399-7 \quad 1.013-4 \quad 2.6058-2 \quad 2.7253 \quad 17.333$

$\begin{array}{lccc}\text { rdum } & 0.8 & & \\ c \text { wwo }: n & 5 & 3 & 5\end{array}$

$\begin{array}{llllll}c \text { wwe:n } & 4.1399-7 & 1.013-4 & 2.6058-2 & 2.7253 & 17.333\end{array}$

nps 8 es

$\begin{array}{lllll}\text { ref } & 0 & 0 & 0 & \\ \text { origin } 0.001 & -38.101 & 0.001\end{array}$

origin 0.

$\begin{array}{llll}\text { axs } & 0 & 1 & 0 \\ \text { vec } & 1 & 0 & 0\end{array}$

$\begin{array}{lllllllll}\text { imesh } & 1.27 & 2.54 & 3.81 & 15 & 20 & 40 & 60 & 80\end{array}$

$\begin{array}{lllllllll}\text { intes } & 10 & 10 & 10 & 10 & 10 & 10 & 10 & 10 \\ \text { jmesh } & 33 & 43 & 53.24 & 60.86 & 76.1 & 101.5 & 139.8\end{array}$

jints $10 \quad 10 \quad 10 \quad 10$

kints $10^{0.25} 10^{.5} 10^{.75} 10$ 
A

\section{$08 / 06 / 99$}

15:46:27

E1: Base Model in Class Problem

message:
datapath=/usr / / ocal/codes/data/me/type1

analog calculation of mfe problem, except for .01 mev energy cutof

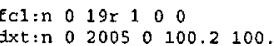

dxc:n $0.018 x \cdot 016.032 .064 \quad 128 \quad 25 \quad 5111103 x$

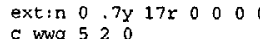

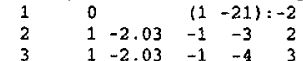

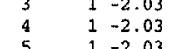

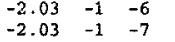

$\begin{array}{lllll}1 & -2.03 & -1 & -8 & 5 \\ 1 & -2.03 & -1 & -1 \\ 1 & -2.03 & -1 & -10 & 0\end{array}$

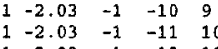

$\begin{array}{llllll}11 & 1 & -2.03 & -1 & -12 & 11 \\ 12 & 1 & -2.03 & -1 & -13 & 12 \\ 12 & 1 & -2.03 & -1 & -14 & 12\end{array}$

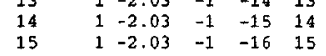

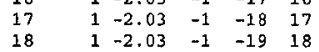

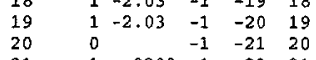

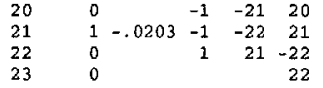

$\begin{array}{lll}1 & c y & 100\end{array}$

$\begin{array}{ll}c y & 100 \\ p y & 0 \\ p y & 10\end{array}$

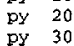

$\begin{array}{ll}\mathrm{py} & 30 \\ \mathrm{py} & 40 \\ \mathrm{py} & 50 \\ \mathrm{py} & 50\end{array}$

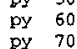

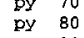

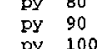

$\begin{array}{ll}\text { py } & 100 \\ \text { py } & 110 \\ \text { by } & 120\end{array}$

$\begin{array}{ll}\mathrm{py} & 110 \\ \mathrm{py} & 120 \\ \mathrm{p} & 120 \\ \mathrm{~b} y & 120\end{array}$

$\begin{array}{lll}\text { py } & 120 \\ \text { py } & 130 & 130 \\ \text { by } & 140\end{array}$

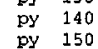

$\begin{array}{lll}\mathrm{py} & 150 \\ \mathrm{py} & 160 & 160 \\ & & \end{array}$

py 170

$\begin{array}{lll}\mathrm{py} & 180 \\ \mathrm{py} & 2000 \\ \mathrm{py} & 2010\end{array}$

the following is pseudo-concrete

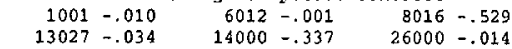

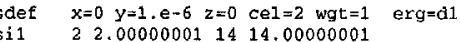

$\begin{array}{llll}\mathrm{sp} 1 & 0.5 & -5 & 1 \\ \text { nos } & 206 & -5 & -5\end{array}$

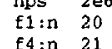

cut:n $\begin{aligned} & \text { to } \\ & \text { cut }\end{aligned}$

EY5:n 2005200

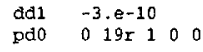

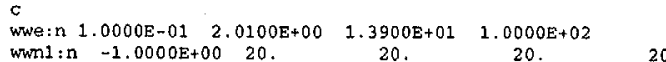

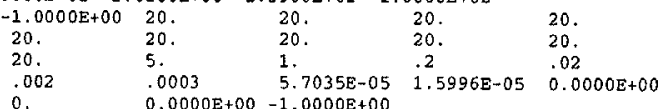

.002

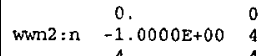

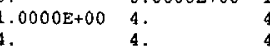

. $0000 \mathrm{E}+00$

$\begin{array}{llllll}2.6523 \mathrm{E}+00 & 1.2598 \mathrm{E}-01 & 3.9091 \mathrm{E}-02 & 1.6071 \mathrm{E}-03 & 4.0000 \mathrm{E}-04\end{array}$

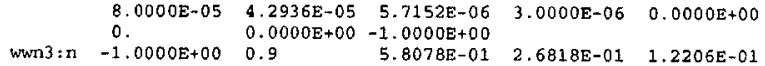
$\begin{array}{llllll}3.7383 \mathrm{E}-02 & 0.9 & 5.9539 \mathrm{E}-03 & 5.8078 \mathrm{E}-01 & 2.6818 \mathrm{E}-01 & 1.2206 \mathrm{E}-01 \\ 5.3697 \mathrm{E}-03 & 2.2019 \mathrm{E}-03 & 6.3324 \mathrm{E}-04\end{array}$

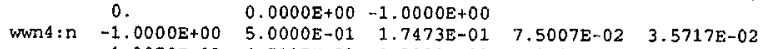
(.7117E-03 $1.3020 \mathrm{E}-01 \quad 7.3007 \mathrm{E}$.

$1.0544 \mathrm{E}-05 \quad 5.5095 \mathrm{E}-06 \quad 3.4483 \mathrm{E}-06 \quad 3.0000 \mathrm{E}-06 \quad 0.0000 \mathrm{E}+00$ $0.0000 \mathrm{E}+00-1.0000 \mathrm{E}+00$ 

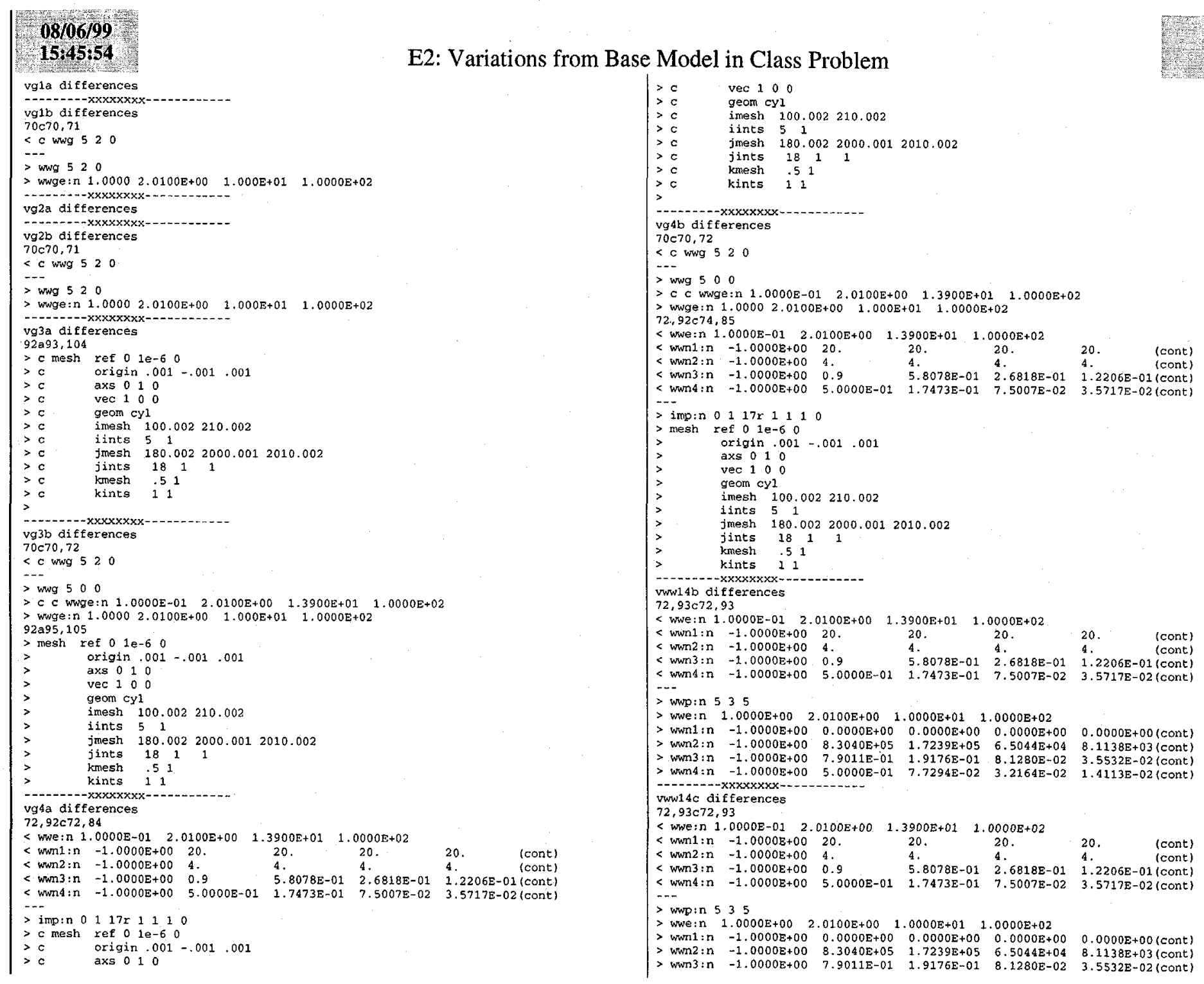


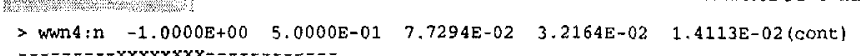

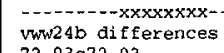

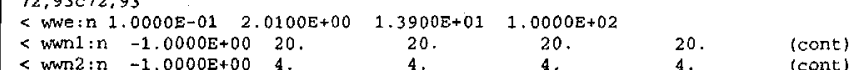

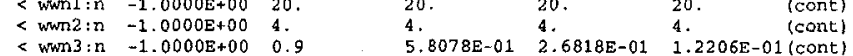

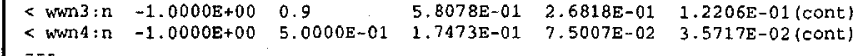

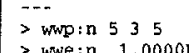

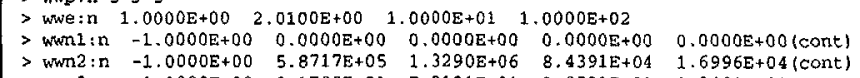

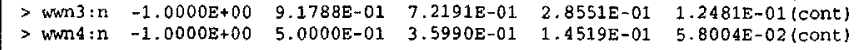
wwite 24 differences

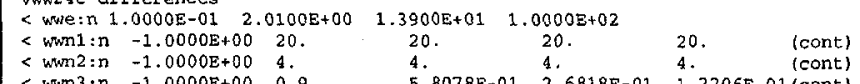

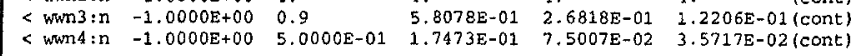
$>$ min: 5 . 53

$\begin{array}{lllll}3 \text { xwe: } n \text { n } & 1.0000 \mathrm{E}+00 & 2.0100 \mathrm{E}+00 & 1.0000 \mathrm{E}+01 & 1.0000 \mathrm{E}+02\end{array}$

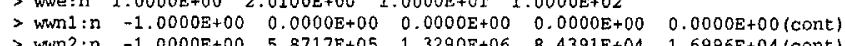

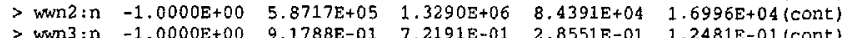
$\begin{array}{lllllll}>\text { wMn } 4 \text { : n } & -1.0000 E+00 & 5.0000 E-01 & 3.5990 E-01 & 1.45198-01 & 5.80048-02 \text { (cont) }\end{array}$ vwis difterences

$70,92070,83$

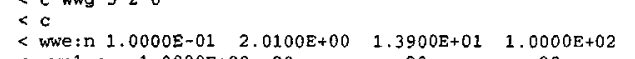

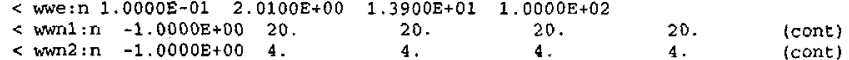

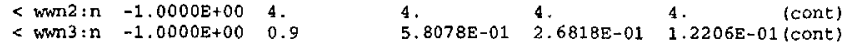

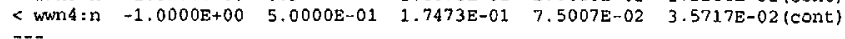
$>c$ wros 500

$>$ imp:n $0117 \times 11110$

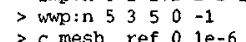

$>>c$ mesh refo 1 re-6 0

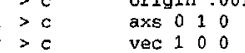

$\begin{array}{lll} & \\ >c & \text { imesh } & 100.002 \\ >c & 210.002\end{array}$

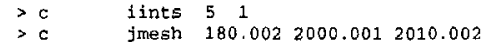

$\begin{array}{lll}3 & \\ >c & c\end{array}$

$\begin{array}{lll}\text { kmesh } & \text {.5 } 1 \\ >c & \text { kints } & i_{1} \\ >c & \end{array}$

Wwis di fiferences

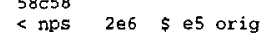

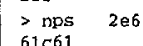

< cut: in $j 0.01 \quad \$ .01$ Mev energy cutoff

$>$ cut:n $; 0.01 \quad 5.01$ Mev energy cutof $f$

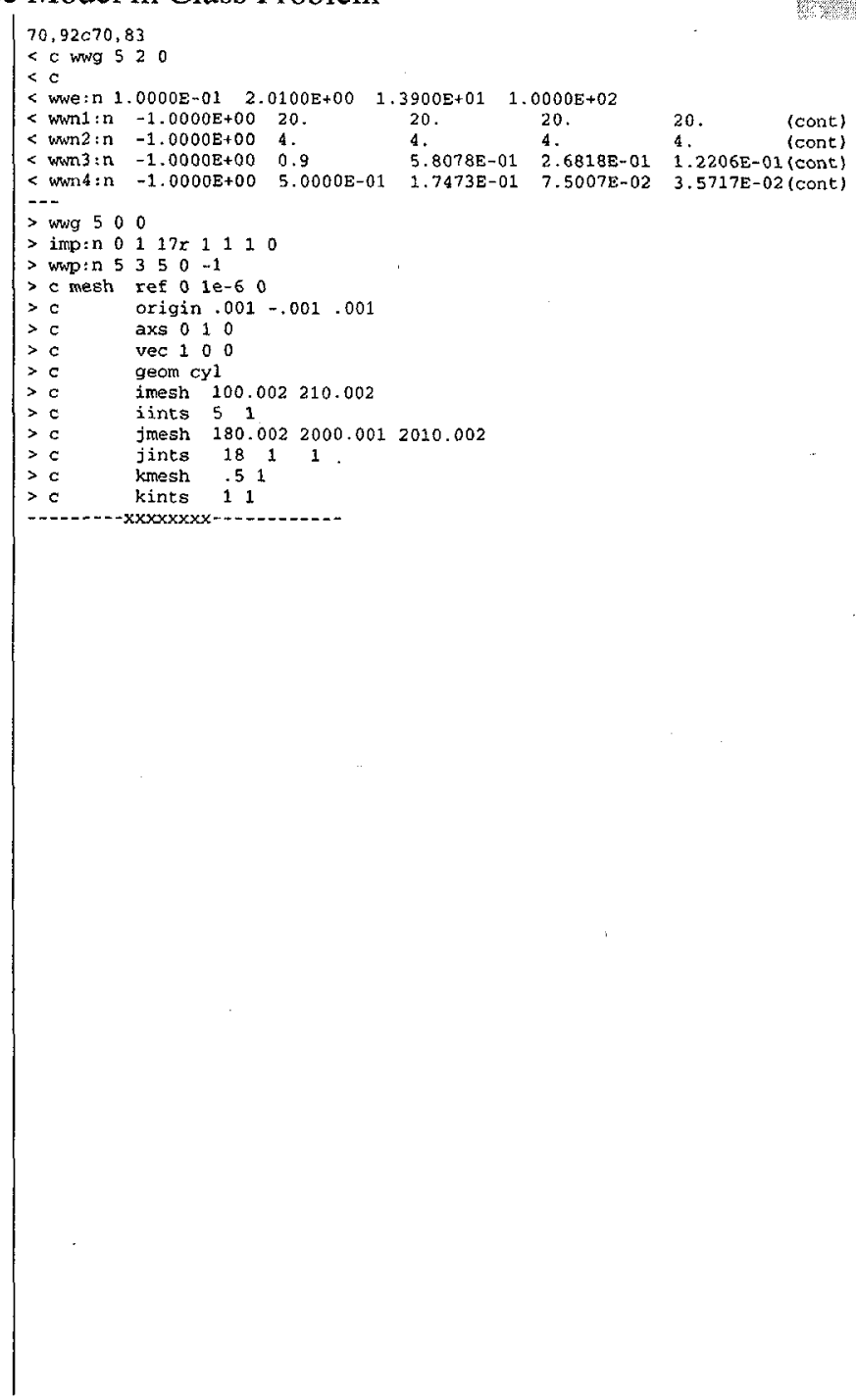


Table E3: Explanation of Runs Performed in Assessment

\begin{tabular}{|c|c|c|}
\hline Run & Explanation & Code Run \\
\hline Vgla & Expert importances, no wwg, no ww used. & MCNP4C \\
\hline Vg1b & $\begin{array}{l}\text { Same as Vg1a, but cell-based ww's } \\
\text { generated. }\end{array}$ & MCNP4C \\
\hline Vg2a & Expert importances, no wwg, no ww used. & MCNP4B \\
\hline Vg2b & $\begin{array}{l}\text { Same as Vg2a, but cell-based ww's } \\
\text { generated. }\end{array}$ & MCNP4B \\
\hline Vg3a & $\begin{array}{l}\text { Expert importances, complex geometry, no } \\
\text { wwg, no ww used. }\end{array}$ & MCNP4C \\
\hline Vg3b & $\begin{array}{l}\text { Same as Vg3b, but mesh-based ww's } \\
\text { generated. }\end{array}$ & MCNP4C \\
\hline Vg4a & $\begin{array}{l}\text { Binary importances, complex geometry, no } \\
\text { wwg, no ww used. }\end{array}$ & MCNP4C \\
\hline $\mathrm{Vg} 4 \mathrm{~b}$ & $\begin{array}{l}\text { Same as Vg4a, but mesh-based ww's } \\
\text { generated. }\end{array}$ & $\mathrm{MCNP} 4 \mathrm{C}$ \\
\hline Vg5a & $\begin{array}{l}\text { Binary importances, simple geometry, no } \\
\text { wwg, no ww used. }\end{array}$ & MCNP4C \\
\hline Vg5b & $\begin{array}{l}\text { Same as Vg5a, but mesh-based ww's } \\
\text { generated. }\end{array}$ & MCNP4C \\
\hline Vww14b & Applies cbww generated in Vg1b & MCNP4B \\
\hline Vww14C & Applies cbww generated in Vg1b & MCNP4C \\
\hline Vww24b & Applies cbww generated in Vg2b & MCNP4B \\
\hline Vww24C & Applies cbww generated in Vg2b & MCNP4C \\
\hline Vww3 & Applies mbww generated in Vg3b & MCNP4C \\
\hline Vww4 & Applies mbww generated in Vg4b & MCNP4C \\
\hline Vww5 & Applies mbww generated in Vg5b & MCNP4C \\
\hline
\end{tabular}


message:
datapathe/usr/1ocal/codes/data/mc/type1

lem -vg5b

analog calculation of mfe problem, except for .01 MeV energy cutof $t$

$\begin{array}{lllll}1 & 0 & -1 & -21 & -2 \\ 2 & 1 & -2.03 & -1 & -20\end{array}$

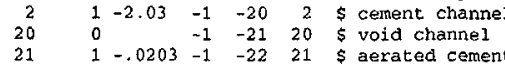

$220 \quad 1 \quad 21 \quad-22 \quad-5 \$$ void channel to ring detector

$\begin{array}{llllllll}24 & 0 & 1 & 21 & -22 & 5 & \$ & \$ \text { zero importance void out side of detector }\end{array}$

1 CY 100

$\begin{array}{rrr}5 & \text { DY } & 210 \\ 20 & \text { py } & 180\end{array}$

$\begin{array}{lll}21 & \text { PY } & 2000 \\ 22 & \text { pY } & 2010\end{array}$

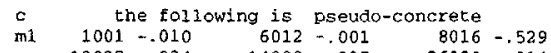

sdef $x=0 \quad y=1, e-6 \quad z=0 \quad$ cel $=2$ wgt $=1 \quad$ erg=d

si1 2 2.000000011414 .00000001

sp1 $2.5 \cdot 5$

$\begin{array}{ll}\text { nps } & 2 e 6 \\ E 1: \mathrm{n} & 20\end{array}$

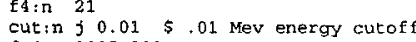

das $-5 . e-18$

da1 $-3 \cdot e-10$

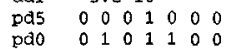

fc $1: n \begin{array}{lllllllll}0 & 0 & 0 & 1 & 0 & 0 & 0\end{array}$

dxt:n 020050100.2100 .2

ext:n 0 . 7y 0000000

$\begin{array}{llllllll}\text { imp:n } & 0 & 1 & 1 & 1 & 1 & 0 & 0 \\ c \text { wwo } & 5 & 3 & 5 & 0 & -1\end{array}$

C C wwge:n $1.0000 \mathrm{E}-01 \quad 2.0100 \mathrm{E}+00 \quad 1.0000 \mathrm{E}+01 \quad 1.0000 \mathrm{E}+02$

$.00002 .0100 \mathrm{E}+00 \quad 1.000 \mathrm{E}+01 \quad 1.0000 \mathrm{E}+02$

mesh ref $010-60$

origin $.001-.001 \quad .001$

$\begin{array}{llll}\text { axs } & 0 & 1 \\ \text { vec } & 1 & 0 & 0 \\ & 0 & 0\end{array}$

geom $\begin{array}{lll}\text { inesh } 100.002 & 210.002\end{array}$

$\begin{array}{llll}\text { iints } & 5 & 1 \\ \text { jmesh } & 180.002 & 2000.0012010 .002\end{array}$

jints 181

$\begin{array}{ll}\text { kmesh } & i^{5} 1 \\ \text { kints } & \end{array}$ 